\title{
Recent Advances and Industrial Applications of Multilevel Converters
}

\author{
Samir Kouro, Member, IEEE, Mariusz Malinowski, Senior Member, IEEE, K. Gopakumar, Senior Member, IEEE, \\ Josep Pou, Member, IEEE, Leopoldo G. Franquelo, Fellow, IEEE, Bin Wu, Fellow, IEEE, José Rodríguez, Senior \\ Member, IEEE Marcelo A. Pérez, Member, IEEE and Jose I. Leon, Member, IEEE
}

\begin{abstract}
Multilevel converters have been under research and development for more than 3 decades, and have found successful industrial application. However, this is still a technology under development, and many new contributions and new commercial topologies have been reported in the last few years. The aim of this paper is to group and review these recent contributions, in order to establish the current state of the art and trends of the technology, to provide readers a comprehensive and insightful review of where multilevel converter technology stands and is heading. The paper first presents a brief overview of the well established multilevel converters, strongly oriented to their current state in industrial applications, to then center the discussion on the new converters that have made their way to industry. Also new promising topologies are discussed. Recent advances made in modulation and control of multilevel converters are also addressed. A great part of the paper is devoted to show nontraditional applications powered by multilevel converters, and how multilevel converters are becoming an enabling technology in many industrial sectors. Finally, some future trends and challenges in the further development of this technology are discussed, to motivate future contributions that address open problems and explore new possibilities.
\end{abstract}

Index Terms-Multilevel converters, modulation, control, highpower applications, wind energy conversion, train traction, marine propulsion, photovoltaic systems, FACTS, active filters, HVDC transmission.

Manuscript received January 26, 2010. Accepted for publication April 3, 2010. This work was supported in part by the Chilean National Fund of Scientific and Technological Development (FONDECYT) under Grant 1080582, in part by the Centro Cientifico-Tecnologico De Valparaiso (CCTVal) $\mathrm{N}^{\circ} \mathrm{FB} 0821$, in part by Ryerson University, in part by the European Union in the framework of European Social Fund through Center for Advanced Studies Warsaw University of Technology, and in part by the Ministerio de Ciencia y Tecnología of Spain under project ENE2007-67033-C03-00.

Copyright (c) 2009 IEEE. Personal use of this material is permitted. However, permission to use this material for any other purposes must be obtained from the IEEE by sending a request to pubs-permissions@ieee.org.

S. Kouro and B. Wu are with the Department of Electrical and Computer Engineering Ryerson University, M5B 2K3 Toronto, ON, Canada (e-mail: samir.kouro@ieee.org; bwu@ee.ryerson.ca).

M. Malinowski is with the Institute of Control and Industrial Electronics, Warsaw University of Technology, 00-662 Warsaw, Poland (e-mail: malin@isep.pw.edu.pl).

K. Gopakumar is with the Centre for Electronics Design and Technology, Indian Institute of Science, 560012 Bangalore, India (e-mail: kgopa@cedt.iisc.ernet.in).

J. Pou is with the Electronic Engineering Department, Technical University of Catalonia,08222 Terrassa, Catalonia, Spain (e-mail: pou@eel.upc.edu)

L. G. Franquelo and J. I. León are with the Department of Electronics Engineering, University of Seville, 41092 Seville, Spain (e-mail: leopoldo@gte.esi.us.es; jileon@zipi.us.es).

J. Rodríguez and M. Pérez, are with the Electronics Engineering Department, Universidad Técnica Federico Santa María, 2390123 Valparaíso, Chile (e-mail: jrp@usm.cl; marcelo.perez@usm.cl).

\section{INTRODUCTION}

$\mathbf{M}$ ULTILEVEL converters are finding increased attention in industry and academia as one of the preferred choices of electronic power conversion for high power applications [1]-[10]. They have made their way successfully into industry and therefore can be considered a mature and proven technology. Currently, they are commercialized in standard and customized products that power a wide range of applications, such as: compressors, extruders, pumps, fans, grinding mills, rolling mills, conveyors, crushers, blast furnace blowers, gas turbine starters, mixers, mine hoists, reactive power compensation, marine propulsion, HVDC transmission, hydro pumped storage, wind energy conversion, and railway traction to name a few [1]-[10]. Converters for these applications are commercially offered by a growing group of companies in the field [11]-[26].

Although it is an enabling and already proven technology, multilevel converters present a great deal of challenges, and even more importantly, they offer such a wide range of possibilities, that their research and development is still growing in depth and width. Researchers all over the world are contributing to further improve energy efficiency, reliability, power density, simplicity and cost of multilevel converters, and broaden their application field as they become more attractive and competitive than classic topologies.

Recently, many publications have addressed multilevel converter technology and stressed the growing importance of multilevel converters for high power applications [4]-[9]. These works have a survey and tutorial nature and cover in depth the traditional and well established multilevel converter topologies like the Neutral Point Clamped (NPC), Cascaded H-bridge (CHB) and the Flying Capacitor (FC), as well as the most used modulation methods. Instead, this paper presents a technology review, focused mainly on the most recent advances made in this field in the past few years, covering new promising topologies, modulations, controls and operational issues. In addition, one of the most interesting topics in multilevel converter technology is the rapidly increasing and diverse application field, which is addressed in this work as well. Also emerging trends, challenges and possible future directions of the development in multilevel converter technology are outlined to motivate further work in this field.

This paper is organized as follows: first, a brief overview of classic multilevel topologies is presented in section II to introduce basic concepts needed throughout the paper. This is 


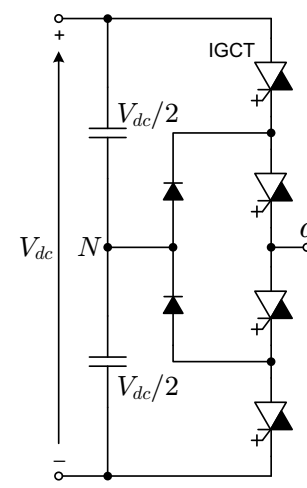

(a)

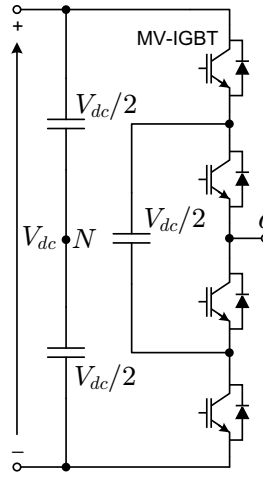

(b)

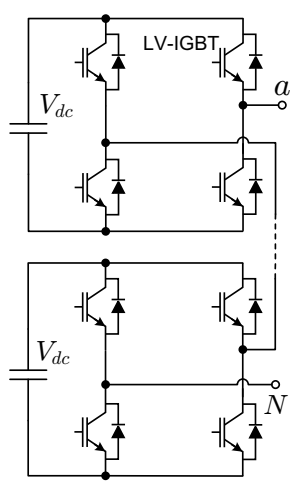

(c)
Fig. 1. Classic multilevel converter topologies (only one phase shown): a) Three-level Neutral Point Clamped (NPC) featuring IGCTs, b) Three-level Flying Capacitor (FC) featuring MV-IGBTs and c) Five-level Cascaded HBridge (CHB) featuring LV-IGBTs.

followed by a review of recent advances in multilevel converter topologies in section III, where those already found in practice and those currently under development are addressed. Section IV covers the latest developments in multilevel modulation methods. Latest contributions on multilevel converter control and different operational issues, such as capacitor voltage balance and fault tolerant operation are reviewed in section V. New and future promising applications of multilevel converters are described in section VI. Finally, in Section VII future trends and challenges of multilevel converter technology are discussed, which is followed by concluding remarks in section VIII.

\section{Classic multilevel topologies overview}

For completeness and better understanding of the advances in multilevel technology, it is necessary to cover classic multilevel converter topologies. However, in order to focus the content of this paper on the most recent advances and ongoing research lines, the well established topologies will be only briefly introduced and referred to existing literature. In the following, classic topologies will be referred to those that have been extensively analyzed and documented and have been commercialized and used in practical applications for more than a decade.

Multilevel converter technology started with the introduction of the multilevel stepped waveform concept with a Series Connected H-Bridge, also known as Cascaded H-Bridge (CHB) converter in the late 60s [27]. This was followed closely by a low power development of a flying capacitor (FC) topology the same year [28]. Finally, in the late 70s, the diode clamped converter (DCC) [29] was first introduced. The DCC concept evolved into the three-level Neutral Point Clamped Converter (3L-NPC) we know today as it was proposed in [30]-[32], and can be considered as the first real multilevel power converter for medium voltage applications. Later, the CHB would be reintroduced in the late 80s [33], although it would reach more industrial relevance in the mid 90s [34]. In the same way, the early concept of the FC circuit introduced for low power in the 60s developed into the medium voltage multilevel converter topology we know today in the early 90s [35]. Through the years the FC has also been reported as the imbricated-cell and multi-cell converter (the latter is also a name used for the $\mathrm{CHB}$, since both are modular and made by interconnection of power cells).

These three multilevel converter topologies could be considered now as the classic or traditional multilevel topologies that first made it into real industrial products during the last two decades. The power circuits of a single-phase leg of these three topologies are shown in Fig. 1, featuring the corresponding commonly used semiconductor device. These converters are commercialized by several manufacturers in the field [11] [26], offering different power ratings, front end configurations, cooling systems, semiconductor devices and control schemes, among other technical specifications. The most relevant parameters and ratings for each od these classic topologies are listed in Table I. The parameters for each category are given for the different manufacturers, whose corresponding reference is given at the bottom of the table. As can be observed from the table, the 3L-NPC and the CHB are the most popular multilevel topologies used in industry. It is not straight forward or fair to compare the commercially available 3L-NPC with the 7L- to 17L-CHB listed in Table I, since the first will have worse power quality and the second a more complex circuit structure. However, some evident differences between them can be concluded from Table I:

- The NPC features medium/high voltage devices (IGCT and MV/HV-IGBTs), while the CHB uses exclusively low voltage IGBTs.

- The CHB reaches higher voltage and higher power levels.

- The NPC is definitely more suitable for back-to-back regenerative applications. The CHB needs substantially higher number of devices to achieve a regenerative option (a 3-phase 2-level VSI per cell).

- The CHB needs a phase shifting transformer, usually to conform a 36 pulse rectifier system. This is more expensive but improves input power quality.

- The NPC has a simpler circuit structure, leading to a smaller footprint.

- Although both topologies generate same amount of levels when using same number of power switches, the commercially available CHBs have more output voltage levels (up to 17 compared to 3 of the NPC). Hence, lower average device switching frequencies are possible for same output voltage waveform quality. Therefore, air cooling and higher fundamental output frequency can be achieved without derating and without use of output filter.

These multilevel voltage source converter topologies belong to the medium-voltage-high-power converter family, whose classification is shown in Fig. 2. Note that generally speaking the medium-voltage range is considered in the power converter industry from 2.3 to $6.6 \mathrm{kV}$, and high power from $1 \mathrm{MW}$ to 50MW. The classification also includes the direct acac converters and current source converters, which currently are the main competitors of multilevel technology: mainly the cycloconverter and load commutated inverters for very high power, high torque and low speed applications, and the 
TABLE I

ClASSIC MULTILEVEL TOPOLOGIES COMMERCIAL RATINGS AND SPECIFICATIONS.

\begin{tabular}{|c|c|c|c|}
\hline \multirow{2}{*}{ Parameter } & \multicolumn{3}{|c|}{ Multilevel topology } \\
\hline & 3L-NPC & $\mathrm{CHB}$ & 4L-FC \\
\hline Max. power & $27 \mathrm{MW}^{(1)}, 31.5 \mathrm{MVA}^{(2)}, 40 \mathrm{MVA}^{(3)}, 44 \mathrm{MW}^{(4)}$ & $120 \mathrm{MW}^{(2)}, 15 \mathrm{MW}^{(3)}, 5.6 \mathrm{MW}^{(7)}$ & $2.24 \mathrm{MW}^{(15)}$ \\
\hline & $33.6 \mathrm{MW}^{(5)}, 3.7 \mathrm{MW}^{(6,9)}, 27 \mathrm{MVA}^{(8)}, 10 \mathrm{MW}^{(14)}$ & $10 \mathrm{MVA}^{(10)}, 11.1 \mathrm{MVA}^{(11)}, 6 \mathrm{MVA}^{(12)}, 6250 \mathrm{kVA}^{(13)}$ & \\
\hline Output voltage $[\mathrm{kV}]$ & $\begin{array}{c}2.3 / 3.3 / 4.0 / 4.16^{(1,2)}, 2.3 / 3.3 / 4.16^{(4,6,8,9,14)} \\
3.3 / 6.6^{(5)}\end{array}$ & $\begin{array}{c}2.3-13.8^{(2)}, 3.3 / 6.6^{(3,12)}, 2.3 / 4.16 / 6 / 11^{(7)} \\
3 / 6 / 10^{(10)}, 3 / 4 / 6 / 10^{(11)}, 3 / 3.3 / 4.16 / 6 / 6.6 / 10^{(13)}\end{array}$ & $2.3 / 3.3 / 4.16^{(15)}$ \\
\hline Max. output freq. $[\mathrm{Hz}]$ & $82.5^{(1)}, 250^{(2)}, 90^{(3)}, 140^{(4,14)}, 300^{(5)}, 120^{(6)}, 100^{(8,9)}$ & $330^{(2)}, 120^{(3,7,11-13)}, 50^{(10)}$ & $120^{(15)}$ \\
\hline Diode front end [\# pulses] & $12 / 24^{(1-5,8)}, 24^{(6)}, 12 / 18^{(9)}, 12 / 24 / 36^{(14)}$ & $18 / 36^{(2,3,12)}, 30^{(7)}, 36^{(11)}, 24 / 30 / 42 / 48^{(13)}$ & $18 / 24 / 36(\text { diode+SCR })^{(15)}$ \\
\hline Active front end option & 3L-NPC in back-to-back $(1-5,8,14)$ & 3-phase VSI per cell ${ }^{(10)}$ & 4L-FC in back-to-back ${ }^{(15)}$ \\
\hline Power semiconductor & $\mathrm{IGCT}^{(1,2,4,8)}, \mathrm{MV} / \mathrm{HV}-\mathrm{IGBT}^{(2,5,6,8,9,14)}, \mathrm{IEGT}^{(3,8)}$ & LV-IGBT $(2,3,7,10-13)$ & MV-IGBT ${ }^{(15)}$ \\
\hline Cooling system & air/water ${ }^{(1,2,4,8,14)}$, water $^{(3,5)}, \operatorname{air}^{(9)}$ & air/water ${ }^{(2,13)}$, air $^{(3,7,11,12)}$ & air $^{(15)}$ \\
\hline Modulation method & $\mathrm{PWM}^{(2-6,14)}, \mathrm{SHE}^{(3,9)}, \mathrm{SVM}^{(8,9)}$ & PS-PWM ${ }^{(2,3,7,10-13)}$ & PS-PWM ${ }^{(15)}$ \\
\hline Control methods & $\begin{array}{l}\mathrm{DTC}^{(1)}, \mathrm{v} / \mathrm{f} \text { and FOC } \\
\mathrm{DPC}^{(1)}, \operatorname{VOC}^{(2-5,14)}, \mathrm{FOC}^{(5,6,8)}, \mathrm{v} / \mathrm{f}^{(9)},\end{array}$ & $\mathrm{v} / \mathrm{f}$ and $\operatorname{FOC}^{(2,3,7,11,12)}, \operatorname{FOC}^{(10,13)}$ & $\mathrm{v} / \mathrm{f}$ and $\mathrm{FOC}^{(15)}$ \\
\hline \# voltage levels & 3 & $\begin{array}{c}\left.9 / 13^{(2)}, 7 / 13^{(3,12)}, 11^{(7)}, 7 / 11 / 13 / 19\right)^{(10)} \\
13^{(11)}, 9 / 11 / 15 / 17^{(13)}\end{array}$ & $4^{(15)}$ \\
\hline \# power cells & - & $\begin{array}{c}4 / 6^{(2)}, 3 / 6^{(3,12)}, 5^{(7)}, 3 / 5 / 6 / 9^{(10)} \\
6^{(11)}, 4 / 5 / 7 / 8^{(13)}\end{array}$ & $3^{(15)}$ \\
\hline References & ${ }^{(1)}[11],{ }^{(2)}[12],{ }^{(3)}[13],{ }^{(4)}[14],{ }^{(5)}[15],{ }^{(6)}[16],{ }^{(7)}$ & $17],{ }^{(8)}[18],{ }^{(9)}[19],{ }^{(10)}[20],{ }^{(11)}[21],{ }^{(12)}[22],{ }^{(13}$ & [23], ${ }^{(14)}[24],{ }^{(15)}[25]$ \\
\hline
\end{tabular}

Note: Information provided in the table is to the authors best knowledge valid to the submission date of this paper, hence some differences or unintentional omissions could be possible.

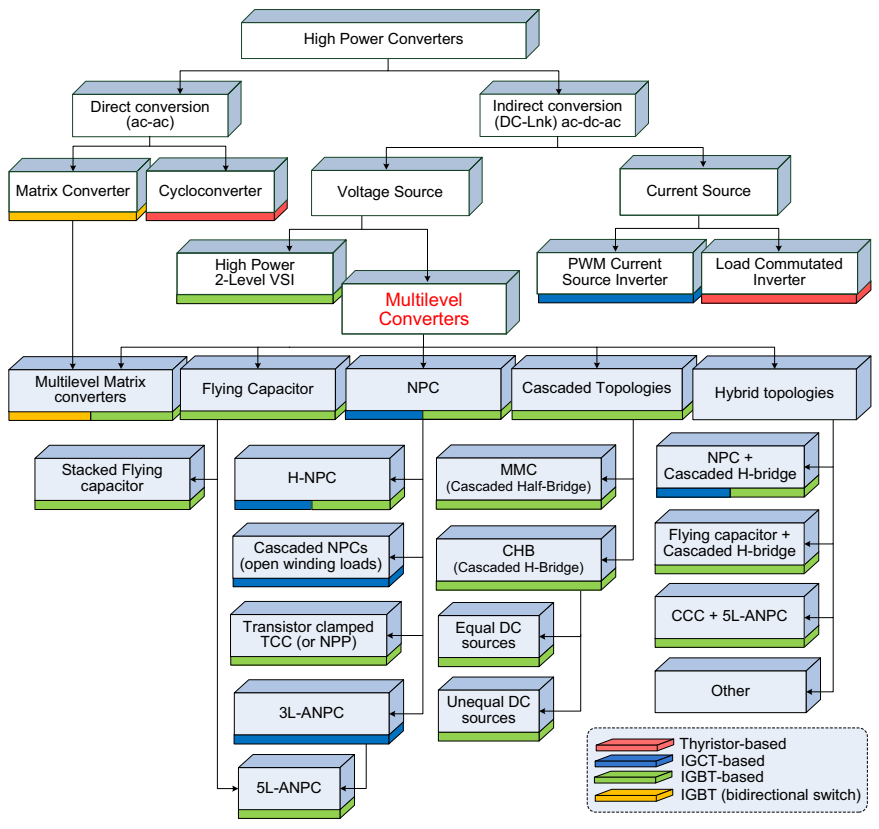

Fig. 2. Multilevel converter classification.

pulse width modulated current source inverter for high power variable speed drives. Other multilevel converter topologies also appear in this classification, some of them have recently found practical application, and will be discussed later in this paper.

The operating principles, multilevel waveform generation, special characteristics, modulation schemes and other information related to the NPC, FC, and CHB can be found with plenty of details and useful references to previous works in [2]-[9], and therefore will not covered in this paper devoted to present research topics.

A number of papers have been published recently comparing the three topologies for specific applications in terms of the losses and the output voltage quality [36]-[38]. A few conclusions from these papers are worth mentioning. The $3 \mathrm{~L}-\mathrm{NPC}$ has become quite popular because of a simple transformer rectifier power circuit structure, with a lower device count when considering both the inverter and rectifier, and less number of capacitors. Although the NPC structure can be extended to higher number of levels, these are less attractive, because of higher losses and uneven distribution of losses in the outer and inner devices [5]. Specially the clamping diodes, which have to be connected in series to block the higher voltages, introduce more conduction losses and produce reverse recovery currents during commutation that affects switching losses of the other devices even more. Furthermore, dc-link capacitors voltage balance becomes unattainable in higher-level topologies with a passive front end when using conventional modulation strategies [39]-[41]. In this case the classic multilevel stepped waveform cannot be retained and higher $d v / d t$ s (more than one-level transitions) are necessary to balance the capacitors for certain modulation indexes.

On the other hand, the CHB is well suited for high power applications because of the modular structure that enables higher voltage operation with classic low voltage semiconductors. The phase-shifting of the carrier signals moves the frequency harmonics to the higher frequency side, and this together with the high number of levels enables the reduction of the average device switching frequency $(\leq 500 \mathrm{~Hz})$, allowing air cooling and lower losses. However, it requires large number of isolated dc sources, which have to be fed from phaseshifting isolation transformers, which are more expensive and bulky compared the standard transformer used for the NPC. Nevertheless, this has been effectively used to improve the input power factor of this converter, reducing input current harmonics.

Although the flying capacitor is modular in structure, like 
the $\mathrm{CHB}$, it has found less industrial penetration compared to the NPC and CHB, mainly because higher switching frequencies are necessary to keep the capacitors properly balanced, whether a self balancing or a control assisted balancing modulation method is used (e.g. greater than $1200 \mathrm{~Hz}$ ) [5]. These switching frequencies are not feasible for high power applications, where usually they are limited in a range from 500 to $700 \mathrm{~Hz}$. This topology also requires initialization of the flying capacitor voltages.

\section{RECENT AdVANCES IN TOPOLOGIES}

Since the introduction of the first multilevel topologies almost four decades ago [27], perhaps dozens of variants and new multilevel converters have been proposed in literature. Most of them are variations to the three classic multilevel topologies, discussed in previous section, or hybrids between them. However, not so many have made their way to industry yet. Among the newer topologies that currently have found practical application are: the five-level H-bridge NPC (5L-HNPC), the three-level Active NPC (3L-ANP), the 5LANPC, the Modular Multilevel Converter (MMC) and the Cascaded Matrix Converter (CMC). Apart from these, several other topologies have been proposed and are currently under development, among them: the Transistor Clamped Converter (TCC), the CHB fed with unequal dc-sources or asymmetric $\mathrm{CHB}$, the cascaded NPC feeding open-end loads, the hybrid NPC-CHB and hybrid FC-CHB topologies, the stacked flying capacitor or stacked multi-cell to name a few. All these topologies are addressed in the following subsections, and can be found in the medium voltage converter classification of Fig. 2.

\section{A. Five-level H-bridge NPC (5L-HNPC)}

This converter is composed by the H-bridge connection of two classic 3L-NPC phase legs as shown in Fig. 3, forming a five-level HNPC (5L-HNPC) converter, and was first introduced in [45]. This topology has been commercialized by two medium voltage drive manufacturers [11], [13], and has received increased attention over the years [42]-[44].

The combination of the three levels of each leg of the NPC $\left(V_{d c} / 2,0,-V_{d c} / 2\right)$ results in the five different output levels $\left(V_{d c}, V_{d c} / 2,0,-V_{d c} / 2,-V_{d c}\right)$. As with the traditional

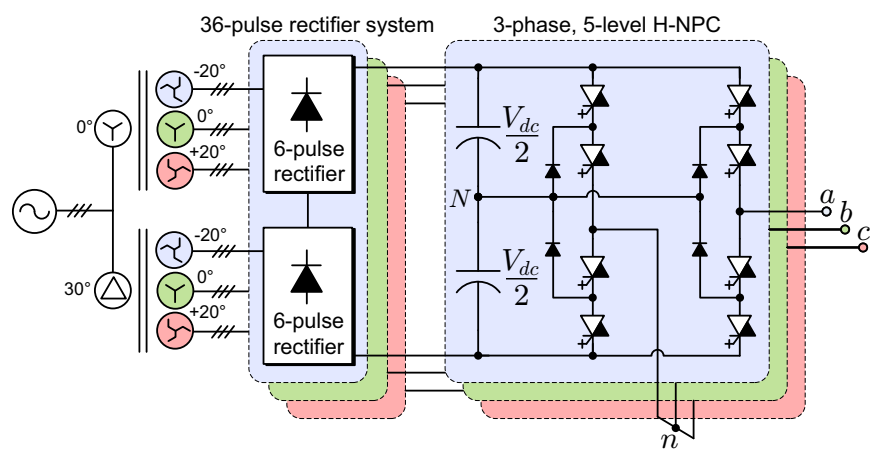

Fig. 3. Three-phase five-level H-bridge NPC (5L-HNPC) [42]-[44].
H-bridge, this topology requires an isolated dc-source for each $\mathrm{H}$-bridge to avoid short-circuit of the dc-links. Therefore a transformer with three dedicated secondary three-phase windings is necessary to supply the H-bridge of each phase of the converter. Moreover, since the semiconductors of the 3L-NPC leg block half of the total dc-link voltage, higher voltage can be reached with a series connection of two diode bridges. This can lead to a 36-pulse rectifier system as can be seen in Fig. 3.

The disadvantage of a more complex transformer comes along with an attractive feature which is the enhanced input side power quality obtained with the phase-shifting transformer and multipulse rectifier configuration. Low order harmonics are effectively canceled up to the 25 th (for a 36 pulse rectifier) improving greatly the input current THD, eliminating the needs of filters just like with the CHB topology [34]. In fact this topology features an identical transformer to the one that would be used for a five-level two cell $\mathrm{CHB}$, with the same amount of diode rectifier bridges, number of capacitors and switching semiconductors, but with the addition of 12 clamping diodes, and need to control the neutral point of each H-bridge.

This converter can be found in practice with a 36-pulse rectifier system, featuring IGCTs, and for a 2 to $7 \mathrm{MW}$ power range air cooled or 5 to $22 \mathrm{MW}$ water cooled. Other characteristics are: it is controlled with direct torque control, reaches output frequency up to $250 \mathrm{~Hz}$ and output voltages up to $6.9 \mathrm{kV}$ [11]. Alternatively, several configurations of the 5LHNPC are available from [13]: with 24 or 36 pulse diode rectifier front end, with medium voltage IGBTs, IEGTs or GCTs, up to $7.8 \mathrm{kV}$ maximum output voltage, up to $120 \mathrm{~Hz}$ output frequency, air or water cooled, vector controlled, with a power range up to $120 \mathrm{MVA}$.

\section{B. Three-level Active NPC (3L-ANPC)}

One of the drawbacks of the 3L-NPC topology is the unequal share of losses between the inner and outer switching devices in each converter leg. Since the semiconductors are cooled with separate heat sinks and cooling system it results in an unsymmetrical semiconductor-junction temperature distribution which affects the cooling system design, limits the maximum power rate, output current and switching frequency of the converter for a specific semiconductor technology (usually the IGCT) [46], [47]. This issue can be solved by replacing the neutral clamping diodes with clamping switches to provide a controllable path for the neutral current, and hence control the loss distribution among the switches of the converter. In other words, with clamping diodes like in the 3L-NPC, the current freewheels through the upper or lower clamping diode depending on the current polarity when the zero voltage level is generated. Instead, with clamping switches, the current can be forced to go through the upper or lower clamping path. This can be used to control the power loss distribution and overcome the limitations of the 3L-NPC, enabling substantially higher power rates. These additional devices are called the active neutral clamping switches and 
are shown in Fig. 4a, and give this converter its name 3LANPC. A detailed analysis on the loss distribution and how to control it through the new switching states provided by the additional clamping switches is performed in [46].

The 3L-ANPC was developed during the past five years [47], [52], and has been recently introduced with a back-toback regenerative configuration as a commercial product [11]. It covers a power range from 20 to 200 MVA and can be connected with a transformer from a $6 \mathrm{kV}$ to a $220 \mathrm{kV}$ grid.

Recently a variation of the ANPC concept has been proposed, namely a five-level hybrid multilevel converter that combines a three-level ANPC leg with a three-level FC power cell connected between the internal ANPC switching devices as shown in Fig. 4b. Although it is a hybrid topology, it has been called 5L-ANPC [48]-[50], [53]. It effectively increases the number of levels of the converter with the levels introduced by the FC cell. The flying capacitor is controlled to $V_{d c} / 4$ so that its series connection to the ANPC dc-link capacitors at $V_{d c} / 2$ or to the neutral at zero volt, using an appropriate switching state generates the additional intermediate voltage levels completing a total of five levels $\left( \pm V_{d c} / 2, \pm V_{d c} / 4\right.$, and 0 ). There are several redundancies that can be used to control the flying capacitor voltage. This hybrid ANPC-FC concept enables somehow the modularity factor that lacks the classic NPC converter family by just adding FC cells to reach easily higher level values [53], without the need to add series connected diodes. Moreover, because only a 3L-NPC leg is used, the problems of capacitor voltage balancing when using passive front ends in higher number of level NPCs explained further in Section $\mathrm{V}$ is avoided as well. These advantages

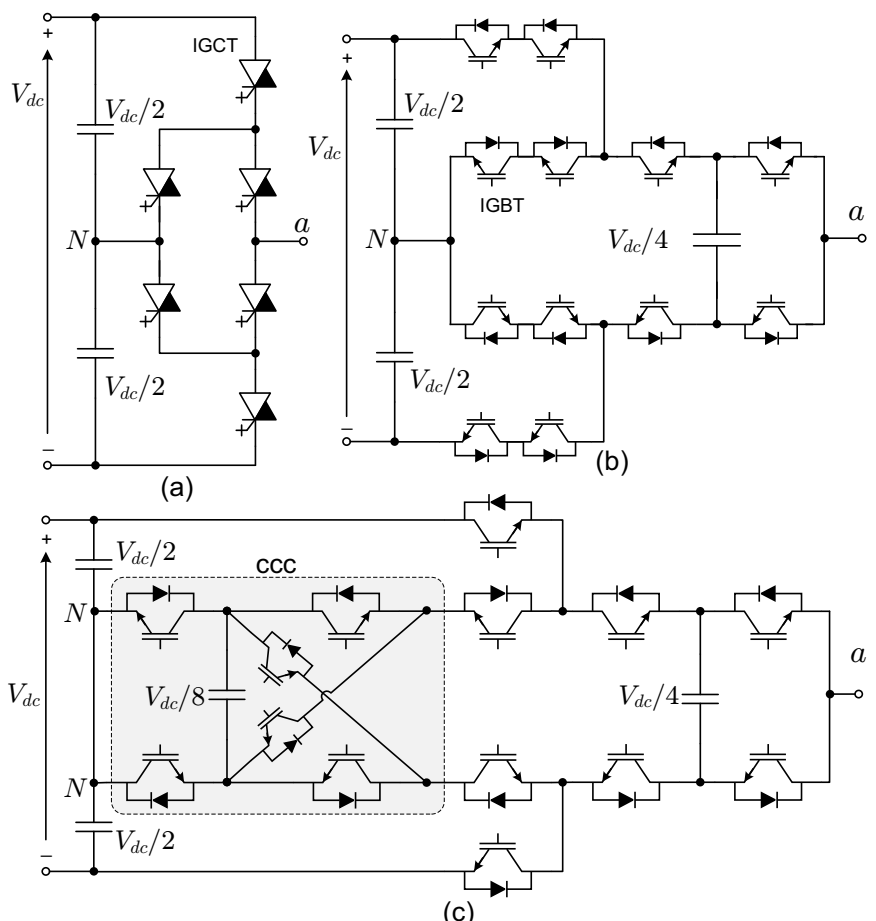

Fig. 4. Active NPCs (only phase $a$ shown): a) 3L-ANPC featuring IGCTs [46], [47], b) 5L-ANPC featuring IGBTs (hybrid between 3L-ANPC and a 3L-FC) [48]-[50], c) Common cross converter stage plus 5L-ANPC hybrid 9-level converter [51]. come at expense of a more complex circuit structure, and with the need to control the flying capacitor voltages and their initialization, besides the NPC dc-link capacitors voltage unbalance control. In contrast to the CHB topology, this modularity does not increase the power rating of the converter but only the number of levels and the power quality, since the flying capacitor adds an intermediate voltage level and does not provide active power, so the power rating is still limited by the ANPC part. Note that instead of IGCTs, series connected IGBTs are used in the NPC part of the converter, probably to keep all semiconductors of the same type. This inherently introduces more conduction and switching losses, and requires a special gate driver to ensure simultaneous control of both switches. Nevertheless, because of the extra levels and the particular configuration of the power circuit, the outer switches commutate at lower switching frequency which compensates for the series losses. Other ratios for the flying capacitor voltage can be used to increase the number of voltage levels at the output. However, in that case higher switching frequencies are necessary to control the capacitor voltage properly and makes it less attractive.

A commercial version of this topology has been recently introduced [11], [50], aimed at medium voltage but not high power. Configurations are available from 0.4 to 1MVA, rated at 6 to $6.9 \mathrm{kV}$, air cooled, with maximum output frequency of $75 \mathrm{~Hz}$, exclusively in back-to-back configuration.

In addition, a variation to the hybrid 5L-ANPC has been proposed by adding a common cross converter (CCC) stage introduced in [54] to the 5L-ANPC resulting in a 9-level hybrid converter introduced in [51] and shown in Fig. 4c. This converter stage can connect any nodes of its input to any node of its output through a set of direct and diagonal connected switches. When this stage is added between the 3L-ANPC part and the FC part of the circuit, the CCC stage capacitor can be clamped in any polarity between the 3L-ANPC dclink capacitors and the flying capacitor producing even more levels. If $V_{d c} / 8$ is chosen for the CCC stage capacitor (i.e. a ratio between the ANPC dc-link voltge, the FC voltage and the CCC voltage equal to $V_{d c} / 2: V_{d c} / 4: V_{d c} / 8=$ 1 : $0.5: 0.25), 9$ different output levels can be generated $\left( \pm V_{d c} / 2, \pm 3 V_{d c} / 8, \pm V_{d c} / 4, \pm V_{d c} / 8\right.$ and 0$)$. More CCC stages can be added to increase the number of levels. Although this additional stage increases the number of levels which greatly improves power quality, this comes at expense of a complex circuit structure and the need to balance both, the CCC and FC stage capacitor voltages. Moreover, the voltage ratio chosen for the CCC stage capacitor can affect the overall maximum modulation index achieved by this topology, which for the ratio 1:0.5:0.25 is $M=0.925$ at full active power [51], limiting its application field. As with the 5L-ANPC this converter is also limited in power range to the ANPC stage, and the CCC does not supply additional active power. On the attractive side, since the CCC stage is common to the three phases this converter reaches 9 levels with less components than the $\mathrm{CHB}$ with equal dc-sources, and with a much simpler transformerrectifier system. 


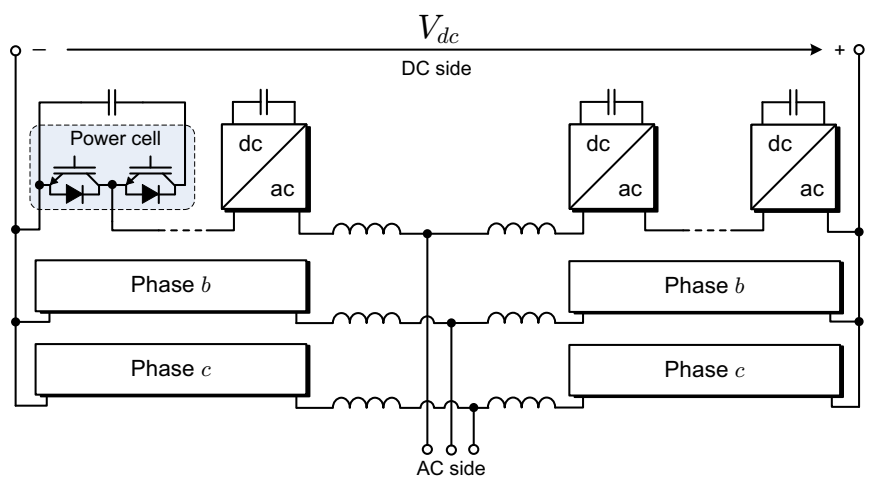

Fig. 5. Modular Multilevel Converter M2C or MMC (series connected 2-level VSIs)

\section{Modular Multilevel Converter (MMC)}

Another multilevel converter that has recently found industrial applications is the Modular Multilevel Converter (M2C or MMC), particularly for HVDC systems [55], [56]. This topology was developed in the early 2000s [57] and received increased attention since then [58]-[60]. Three-phase ac-ac and also ac-dc topologies have been proposed. Basically the MMC is composed of single-phase two-level voltage source converter (2L-VSC) legs, also known as half-bridges, connected in series as illustrated in Fig. 5. The phase leg is divided in two equal parts (number of cells must be even) to be able to generate equal number of positive and negative levels at the ac side. Also H-bridge cells have been proposed [60][62]. Some inductors are usually included within each leg to protect during transitory short circuits.

The two switches of the power cell are controlled with complementary signals and produce two active switching states that can connect or bypass its respective capacitor to the total array of capacitors of the converter leg, generating in this way the multilevel waveform. There is a third switching state: both switches off that is used during start up or failure condition, allowing the current to circulate freely trough the diodes (and through capacitors if so demanded by the current polarity). In practical application there is an additional bypass switch to fully isolate each cell for fault tolerant operation [55].

Since the capacitors are floating, an appropriate voltage balance control is necessary to keep each one at a constant voltage level [59]. The total dc side will be the sum of all the capacitor voltages in one leg. The attractive feature of this topology is its modularity and scalability to reach easily medium and high voltage levels, meanwhile greatly improving ac side power quality compared to the classic series connection of power switches in a two-level converter configuration used in HVDC (also the uneven voltage sharing problem between series connected devices is solved). In addition, there is no need for high voltage dc-link capacitors (or series connected), since the intrinsic capacitors of the cells perform these task. The high number of levels enables a great reduction in the device average switching frequency without compromise of power quality. This topology can be found in practical applications reported with 200 power cells per phase reaching up to $400 \mathrm{MW}$ [55], and is commercialized up to $1 \mathrm{GW}$ [56].

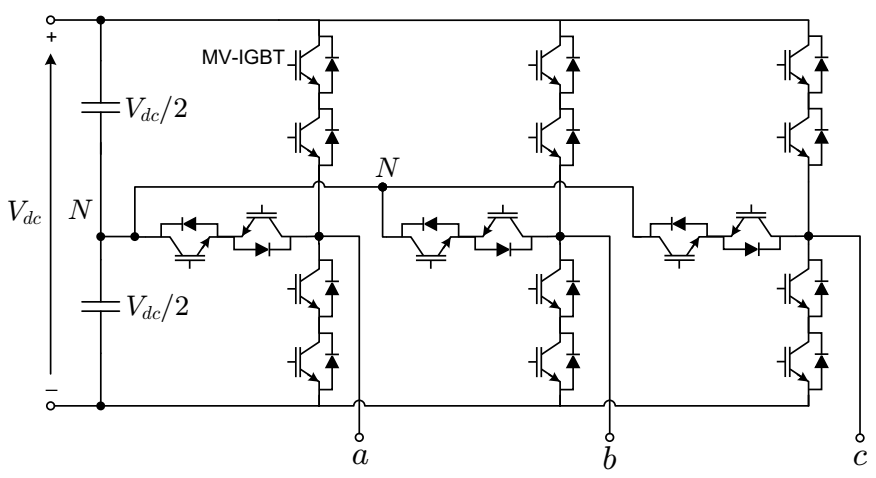

Fig. 6. Three-phase three-level transistor clamped converter (3L-TCC).

\section{Transistor Clamped Converter}

The transistor clamped converter (TCC) concept is very similar to the one of the DCC and was first introduced in 1077 [63]. Instead of clamping the connection points between switches and the capacitors through diodes, it is done by bidirectional switches This gives a controllable path for the currents through the clamping devices, like with the ANPC. In [64] a bidirectional switch using 4 diodes and one transistor is presented, and the topology is explored from three to several levels. In [65] a three-level version with a bidirectional switch based on two anti-series connected IGBTs is proposed. Since the three-level case has a neutral point, just like the NPC and it is fully controllable, this topology is also known as Neutral Point Piloted (NPP), and can be seen in Fig. 6. Note that two switches in series are necessary in the upper and lower part of the converter leg to reach medium voltage. The two central IGBTs form the bidirectional switch, that when on generates the zero voltage level.

This topology has found industrial application [15], [66], and is aimed for medium voltage $(3.3,6.6$ amd $9.9 \mathrm{kV})$ and high power up to $48 \mathrm{MW}$. The losses shared by the devices, enable to switch at higher switching frequencies which can effectively increase the maximum output frequency. Hence this converter can be suitable for variable high speed applications such as train traction drives.

\section{E. Multilevel Matrix Converters}

The matrix converter belongs to the direct conversion family of the classification in Fig. 2 since it connects directly the input ac lines to the output ac lines trough bidirectional switches and without need of energy storage devices like capacitors or inductors. As consequence, their strengths are an important weight/volume reduction and inherent four quadrant operation, which are desirable features for transportation systems (electric vehicles, more electric aircraft, military vehicles, etc.).

The lack of energy storage devices does not favor the possibility to arrange semiconductors in such a way that higher voltages and more voltage levels can be reached. This is why this topology was limited to a small application scope. However, recently several multilevel matrix converter topologies have been reported [69]. Most of them are actually based 


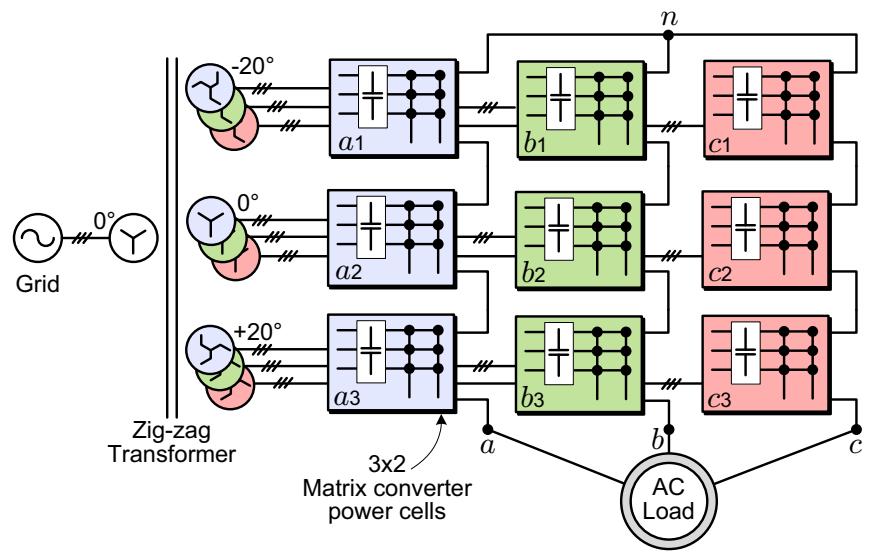

(a)

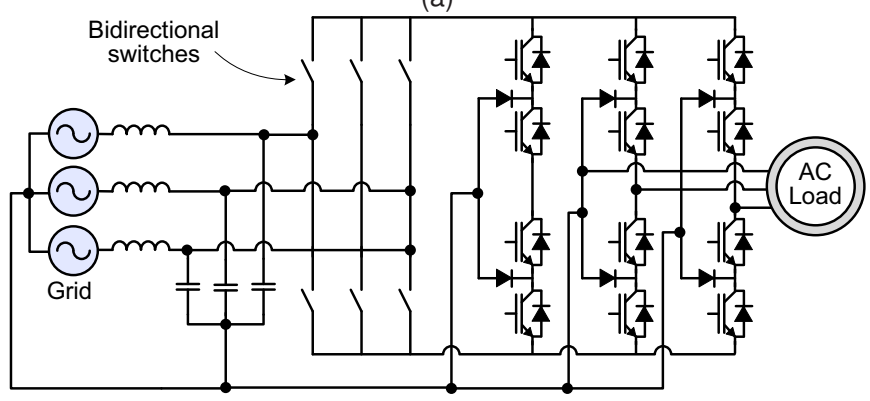

(b)

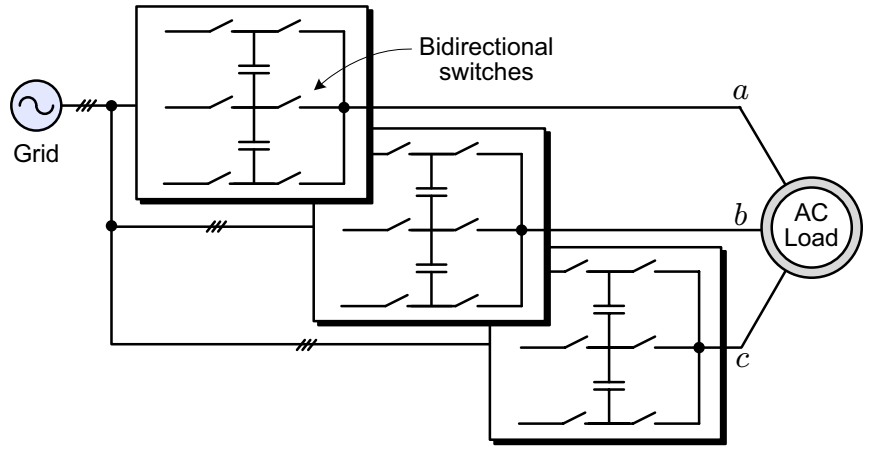

(c)

Fig. 7. Multilevel matrix converter topologies: a) Cascaded Matrix Converter [67], b) Indirect Matrix-NPC [68], [69] and c) Flying Capacitor Matrix Converter [70].

on the three classic multilevel topologies discussed earlier: the Cascaded Matrix Converter [67], the Indirect Matrix-NPC [68], [69] and the Flying Capacitor Matrix Converter [70], shown in Fig. 7a, Fig. 7b and Fig. 7c respectively.

The cascaded matrix converter is the only one that effectively increases the power rating of the converter. Like the $\mathrm{CHB}$, this topology elevates the voltage by the series connection of power modules. This is achieved by introducing a phase shifting power transformer that provides isolated and phase-shifted three-phase secondary ac sources that are connected to the load side by a power cell composed of a $3 \times 2$ matrix converter and its corresponding three-phase input capacitive filter. Each cell connects through bidirectional switches (shown as connection nodes in each cell of Fig. 7a) two input ac lines to the two output ac lines of each cell provided the following restriction: each output line must be connected to one, but not more than one input line. This means that if the output line is not connected to one input line, no current path is available at the load side, and if it is connected to more than one, a short circuit of the input lines is produced. The series connection of the two output lines of the cells is possible due to the isolation of the ac inputs provided by the transformer. The phase shifting transformer not only supplies isolated ac sources, but the phase shift has a multipulse effect reducing the input current harmonics, just as with the CHB. In addition the phase shifts at the secondary side produce the effect of having a multiphase ac source (6 phases for a 2-cell converter, 9 phases for a 3 -cell converter), that enables the generation of more output voltage levels. The proper control of the switching states produces a stepped multilevel output voltage waveform at the load side. More details on this can be found in [67].

The cascaded matrix converter is the only one of the matrix converter based multilevel topologies that recently has found commercial presence [22]. Two commercial versions are available featuring 3 or 6 matrix converter cells in series per phase. The 3 (or 6) cell version generates a 7 (or 13) level phase voltage to feed the ac load up to $3.3 \mathrm{kV}$ (or $6.6 \mathrm{kV}$ ), covering a power range of 0.2-3MVA (or 0.4-6MVA).

Although the phase-shifting transformer is needed to enable the series connection of matrix converter cells to reach medium voltage and high power operation, and also improves the input/output power quality, it adds volume and weight affecting negatively one of the features of classic matrix converters. In addition, one of the mayor drawbacks is the switch count: 6 bidirectional switches per cell will require 108 switches for a 3-cell 3-phase 7-level cascaded matrix converter compared to 36 switches used in a 3-cell 3-phase 7-level CHB. This reduces reliability (higher failure probability) and reduces efficiency (more conduction and switching losses).

\section{F. $C H B$ with unequal dc sources (asymmetric CHB)}

If the CHB topology, shown in Fig. 1c, is fed with unequal dc voltage ratios between cells, some or even all voltage level redundant switching states can be eliminated, maximizing the number of different voltage levels generated by the converter. This concept of asymmetric dc source ratios was introduced in [71] for magnetic resonance imaging applications. Later this idea was further explored for medium voltage converters [72] with two or more cells in series with a powers of two voltage ratio asymmetry $\left(1: 2: \ldots: 2^{n-1}\right)$, capable of generating 7 different voltage levels with only two cells. Later voltage ratios in powers of three $\left(1: 3: \ldots: 3^{n-1}\right)$ were introduced [72], [73] that eliminate all redundancies and maximize the number of levels at the output. This converter asymmetry is also known as trinary hybrid multilevel converter [74]. Another popular ratio is $1: 2: 6: \ldots: 2 \cdot \Sigma$ (previous ratios), which can maximize the number of levels while still being able to apply hybrid PWM modulation [75]. A comprehensive work analyzing this topology in depth is presented in [76]. A variant to this topology was introduced in [77], in which all the cells have the same voltage rating at the dc side and the asymmetry is introduced in the output transformer primarysecondary ratios, so that the voltage when connecting the secondaries in series has the multilevel waveform. 
Besides the exponential increase in the number of levels when adding more cells, this topology allows to switch the higher power cells at fundamental frequency reducing the switching losses of the converter, improving efficiency. However, this advantage is also its greatest weakness, since power is not evenly distributed among the converter cells, eliminating the input current low order harmonics cancelation effect of the multipulse rectifier system of the traditional CHB. Moreover, to reach medium voltage operation different switching device families are necessary, as well as different thermal design for each power cell, eliminating the modularity advantage of the $\mathrm{CHB}$. The impact on the input current harmonics is addressed in [78].

Another disadvantage is that for some asymmetries and some modulation indexes the circulating current among the cells produces regeneration in small power cells even if the overall converter is in motoring mode, forcing the use of resistive choppers, regenerative front end or non-conventional modulation schemes to keep the capacitors at the desired voltage ratio. Despite its great advantages in power quality and efficiency, these drawbacks have kept back this converter to have practical application. Nevertheless, the concept of asymmetric voltage ratios to maximize number of voltage levels when cascading other topologies (even hybrids between topologies) has further been explored and has interesting potential to become applicable. Some of these topologies are discussed in following subsections.

\section{G. Hybrid Multilevel Converters}

The combination of two, or even just part of classic and not so classic multilevel converter topologies gives birth to an overwhelmingly wide range of hybrid multilevel converter topologies found in literature. Due to space limitations these cannot be covered comprehensively in this technology review. Some hybrid topologies have been already discussed earlier in this paper, for example: the H-NPC, the 5L-ANPC and the cascaded matrix converter. The first combing the $\mathrm{H}$-bridge and NPC, the second merging the ANPC and the FC, and the later an hybrid between CHB and matrix converters.

Another hybrid that has received sustained attention in the last decade is the NPC-CHB multilevel converter [79]-[83]. A generic power circuit of the NPC-CHB is illustrated in Fig. 8. As the name suggests, it is an hybrid between the 3L-NPC and single phase $\mathrm{H}$-bridge cells connected in series at the output between the NPC and the load. The H-bridge dc side is a floating capacitor without a voltage supply. Hence, the addition of H-bridge stages only introduces more voltage levels, but does not effectively increase the active power rating of the overall converter. The number of H-bridge cells connected in series varies are usually one or two [79]-[83].

The CHB stage acts as a series connected active filter. Although it contributes to enhance the power quality and reduce the common mode voltages, it also introduces additional conduction and switching losses. The H-bridge dclink capacitor voltage control, necessary to keep a desired voltage ratio between the NPC and the CHB, also adds to

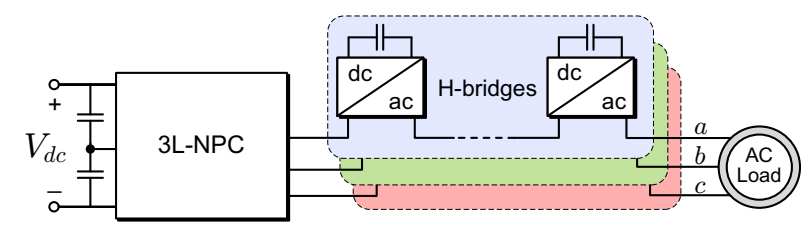

Fig. 8. Multilevel NPC-CHB hybrid converter with one or more H-bridges in series connection per phase (can also have unequal dc voltageratios) [79][83].

the complexity of the control system and requires additional voltage sensors.

Similar to the NPC-CHB, the traditional CHB has been modified by using a single dc-supply per phase, leaving the other cells floating [84], [85]. This simplifies the CHB topology by eliminating the complex face shifting transformer, but limits the total active power rate of the converter. As with the NPC-CHB special control of the floating dc-link capacitors is necessary.

A sub-category of hybrids has been specially conceived for open-end stator winding motor drives, and have very particular features. These are addressed in next sub-section.

\section{H. Hybrid Multilevel Converters feeding open-end stator winding motor drives.}

The concept of cascading two converters, one at each side of an open-end stator winding of an induction motor, was first introduced in [86] with several configurations, including two 3L-NPC converters at each side of the machine. Later, in [87] two separately exited two-level voltage source inverters with different voltage ratios generating a four level converter was introduced. More recently, this concept has found more acceptance cascading two 3L-NPC one at each side [88]-[91], with only one supplying active power (main NPC inverter) fed by dc-source, and the other used for power quality improvement as a series active filter (conditioning NPC inverter) with floating dc-side capacitors with different voltage ratios, as shown in Fig. 9. With a 1:3 voltage ratio 9-levels can be generated. The latest contributions feature IGCTs for the large converter and IGBTs in the smaller one, being the first one the classic of-the-shelf commercially available 3L-NPC discussed in previous section [90], [91].

Several other variants of the cascaded open-end winding converter have also been reported, some with different topologies at both sides, with other voltage ratios, with two or one dc-source, and even some with more than two converters in series connection [73], [92]-[100].

In order to produce the same air-gap flux in the machine, the voltage amplitude required for the motor is divided in the two total dc voltages of the converters at both sides of the stator, in two equal or unequal parts (depending on the dc ratio used). This automatically reduces the device ratings and $d v / d t$ stress on the machine and the inverters. Many additional advantages of open-end induction motor drives like commonmode voltage elimination and capacitor voltage balancing has been reported recently [95]-[98].

The use of asymmetric dc sources together with an open-end winding has produced a new voltage space vector disposition 


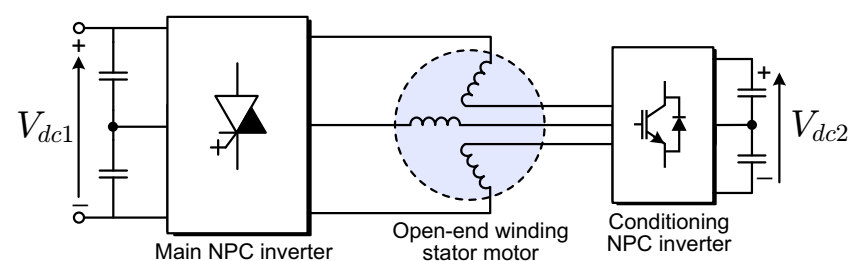

Fig. 9. Cascaded NPC multilevel converter connected in series through an open-end winding stator motor.

following a 12-sided polygonal shape rather than the classic hexagonal shape [101]-[104]. This converter configuration serves also as an active harmonic filter to the voltage fed to the motor, since all the $6 n \pm 1$ harmonics (with $n$ odd) are absent throughout the modulation index range including overmodulation region. Since the 12-sided polygon is closer to a circle than a hexagon, the linear modulation range is also extended. This has also been extended to multilevel 12-sided [105] and 18-sided polygonal voltage space vector dispositions [106].

It is worth to mention that in those cases when the conditioning (usually smaller rated) converter is floating it does not supply active power, so additional power electronics is used without actually increasing the active power rating of the converter. Although this improves the power quality by introducing more levels, it adds complexity to the topology, to the control/modulation scheme and introduces new conduction and switching losses. On the other side if both converters are connected to a rectifier front end, and both supply active power, the asymmetry in the voltage ratios introduces same problems as with the CHB with unequal de sources, namely the multipulse rectifier configuration looses its effect in canceling low order input current harmonics.

The concept of the cascaded conditioning converter of the hybrid topology of Fig. 8 and the cascaded connection through open end winding of Fig. 9 competes with other available solutions, such as active filters in shunt connection directly between the converter and motor drive with a separate control/modulation scheme.

\section{Multilevel topologies by interconnection of 2L-VSIs}

The concept of interconnecting three classic of-the-shelf three-phase 2-level voltage source inverters (2L-VSIs) to generate a multilevel waveform was first introduced in [107]. This topology has been recently further explored in [108]. Basically two of the phases of each VSI are connected to the other two through inductors, leaving one unconnected phase per converter, which together constitute the three output phases of the overall multilevel topology, as shown in Fig. 10. Since it is based on three-phase converters rather than single-phase $\mathrm{H}$-bridges at the output compared to the $\mathrm{CHB}$, it requires less cells and therefore features a simpler transformer with less secondary windings. It also has fewer power semiconductors and capacitors, although it introduces inductors and has lower number of output levels [108]. This concept has also been further extended interconnecting six 2L-VSIs, which yields

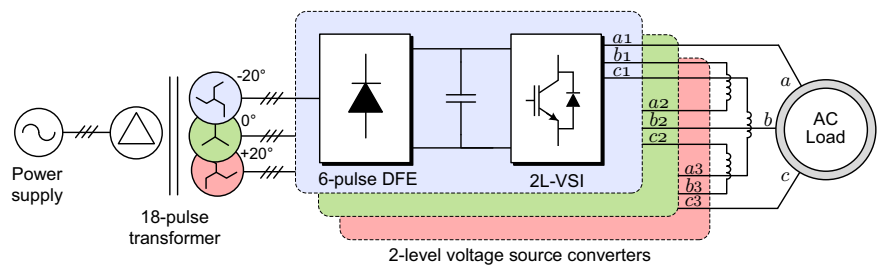

Fig. 10. Interconnected three-phase 2L-VSIs [108].

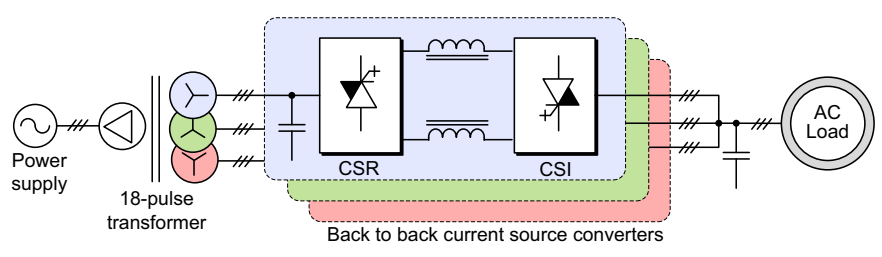

Fig. 11. Power circuit of 7-level current source converter [111].

to a six-phase multilevel converter topology called Hexagram inverter [108]-[110]. It can also be used for three-phase drives with open end stator windings, by connecting two of the converter phases to each winding of the motor.

\section{J. Multilevel current source topologies}

The current source multilevel converter concept has also been reported [111]. They are conceived following a duality principle between voltage source and current source converters, which is based mainly on translating the stepped series connection of capacitors voltages to stepped shunt connection of inductor currents. In this way several multilevel current source converter topologies analogous to their voltage source counterparts have been discussed in [112]. Figure 11 shows a simplified power circuit of a 7-level current source converter. It uses an 18-pulse rectifier system to feed three back-to-back current source converters. Each one produces a 3-level line current, including a zero current level, thus by controlling the switching angles of each current source converter appropriately, a 7-level stepped current waveform can be generated at the node of interconnection.

Instead of avoiding series connection of devices to reach higher voltage operation while improving voltage waveform quality with a voltage source multilevel converters, the multilevel current source avoids parallel connection of devices and reaches higher output currents while improving current waveform quality. Hence this topology is well suited for high current demanding applications.

\section{K. Other topologies}

As stressed throughout this paper, multilevel converter technology has evolved into a such wide and rich variety of different topologies, that it is impossible to analyze and discuss each one of them. In this subsection other topologies will be briefly addressed and referenced focusing mainly on those reported during the last years.

As can be observed in Table I, the CHB has only one regenerative commercial version. The main reason is that 
the diode front end is replaced by a thee-phase 2L-VSI, adding 6 low voltage IGBTs with freewheeling diodes per cell, increasing the device count and fault probability. This problem has been addressed in [113], where alternatives for the active front end are explored based on single phase H-bridge and half-bridge topologies, the later having only two low voltage IGBTs and two freewheeling diodes.

Another disadvantage of the CHB is the bulky and complex input phase-shifting transformer. An alternative using a medium frequency isolated $\mathrm{dc}-\mathrm{dc}$ converter stage has been proposed [114]. The dc-dc stage is composed of two H-bridges connected through a high or medium frequency transformer, reducing the size and weight of the converter while providing galvanic isolation. However, this solution introduces a lot more power electronic devices, which also need to be controlled through modulation, increasing implementation complexity and reducing converter efficiency (more conduction and switching losses). Nevertheless, this solution can provide bidirectional power-flow and controllable input power factor and has been considered as a possible candidate to eliminate the bulky input transformer in train traction drives [115], [116], or to act as a power decoupling stage in CHB power converters used for flexible power management systems that interconnect different grids and ac systems [117].

The flying capacitor topology also originated some variants to overcome its limitations. In order to reach higher voltages, and increase the number of voltage levels the Stacked Multicell Converter (SMC) was introduced in the early 2000 [118]. Quite literally the SMC are two classic FC stacked one over the other. This reduces the voltage stress on the devices and capacitors, enabling higher voltage operation while reducing the device switching frequency while even improving the converter output voltage waveform due to the new voltage levels. Despite these improvements the SMC has not yet found industrial presence, mainly because of the high number of capacitors needed compared to other topologies. Nevertheless, recent contributions show there is still interest in this topology [119], [120].

In relation to variations to the classic 3L-NPC, several of them were discussed in previous subsections (H-NPC, 3LANPC, 5L-ANPC, NPC-CHB, and cascaded NPC through open end windings), with some of them already commercial products. In addition, the classic NPC structure has been extended to four [121], five [122] and even more levels [123]. Since the 4-level version actually has no neutral or zero voltage level node, and together with the 5-level version they have more than just one clamping point compared to the 3L-NPC, it has more sense to talk here of diode clamped converters (DCC) instead of neutral point clamped converters. These topologies increase the voltage and power rating of the converter along with the number of levels, while enabling a reduction of the device switching frequency, like all other multilevel topologies with more levels. However, they have not found industrial acceptance because the series connection of diodes are necessary to block the increased voltage produced by the series connection of the capacitors above and below the node where the output phase has been clamped. This increases the conduction losses of the converter. In addition, for DCC above 3-levels with diode front ends, the voltage balancing of the dc-link capacitors cannot be achieved for all modulation indices while keeping the traditional multilevel stepped waveform [123]. This issue may not be a problem in back-to-back configurations were the capacitor voltages are controlled by the active front end, but for applications where an active input rectifier is not required (not regenerative applications like fans, blowers, pumps, and compressors) other solutions have been proposed by introducing additional hardware. For example, a two bidirectional buck-boost dc-dc converter stage has been proposed to assist the voltage balancing of the capacitors for the 5-level DCC [124]. However, this extra dc-dc stage adds complexity to the topology, including additional switching devices, inductors, sensors and control scheme. Although, the dc-dc stage does not drive all the converter power, it has an unfavorable effect on the converter efficiency due to the additional conduction and switching losses, which for the power levels of the application field of this converters is considered a weakness. Therefore, the back-to-back solution seems more attractive, even for non-regenerative applications (despite the higher manufacturing cost), since it has the intrinsic ability to provide input power factor control, compared to the diode front end solution that besides the extra dc-dc stage will need passive or active filters to meet grid codes at these power levels, which all together is as much hardware and cost as the back-to-back solution. It is worth mentioning that these variants do not solve the problem of the series connected clamping diodes.

\section{Recent Advances In Modulation}

Many new modulation techniques have been developed to cater to the growing number of multilevel inverter topologies. They are aimed at generating a stepped switched waveform that best approximates an arbitrary reference signal with an adjustable amplitude, frequency and phase fundamental component, usually a sinusoid in steady state. Since the modulation scheme is intended to be used in high power converters the main figures of merit pursued are high power quality and minimum switching frequency. These two requirement compete with each other, and therefore, it is considered one of the mayor challenges in multilevel converter technology. Despite this, some basic extension of classic modulations methods used for $2 \mathrm{~L}-\mathrm{VSI}$ are the ones that have been used in commercial converters.

\section{A. Classic multilevel modulation methods}

The level shifted PWM (LS-PWM) and phase shifted PWM (PS-PWM) techniques have been the natural extensions of carrier based sinusoidal PWM for the NPC and for multicell converters (CHB and FC) respectively [9]. The LS-PWM, also known as phase disposition PWM and other carrier disposition variants [125], [126] is a simple way to relate each carrier with the gating signals of NPCs and therefore is one of two modulations schemes used in industry, and is commonly referred simply as sinusoidal PWM (SPWM) as shown in Table I. The PS-PWM associates a pair of carries to each cell of the CHB and FC, and a phase shift among the carries 
of the different cells introduces asynchronism that generates the stepped waveform. In this case the advantage lies in that power is evenly distributed among the cells across the entire modulation index, which enables the correct operation of the multipulse rectifier configuration of the $\mathrm{CHB}$ and a natural balancing of the flying capacitors in the FC [9]. Therefore, PS-PWM is also the only real commercial modulation scheme used in CHB and FC, which can be corroborated in Table I. Although it has been reported that PD-PWM has better output voltage harmonic profile than PS-PWM [126], these are very small differences in the high frequency harmonic content, which are filtered by the load. Therefore, from a practical point of view, the operational advantages of PS-PWM for CHB and FC are far more relevant than the superior harmonic content of PD-PWM, explaining the trend followed by industry.

Another commercially available modulation method that also comes from the two-level version is multilevel selective harmonic elimination (SHE) [9], [127], [128]. This method is the second one available for 3L-NPCs (see Table I). The main feature is that, unlike with carrier based PWM methods, the switching angles are computed off-line, and are designed in such a way that arbitrary harmonics (usually of low order) are eliminated. This method has the advantage of having very few commutations per cycle and is therefore the one that achieves better efficiency and enables air-cooling. On the negative side, the SHE angles are computed based on Fourier series and the assumption of steady state sinusoidal voltages, hence for variable speed operation these angles will not fully eliminate the harmonics, which through feedback can be greatly amplified by the closed loop controller, degrading overall performance, and therefore is limited in practice to low dynamic performance demanding drive applications (pumps, fans, etc.).

\section{B. New multilevel modulation methods}

In contrast with the high amount of recently introduced multilevel topologies, no new multilevel modulation schemes have made their way to industrial applications, despite the great amount of recent contributions and advances on this topic. The main reason could be that manufacturers favor the proven technology and simplicity of carrier based PWM schemes over new methods that have advantages but usually at expense of more complex implementation. Nonetheless, multilevel converters have many additional degrees of freedom compared to two-level converters: more voltage levels, zero common mode voltage vectors, switching state or voltage level redundancy and space vector redundancy, that are not always fully exploit by carrier based PWM schemes, which together with the appearance of new converter topologies are the main drivers for the development of new modulation strategies.

One of the modulation methods that has the potential to use more effectively these new degrees of freedom is space vector modulation (SVM). SVM has also been extended and even generalized for n-level multilevel converters using two-dimensional and three-dimensional algorithms [42], [78], [129]-[140]. A common characteristic to all SVM based schemes is that the modulation algorithm is divided into three stages: in the first, a set of switching states or vectors need to be selected for modulation, usually those are the closest three vectors to the reference [129]; the second stage computes the duty cycles (or On and Off-times) of each vector to achieve the desired reference over a time average; and the final third stage is the sequence in which the vectors are generated, usually center distributed or symmetric sequences are favored due to synchronous digital sampling of the current. The different contributions that report variations on the three basic stages of SVM pursue different goals which in many cases are one or more of the following: switching frequency reduction, lower computational cost, common mode voltage elimination or reduction, lower THD, SVM for multi-phase systems, unbalanced system operation, capacitor voltage balance, feedforward of dc-link ripple, etc. Despite all these reported improvements, SVM based multilevel algorithms are not the dominant modulation scheme found in industrial applications to this date. A probable reason is that carrier based PWM requires only the reference and carrier signal and a simple comparator to deliver the gating signals, while even very low complexity and low computational cost SVM methods require an algorithm with at least the three stages mentioned before.

Recently it has been demonstrated that the same voltage waveform generated by the most common SVM algorithms can be obtained in a much simpler way using a single-phase modulator [141]. The advantages are that it can be easily extended to converters with any number of phases and any number of levels, hereby reducing the design, implementation and computation complexity usually associated to SVM algorithms.

Cascaded converters feeding both sides of an open end winding stator can generate (depending the voltage ratio between them) non-conventional voltage space vectors distributions that follow a different pattern than the traditional concentric hexagonal layout in the $\alpha-\beta$ complex plain. In fact, they generate 12-sided and 18-sided polygonal space vector distributions [105], [106]. As the number of sides of the polygon increase, the space vector distribution for a same magnitude becomes closer to a circle. As such, the instantaneous error between the reference vector and the switching state space vectors decreases. This further reduces $d v / d t$ s and improves the harmonic content in the output voltage without need to increase the device switching frequency. SVM schemes for these polygonal distributions are presented in [105], [106].

As stressed throughout the paper, one of the most important parameters that is strongly related to the modulation stage is the average device switching frequency. This is why much of the recent works published on this subject have as central focus the switching frequency reduction. A comparison of switching losses produced by different modulation methods applied to CHB and NPC converters are presented in [142] and [143] respectively.

As an alternative to SHE, other low switching frequency modulation schemes have been proposed, like selective harmonic mitigation (SHM) schemes [144], [145] and synchronized optimum PWM techniques [146]-[148]. These two 
techniques require important off-line computations like SHE, and the computations increase over-proportional with higher number of levels. However, once the formulation of the equations and the numerical solving has finished, the results only need to be stored in look-up tables in the digital interface control board. These methods have the same drawback of SHE, that variable speed operation in closed loop operation will require a low bandwidth control loop, with the consequent low dynamic performance. SHM differs from SHE in the fact that the harmonic are not fully eliminated, instead some content is allowed up to the grid code limits, which enables to control more harmonics with the same amount of angles (commutations). In this way, SHM achieves a reduced THD which is in compliance with the grid code, while SHE fully eliminates low order harmonics, which usually moves harmonic energy to the higher frequencies increasing their amplitude even over grid code limits.

SHE has been extensively analyzed for a wide variety of converter topologies [44], [48], [127], [149]-[153]. Recently real-time (on-line) SHE methods have been proposed based on a total THD minimization rather individual harmonic analysis [154], [155]. Although the on-line part is an attractive feature, the fact that the overall THD is considered does not give any warranty that grid codes are always met, irrespective of the modulation index and operating condition. In fact the THD could be minimized at expense of having all the harmonic energy in the low order harmonics. In [156], a predictive control based SHE method has been proposed which is also performed online, but considers the amplitude of each harmonic in real time thanks to a Sliding Discrete Fourier Transform. A predictive model is used to select the switching state that minimizes all the desired harmonics. The predictive model together with the sliding discrete fourier transform allow to use this modulation method on closed loop operation with higher dynamic performance capability.

\section{RECENT AdVANCES In CONTROL AND OpERATIONAL ISSUES}

In contrast to modulation methods which required substantial research and development, and still are, to adapt to the special needs and switching states of the multilevel topologies, the control of them has been a more straightforward extension. In fact, multilevel converter powered variable speed motor drives are controlled using the same methods used for twolevel voltage source converters, namely: v/f control (or scalar control), Field Oriented Control (FOC, also know as Vector Control) and Direct Torque Control (DTC) [4]. The main reason is that both v/f control and FOC have a modulation stage embedded in the control loop, hence the control scheme does not change, only the modulation stage must be replaced. In other words, the two-level PWM or SVM needs to be replaced by an appropriate modulation scheme that best fits the particular multilevel converter. As can be appreciated in Table I both methods are used by several manufacturers in the field.

In contrast, DTC relates each switching state or voltage vector generated by the converter to a specific change in the motor flux and torque, which cannot directly be extended from the two-level to the multilevel case. The main reason is that the number of vectors increases over-proportional to the increase of voltage levels, making difficult to define a voltage vector selection criteria according to the flux and torque errors. Nevertheless, this has been addressed for 3LNPC converters by using multiple hysteresis bands controllers and a finer sector division of the space vector complex plane [157], and has been successfully used in industry, as can be observed in Table I. The extension of direct torque control for other topologies and converters with more levels has also been reported in [158], [159].

More recently some characteristics of FOC and DTC have been combined into another motor drive control method called SVM-DTC [160], that combines linear controllers and the SVM modulation stage of the FOC scheme with the load angle control concept of DTC (control of the angle between stator and rotor fluxes). This control method achieves fast dynamic control of the torque like DTC but introduces a modulation stage that fixes the switching frequency, which is one of the mayor drawbacks of traditional DTC. This method can be easily extended to multilevel converters, again by just replacing the two-level modulation stage by a multilevel modulation method [161]. In case of multilevel converters with high number of levels, the modulation stage is even not necessary, and the nearest level generation can be used [162].

Following the analogy between motor side and grid side control schemes, multilevel converters connected to the grid are controlled with Voltage Oriented Control (VOC) and Direct Power Control (DPC) [163], which are the grid side counterpart of FOC and DTC respectively. Further enhancements that use a grid virtual flux concept to better synchronize the control method to the grid have been introduced in [164] and applied to multilevel converters in [49]. As with motor control, a combination of both methods has been proposed originating SVM-DPC and has been applied to a 3L-NPC [165]. Both VOC and SVM-DPC need only a multilevel modulation stage update, while DPC has been extended for multilevel converters in [166].

Apart from the development of modulation methods and the extension of control methods for multilevel converters, some operation specific issues like capacitor voltage control, common-mode voltage reduction/elimination and fault detection, diagnose and tolerant operation of multilevel converters are equally important.

Several multilevel converter topologies suffer from voltage unbalance among the dc-link capacitors at certain modulation indexes and operating conditions [40], [41], [123], [167][176]. Probably the most well known problem in this topic is the capacitor unbalance of NPC or DCC topologies. Particularly the unbalance in 3L-NPC has been extensively studied and several solutions have been reported [9]. Considering the successful industrial presence of the 3L-NPC and the fact that it is commercialized by at least nine manufacturers it can be concluded that from a practical point of view this is a solved problem. This is not the case for 4-level and up DCC topologies. The reason is that for diode front end DCCs of more than 4-levels the capacitors cannot be properly balanced 
with conventional modulation techniques producing a typical multilevel converter stepped waveform. Instead some switching states are avoided to perform balance control, leading to higher $d v / d t$ s. This is why it is still subject of attention and research. As an alternative, additional hardware, usually a dcdc stage is added aid in the control of the capacitor voltages [124]. The unbalance problem is not an issue in back-to-back configurations, since the active front end is responsible of the dc-link voltage control

The challenge of dc-link voltage balance is not exclusive to the NPC family. In fact, although flying capacitors have an autobalance property when used with PS-PWM, the dynamic response of the capacitor voltages is very slow. Therefore some works propose additional control mechanisms also based on switching state redundancies, to improve the dynamic performance of the voltage balance. In [172], [177] a model and an analytical study on the balancing problem and dynamics of FC is presented. Recently a voltage balancing passive circuit has been proposed to assist the voltage balancing in a FC [178], [179]. In [180], the voltage balancing control of the capacitors of a modular multilevel converter is studied.

The CHB is the only one that has no unbalance problems, since each dc-link is fed by an isolated dc-source. However, for STATCOM, active filters and other applications in which the capacitors are floating (not connected to a dc source), a voltage control algorithm is necessary to keep the voltages controlled at the desired level. This issue is not exclusive for the CHB, in fact the same challenge applied to any other topology used in applications where the capacitors are floating.

The common-mode voltage generated due to inverter switching is detrimental to the motor shaft and bearings. Several new strategies to eliminate the common-mode voltage have been proposed recently [74], [94]-[97], [122], [251].

The use of predictive control in the field of multilevel converters has been introduced very recently as a very attractive and promising alternative [252]. In effect, the use of predictive control avoids the need of modulators and linear controllers to generate, for example, controlled currents to the load. This method uses a simple cost or quality function that has to be minimized. This function can also include additional terms to balance the capacitor voltages in a NPC inverter and to reduce the number of commutations [253].

Since some of the multilevel converter topologies have modular structure, there is a more straight forward fault tolerant capability of these topologies under abnormal conditions. The faulty circuit can be bypassed and the converter can be reprogrammed to generate reduced voltage [254], [255]. In [256]-[259] fault analysis and fault operation for an NPC and ANPC are presented.

\section{RECENT ADVANCES IN MULTILEVEL CONVERTER APPLICATIONS}

Before the introduction of multilevel converters, current source topologies like the PWM current source inverter (PWM-CSI) and the load commutated inverter (LCI), and direct conversion topologies like the cycloconverter dominated the medium-voltage high-power application field. Currently the load LCI and cycloconverter still dominate for very high power applications, like ship propulsion, hydro-pumped storage, large fans and low speed high torque applications like grinding mills [260]. The PWM-CSI has also a very important presence in megawatt motor drives applications (pumps, fans, compressors, etc.) due to transformer-less operation, low switching $d v / d t$ s, simple converter structure, low switch count, and reliable over-current/short-circuit protection [260].

The main drawback of the current source topologies lies in the limited dynamic performance due to the use of large dc-chokes as dc-link. This is where multilevel voltage source converters step in as an interesting alternative, since they can achieve higher dynamic performance, but without the $d v / d t$ problems and voltage limit of the classic 2-level voltage source inverter. However, this comes at expense of more complex circuit structures and lower reliability. Nevertheless, multilevel voltage source converters, have been successfully applied and are an important alternative that competes with PWM-CSI in classic applications: compressors, pumps, fans, rolling mills and conveyors to name a few [2], [3], [5]-[9]. It is worth noticing that these processes are the most common medium voltage applications in industry today.

In this section, newer and more dynamic performance demanding applications now commercially available and other promising applications under research and development are briefly discussed and referenced for further reading. Table II groups the most recent references per application for a particular topology family, and due to the high amount not all of them can be discussed in detail. Table II also serves to show how active a particular topology is for a particular application by a simple reference count per topic.

\section{A. Applications in power systems}

An actual problem of the electrical grid is the power distribution control and management. In this area, Flexible ac Transmission Systems (FACTS) have been introduced as the solution in order to enhance the controllability and the power transfer capability of the network. Among the many different technologies that are considered as FACTS are active filters (AF), static compensators (STATCOM), dynamic voltage restorers (DVR), unified power flow controllers (UPFC) and unified power quality conditioner (UPQC). All these systems can in one way or another provide instantaneous and variable reactive power compensation in response to grid voltage transients (voltage sag, swell, harmonics, etc.), enhancing the grid voltage stability [225], [228], [245], [248], [249]. These devices (AF, STATCOMs, DVRs, and UPFCs) are currently gaining importance due to more demanding grid codes [261], that even require low voltage ride through capability during voltage sags. Several multilevel converter applications for these systems have been proposed, which are listed in Table II. Figure 12a, b and c show a CHB based STATCOM, a NPC based active filter and a 7-level FC H-bridge active filter proposed for a marine propulsion power system respectively.

The CHB and NPC topologies seem to be the most suited for STATCOM applications. In this case the CHB and NPC have both floating capacitors and therefore the first does not suffer 
TABLE II

HIGH PERFORMANCE MULTILEVEL CONVERTER APPLICATIONS REFERENCE SUMMARY BASED ON TOPOLOGY.

\begin{tabular}{cccc}
\hline \hline \multirow{2}{*}{ Application } & \multicolumn{3}{c}{ Multilevel topology } \\
\cline { 2 - 4 } & NPC/ANPC-based & Cascaded-based & FC-based \\
\hline Photovoltaic & {$[121],[181]-[185]$} & {$[181],[186]-[193]$} & {$[181]$} \\
Wind power & {$[165],[194]-[198]$} & {$[199]$} & - \\
Marine propulsion & {$[81],[93],[200],[201]$} & {$[81],[201]$} & {$[201]$} \\
Train traction & {$[43],[202]-[206]$} & {$[61],[115],[116],[202],[205]-[208]$} & {$[209],[210]$} \\
Automotive applications & {$[211]$} & {$[212]-[214]$} & {$[215]-[218]$} \\
Regenerative Conveyors & {$[219],[220]$} & - & - \\
Class D amplifiers & - & {$[221]-[223]$} & - \\
Hydro-pumped storage & {$[224]$} & - & - \\
FACTS \& Dist. generation & {$[225]$} & {$[117],[225]-[227]$} & {$[225]$} \\
STATCOM & {$[228]-[230]$} & {$[55],[62],[192],[228],[231]-[234]$} & - \\
Active filters & {$[235]-[239]$} & {$[240]-[242]$} & {$[243],[244]$} \\
\hline UPFC \& UPQC \& DVR & {$[245]-[247]$} & {$[245],[248],[249]$} & {$[250]$} \\
HVDC & {$[175]$} & {$[55],[56],[180]$} & - \\
\hline \hline
\end{tabular}

from the complex transformer needed for motor applications. A comparison of both topologies for a STATCOM with energy storage is presented in [228]. The study shows the CHB presents better efficiency and dynamic performance as well as a much simpler control method. Nevertheless for the topologies analyzed in [228] the NPC features a higher operating range. Currently at least one mayor manufacturer offers 3LNPC based commercial STATCOM systems [11], from 6 to $32 \mathrm{MVAR}$, capable to connect from $10 \mathrm{kV}$ up to a $132 \mathrm{kV}$ grid with the aid of a transformer, featuring IGCT devices and water cooled (plus water/air heat exchanger) system. A MMC based system called SVCplus is also commercialized for STATCOM applications by [12].

Distributed generation has also experienced an important development in the last decade. The integration of several grids to interconnect and distribute power generated at a more local level by diverse renewable energy sources and even interconnect storage or grid compensation systems, will demand a smarter grid with new converter topologies that operate at higher voltages and power, with increased efficiency an power quality to ensure proper power management. This complex mixture of grid requirements and system flexibility imposes challenges difficult to achieve with classic topologies, therefore multilevel converters are also being proposed in this application field. Particularly in [117], [226], [262], [263] a Universal Flexible Power Management system (UNIFLEXPM) is presented, capable of interconnecting different grids, each one with their loads, possible renewable energy sources, different power flows and particular characteristics (power rating, number of phases, etc). In Fig. 13 a three-port UNIFLEXPM system is shown, capable of interconnecting three different points of common coupling, symbolized as three-phase grids. The power converter is based on three-phase CHB multilevel converters in back-to-back configuration with an intermediate DC-DC converter stage with medium frequency isolation transformer to decouple the grids and provide galvanic isolation between them.
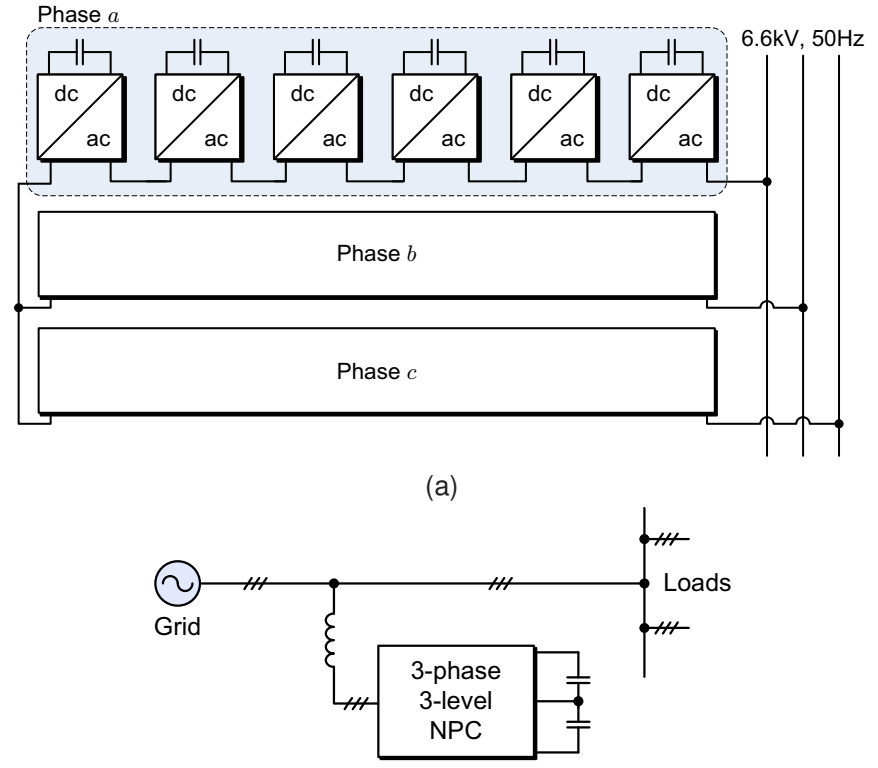

(b)

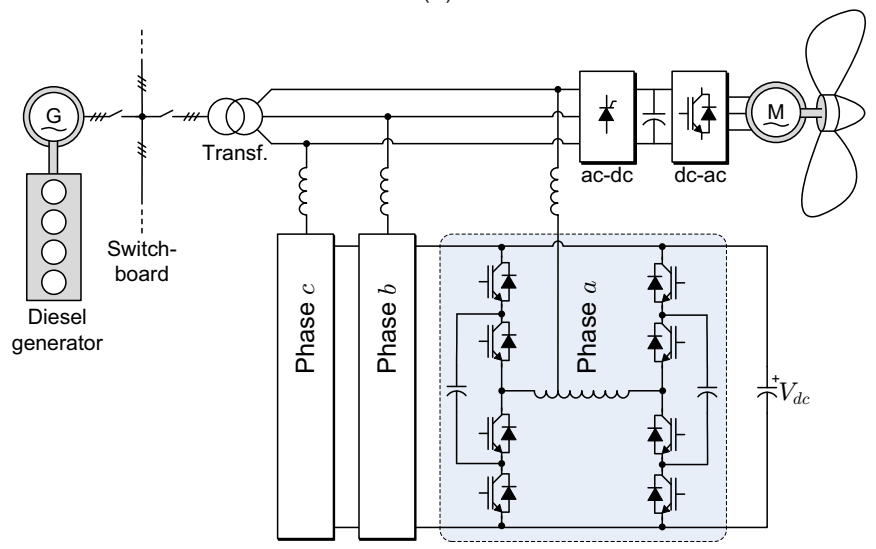

(c)

Fig. 12. a) 13-level CHB based 6.6kV 1MVA transformer-less STATCOM [232], b) 3L-NPC based active filter [239], and c) 7-level Flying Capacitor H-bridge active filter with tapped reactor connection for Marine power system [244].

B. Train traction, ship propulsion and automotive applications.

Another interesting field of application for multilevel converters is train traction power conversion systems. Traction 


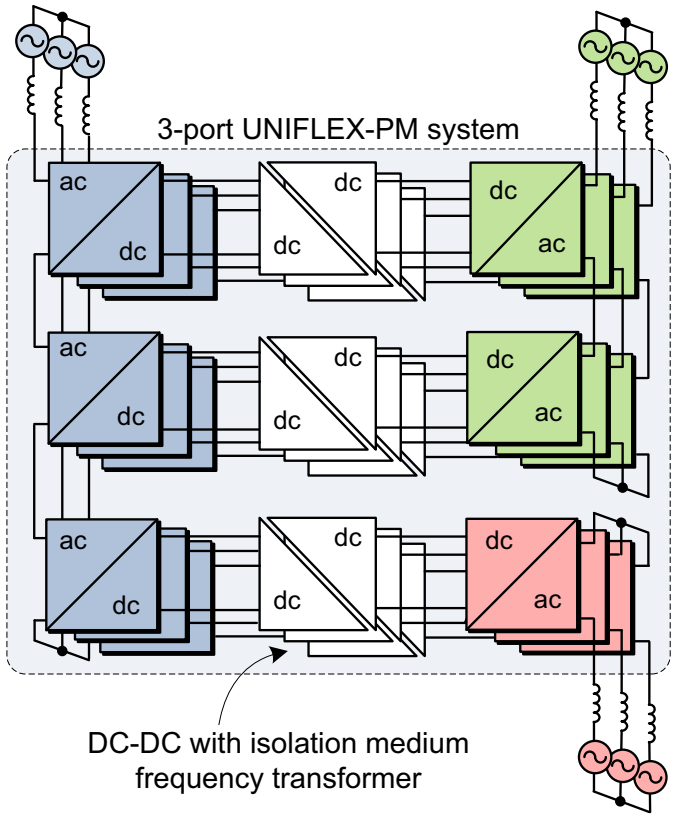

Fig. 13. Three-port UNIFLEX-PM system based on CHB multilevel converters, for power management of integrated power systems in distributed generation [117].

drives are in the medium voltage high power range, and require very high performance over a wide range of frequencies up to high speed. Usually to achieve high speed, higher switching frequencies are necessary to be able to control the fundamental frequency. Multilevel converters can produce an apparent higher frequency switched output waveform, without actually increasing the device average switching frequency. Moreover, the additional levels improve intrinsically the voltage THD, thereby enabling a further reduction of the switching frequency. In addition, the large inertia of a train makes this application specially interesting for regenerative braking and 4 quadrant operation. Therefore the 3L-NPC in back-to-back configuration has already been used for train drive systems, in particular it has been used for the Transrapid maglev train [203], [204]. A simplified system diagram is illustrated in Fig. 14a. The back-to-back NPC converters power the segments of the long stator linear synchronous motor creating a traveling magnetic field that interacts with the support magnets of the rotor (train) producing the horizontal thrust.

The traction transformer used to step down the catenary voltage to adapt for the needs of the motor drives is usually bulky and adds weight to the train. Therefore there have been several proposals to use multilevel converter topologies that can reach high enough voltage at the catenary (grid) side and use a dc-dc medium frequency isolation stage in each dc-link to distribute the voltage to the different motor drives. This has been proposed in several configurations for the $\mathrm{CHB}$ and NPC converters [43], [115], [116], [202], [210]. Particularly in [207] a single-phase transformerless CHB front end is used to connect directly to a $15 \mathrm{kV} / 16.7 \mathrm{~Hz}$ catenary. Each h-bridge is used to power one of the motor drives of the traction system, as seen in Fig. 14b. Another example is a CHB topology with medium-frequency isolation $\mathrm{dc}-\mathrm{dc}$ stage for the ac-dc
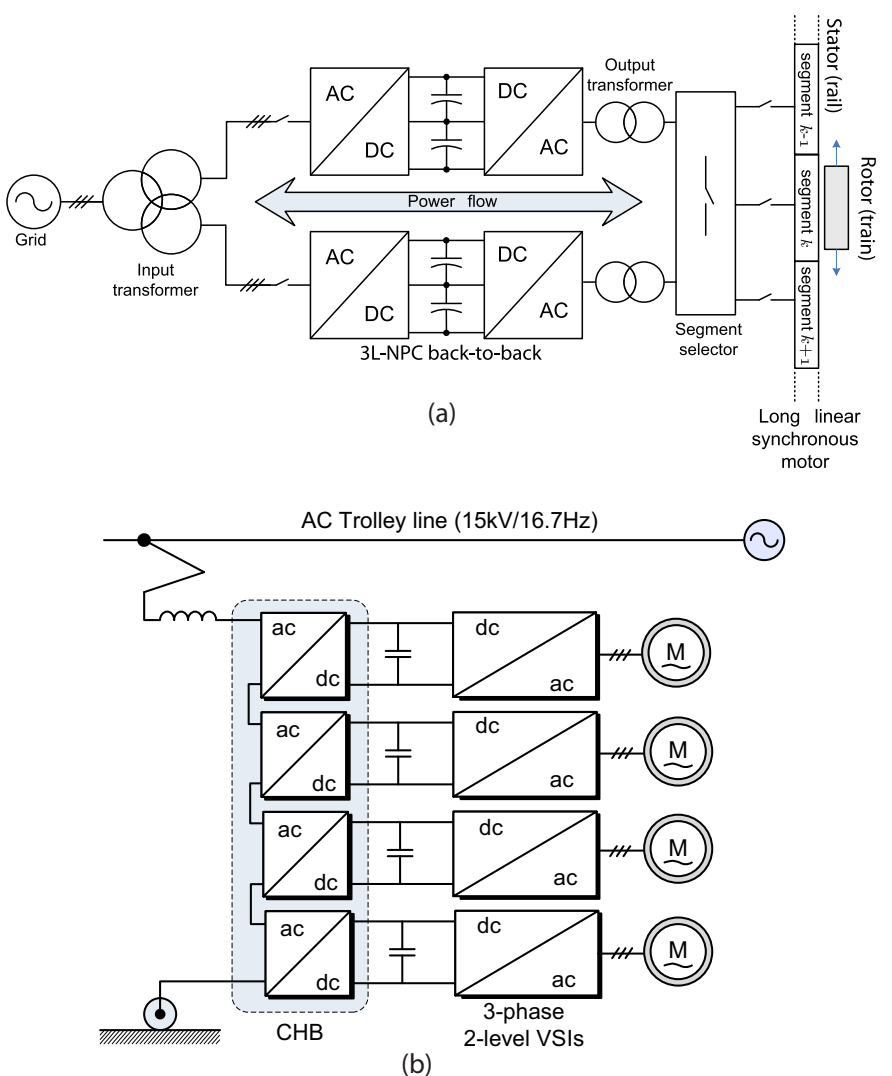

(b)

Fig. 14. a) Transrapid Maglev train long linear synchronous motor with back-to-back 3L-NPC drive system [203], [204], and b) CHB transformerless front-end for power interface of a locomotive traction drive [207].

grid interface of the traction drive [115], to get rid of the bulky transformer. In [43] an H-bridge NPC is proposed for the front end of a traction drive system. In [206] a study of medium frequency transformer topologies is carried out, also to get rid of line frequency bulky transformer.

As mentioned before ship propulsion is dominated by the LCI and cycloconverter topologies due to high power capability, efficiency reliability, lower cost and lower size. Although they have poor dynamic performance, their greatest weakness for marine propulsion applications is the poor input power quality that can affect the stability and management of the onboard ship power system. As these systems become more complex there is need to include passive or active filters or other FACTS, between the propulsion converter and the ship switchboard to compensate and support the power system. This adds cost, size and affects the other merits of the cycloconverter and LCI mentioned before. Multilevel converters, instead have these features already built in, and therefore, are becoming more competitive and are attracting increased attention for this application, with successful systems already operating in the field. In [201] an assessment between cycloconverters and other topologies, including the NPC multilevel converter, for variable speed electric marine propulsion systems in the $30 \mathrm{MW}$ range is performed, and concludes that cycloconverter however more efficient, and smaller could be replaced by NPC due to its improved power 


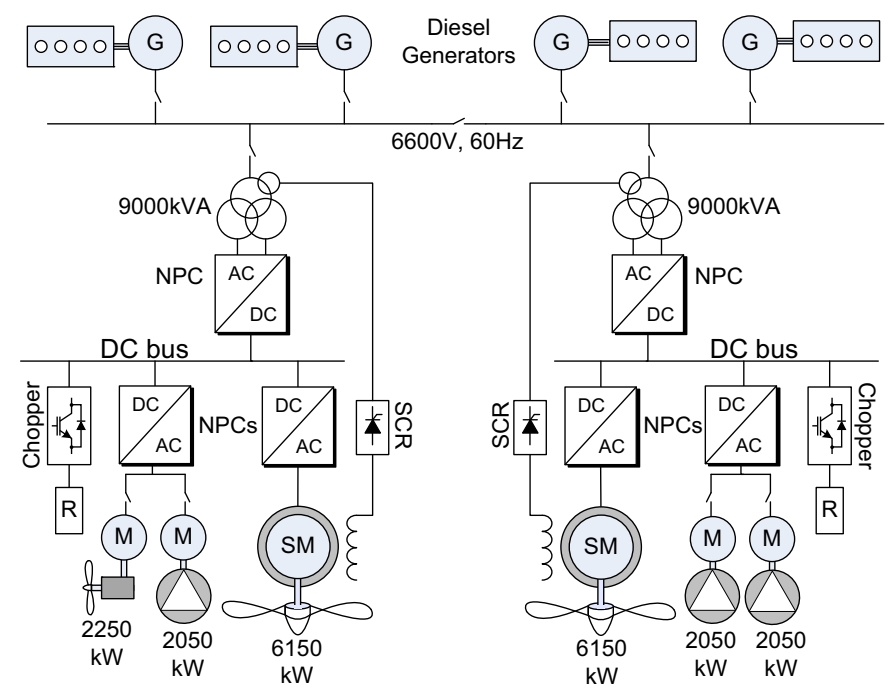

Fig. 15. Tanker ship power system, featuring redundant 3L-NPC back-toback propulsion drive [200].

quality.

Figure 15 shows a simplified diagram of the power generation, distribution and load systems of a tanker with a twin screw, redundant electrical propulsion system. Two commercial NPC back-to-back converters drive a 6.15 MW synchronous motor drive each. In addition, the tanker uses a multimotor system in which several motors are fed by the same converter, for example, to drive both the pumps for cargo loading/unloading and the propulsion motors. Since cargo pumps and propulsion motors normally are not used simultaneously, the active front end NPC is shared among both drives, reducing the overall cost of the system.

Another important development of multilevel converters for ship propulsion has been motivated more from the motor side, namely by multiphase machines. During the last decade multiphase machines have experienced a growing interest due to several attractive advantages like high reliability, fault tolerance improved torque performance and higher power density, which makes them specially suitable for marine/naval propulsion systems. Hence, the combination of multiphase and multilevel technologies add up a series of advantages useful for this application [93], [135], [138], [264]. In [93] the 3LNPC for a five-phase motor drive is analyzed. The increased number of different voltage space vectors that a multi-phase 2L-VSI already can generate is boosted from 31 to 211 by just adding the extra level of the 3L-NPC, resulting in a much richer power actuator, which consequently can greatly improve the motor torque control performance.

Electric vehicles and hybrid electric vehicle traction converter/drive systems have been experiencing a great development over the years. However, since they are not in the high power range, multilevel converters have not played a key role in this area. Nevertheless, at an academic level the superior power quality, increased efficiency and the fact that multilevel converters greatly benefit of independent dc-sources like batteries, have motivated some interesting concepts and contributions in this field [211]. The power quality in particular is very welcome because of EMI/EMC issues, which impose strong requirements in the automotive industry. As an example, in [215] a modular $5 \mathrm{~kW}$ multilevel dc-dc converter based on a modified flying capacitor cell has been proposed for hybrid electric and fuel cell automotive applications. In [218] a dc-dc flying cap for batery/inverter interface without electromagnetic devices is presented, which is suitable for high temperature operating conditions as is the case in some battery systems.

Multilevel converters have also been proposed for the automotive traction [212], [214]. In [214] 2L-VSI hybrid with an H-bridge stage at the output as the NPC-CHB converter shown in Fig. 8, but considering the 2L-VSI instead of the NPC, has been proposed for electric and hybrid electric vehicles. The topology increases the voltage and acts as a boost converter, but without need of inductors, increasing the power density of the converter stage, with the corresponding benefits in automotive applications.

A great part of the state of the art large mining haul trucks are diesel-electric hybrids that currently reach the $3 \mathrm{MW}$ range and could benefit of multilevel topologies. In [211] the NPC and ANPC are proposed for large electric and hybrid-electric vehicles using emitter turn-off thyristor of 4th generation semiconductors. This is a possible area for future development of multilevel converter technology.

\section{Energy generation, conversion and transmission}

Wind turbines have been for a while in the megawatt range, and the Doubly Fed Induction Generator operated at variable speed with partially rated converter (approx. 30\% of the total power) has been the most widely adopted by industry. This enables a variable speed range of $\pm 30 \%$ above and below synchronous speed [265], which is sufficient to cover most of the useful wind speed conditions and improve the energy conversion efficiency compared to fixed speed systems. However, recent grid codes demand large wind energy conversion systems to control reactive power and even even impose bands of voltage sags and their duration in which the systems must remain operative (low voltage ride trough) [261]. The capability to accomplish these requirements by partially rated power converter based turbines is then limited to the $30 \%$ rating of the converter. With the continuous increase in size and power rating of wind turbines, that currently reach $5 \mathrm{MW}$ in practice, and even some industrial prototypes already above $6 \mathrm{MW}$, the use of a reduced capacity converter stage can challenge the ability of the system to fully comply with the new grid codes. In addition, variable speed operation at a wider range has shown advantages in terms of reduced structural stress, reduced audible noise and increased power generation and efficiency in larger turbines [266].

Currently one of the trends in development is to use synchronous generators with fully rated power converters. To reach the power levels of state of the art turbines, several converters in parallel are needed to handle the full power, since the current rating is generally high considering the output voltage of the conversion systems is usually around $690 \mathrm{~V}$. Nevertheless, operation in medium voltage appears now very attractive considering ir would lead to lower currents, hence cable width and cost reduction, which also has a positive 


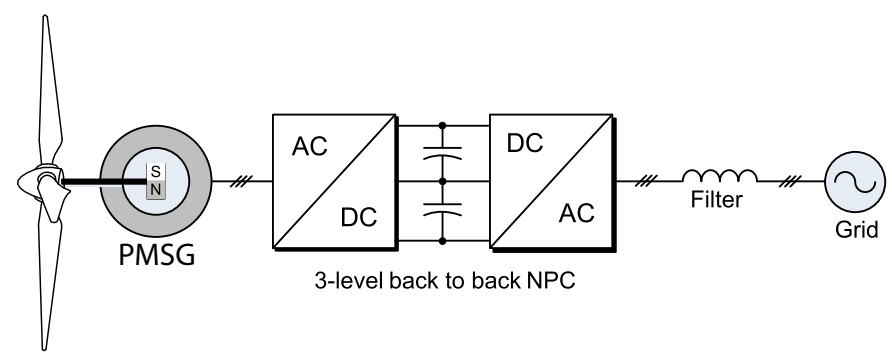

Fig. 16. Back-to-back NPC fully rated power converter for permanent magnet synchronous generator based variable speed wind turbine.

impact on the size and cost of line filters. It also reduces the voltage step-up requirement for connection at the PCC. Because of these reasons, and considering current turbines are in the megawatt range, multilevel converters emerge as a promising alternative as power converter interface for wind energy systems [165], [194]-[199].

In particular the back-to-back 3L-NPC seems to be a natural choice, since it allows high performance generator side control to achieve maximum power point tracking and grid side control to be able to regulate active and reactive power while decoupling grid and generator with the dc-link. This is why the 3L-NPC in back-to-back is the most reported multilevel topology for this application [194], [195], [198]. Figure 16 shows a simplified diagram of a 3L-NPC back-to-back configuration for a permanent magnet synchronous generator wind turbine. If multipole generators are considered, the gearbox can be avoided by achieving electromechanically the speed conversion between the low speed rotor shaft (around $15 \mathrm{rpm}$ ) to the grid frequency (usually 50 or $60 \mathrm{~Hz}$ ). Currently at least two manufacturers provide 3L-NPC back-to-back converters for wind power conversion [11], [15]. The hybrid 5L-ANPC analyzed in this paper has also been proposed in back-to-back configuration in [196], [197].

Another interesting configuration is the use of a 3L-NPC at the grid side, and a three-phase diode full bridge rectifier with a boost converter dc-dc stage at the generator side [165]. The boost converter performs the MPPT of the generator side while the NPC regulates active and reactive power. The boost naturally elevates the voltage, suitable for MV operation of the NPC. The main advantage over the back-to-back NPC is a simple, low cost and reliable front end. Nevertheless it comes at expense of current harmonics ar the generator side and lower dynamic performance.

The CHB on the other side requires multiple isolated dcsources and therefore its application is not straight forward. Nonetheless, some interesting concepts have been proposed based on rectifiers fed from independent generator stator windings of a permanent magnet synchronous generator, each one rectified and used to provide the dc-source for each $\mathrm{H}$ bridge of the CHB converter [199]. This naturally elevates the voltage of the system enabling transformerless operation. The increase in the number of levels of the converter allows lower switching frequency operation while improving the grid side power control performance and grid code compliance without filters. This system is specially useful for off-shore wind turbines, where usually a step-up transformer is included at top of the tower, producing mechanical stress on the structure.

The use of multilevel converters as power interface for Photovoltaic grid connected systems seems at a first glance not very appropriate due to the low power level of current photovoltaic systems. However, grid connected photovoltaic power plants are consistently increasing in power rating mainly due to the reduction in cost of photovoltaic modules (among other factors), and now hundreds of large photovoltaic-based powerplants over 10MW [267] are operating and even more under development. In addition photovoltaic grid connected systems is one of the fastest developing renewable energy sources in the last years [268]. For large photovoltaic power plants centralized and multi-string configurations are used with a central dc-ac converter that interfaces the power to the grid. Now they reached the megawatt range, classic topologies as the 2-level voltage source converter will not be able to deliver the necessary power quality, maximum allowed switching frequency, higher voltage operation and reduction of filter size that multilevel converters can provide.

Multilevel converters can be used to interconnect the photovoltaic strings in a more intelligent way to reach higher voltages closer or even of same value of the point of common coupling. As grid code requirements for photovoltaic systems will become more demanding, multilevel topologies will also become even more attractive. In [121] a three-phase fourlevel NPC-based converter interface and its control method is proposed. In [191] a 5-level converter formed by a 3-level Hbridge with a bidirectional switch arrangement that can clamp two additional levels to the output has been proposed as dcac converter stage in a multistring photovoltaic configuration. In [187]-[189] CHB-based grid interfaces are proposed with their respective control scheme.

Figure 17a and b show a CHB-based and an NPC-based multilevel-multistring photovoltaic topology respectively. The $\mathrm{CHB}$ seems to be very appealing since the series connection of the H-bridge, thus the strings, naturally elevates the voltage eliminating the need of a boost stage or step-up transformer. It also increases the apparent switching frequency of the total converter waveform, enabling a reduction in the average device switching frequency. The higher amount of voltage levels produces an intrinsic reduction of all the harmonics, which reduces the need of grid side filters, along with the correspondent efficiency improvement. Currently one manufacturer offers 3-level converters as centralized dc-ac stage [15].

Although the trend clearly shows an exponential growth of grid tied photovoltaic systems compared to the evolution of the stand-alone technology due to improved efficiency (no losses in energy storage and additional converter stages), there are still some places where stand alone (island operation) of photovoltaic systems are the only, or most viable, source of energy. Even in this field multilevel converters have been proposed as possible solution [181], [183], [186].

Another recent application of multilevel converters is hydropumped energy storage. This is a large scale energy storage system in which water is pumped from a lake, river or 


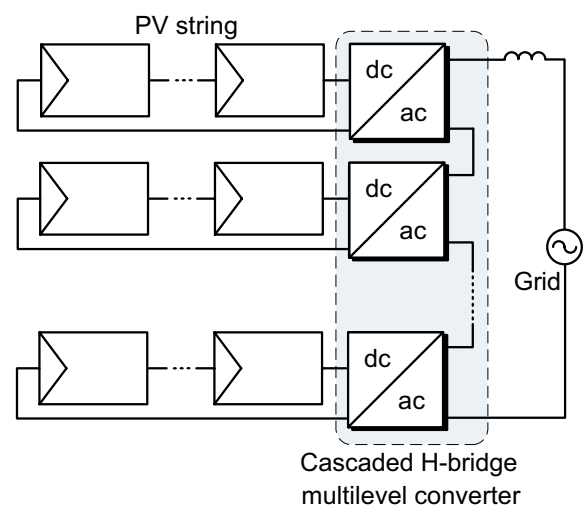

(a)

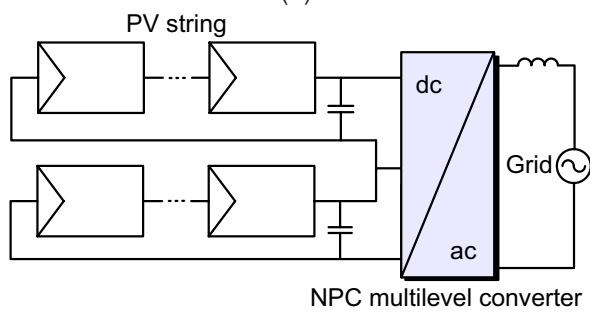

(b)

Fig. 17. Multilevel converter based photovoltaic grid connected systems: a) CHB-based, b) NPC-based.

even ocean to a higher located reservoir, then when needed the same water is used for hydro power generation. Hydropumped storage is specially useful for nuclear power plants since the reactor operation level cannot be changed abruptly, and during low power demand the excess energy can be used to pump water to the reservoir. The same idea can be applied for wind power plants, when the wind energy surpasses the consumption demand. Alternatively, during a high power demand period (peak hours) the water from the reservoir is used to generate the additional required energy. A simplified overview of a hydro-pumped energy storage system is illustrated in Fig. 18. The system uses a reversible Francis hydro pump/turbine, that can be used either for water pumping or for generation. These systems are usually operated at fixed speed with synchronous motor/generator due to their high power rating. However, it has been shown that even a small $\%$ of variable speed operation above and below synchronous speed can improve efficiency at different load and operating conditions. Therefore, a doubly fed induction generator, with a partially rated converter interconnecting the rotor to the grid, can provide a percentage of variable speed for a much higher power rated pump/turbine [224]. Currently one manufacturer produces the 3L-ANPC, which has been used for a 200MVA hydro-pumped energy storage system [11]. Approximately a $10 \%$ of efficiency improvement is achieved with this solution. In addition the active front end converter can improve power system stability, by reducing power system fluctuation and introducing reactive power control.

High voltage direct current (HVDC) transmission is an efficient and cost effective energy transportation system for

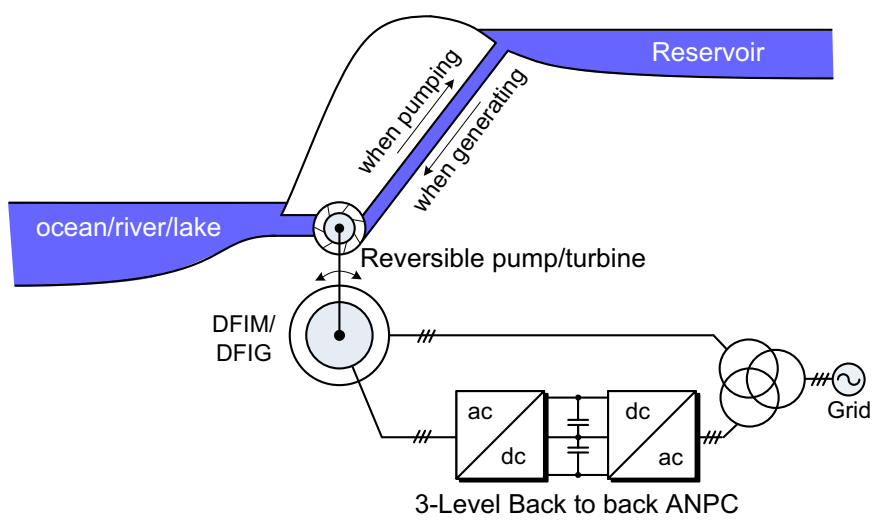

Fig. 18. Back-to-back ANPC doubly-fed induction generator/motor for hydro-pumped energy storage application [11], [224].

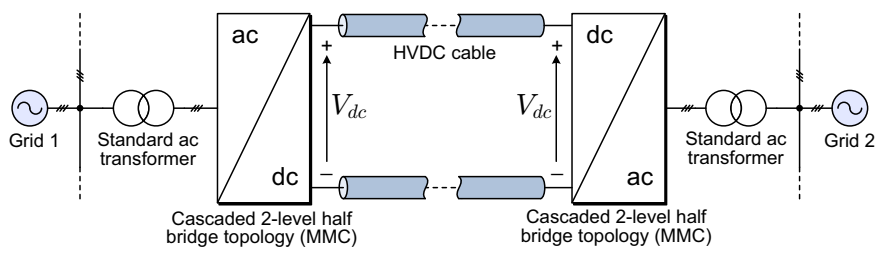

Fig. 19. HVDC-plus transmission system, based on Modular Multilevel Converter (MMC) [55].

long distances $(>600 \mathrm{~km})$. The ac-dc-ac conversion is traditionally performed by line commutated converters in backto-back configurations connecting two different ac systems. They are also useful for shorter distances to connect offshore wind and offshore oil/gas platforms with the land through under water cables. Since the transmission voltage and total power can reach up to $800 \mathrm{kV}$ and $7 \mathrm{GW}$ [12], many thyristors need to be connected in series. Recently, for the same reasons and advantages presented in previous applications, multilevel converters have also been proposed as a feasible solution for this application [55], [175], [180], [269]. In [55], [180] the MMC in a back-to-back configuration is proposed. This topology has recently entered the market and is produced by one manufacturer [12], [56] for back-to-back systems up to 1000MW. Fig. 19 shows a HVDC-plus transmission system interconnecting two ac grids through a back-to-back MMC topology. In [55] a 200 modules per phase MCC is analyzed for a 400MW system. The NPC has also been proposed for HVDC transmission [175] with a five-level NPC in back-toback configuration.

\section{Other applications}

Although class-D digital audio power amplifiers are not in the high power and medium voltage range, the improved power quality (mainly reduced THD) and the possibility to reach higher apparent switching frequencies, without increasing the average device switching frequency have motivated research lines to apply multilevel technology in this field [221]-[223]. Here the cascaded topologies, in particular the CHB fed with unequal dc sources seem more attractive, since they can easily reach high number of levels (less THD) improving audio 


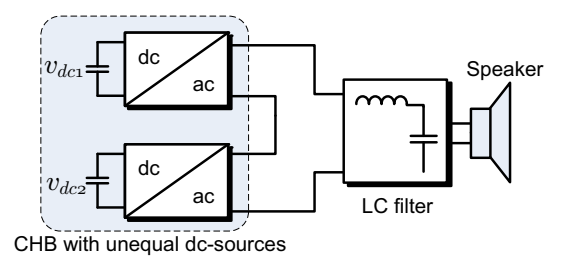

Fig. 20. Nine-level asymmetric fed CHB class-D digital audio amplifier [222].

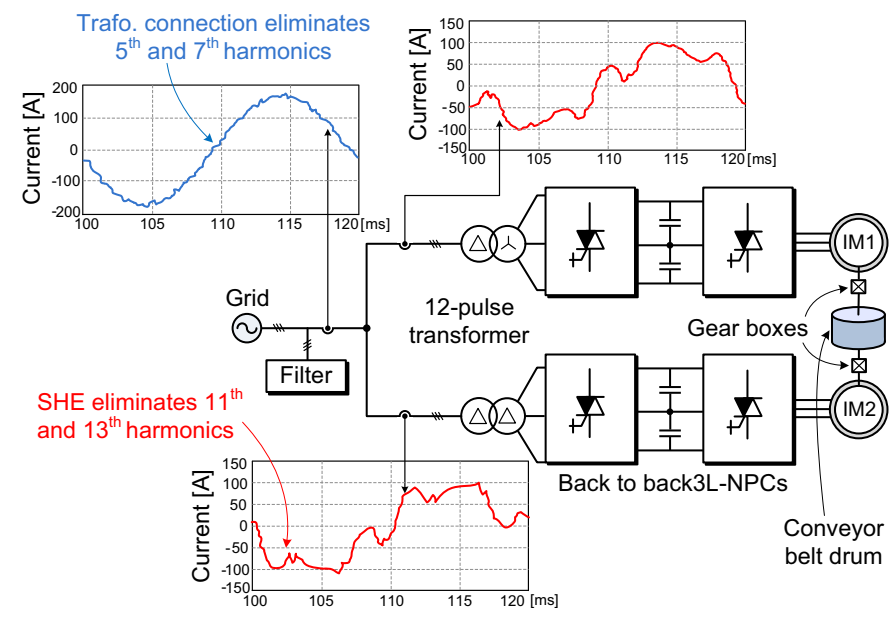

Fig. 21. Regenerative downhill conveyor system based on two back-to-back 3L-NPCs, a 12-pulse transformer and SHE [219], [220].

quality while facilitating high frequency filtering. Figure 20 shows a nine-level class-D digital audio amplifier proposed in [222].

As mentioned before large conveyor systems are one of the standard applications of multilevel converters, not necessarily demanding high performance and high dynamic control. However, large downhill conveyors systems operate essentially in regenerative mode, and due to the amount of power involved, resistive braking is not only very inefficient but also requires large power resistors and cooling system. For this application the back-to-back multilevel solution has great advantages, despite the higher initial converter cost. The 4-quadrant operation enables bidirectional power flow increasing the efficiency of the overall system and also enables input power factor control. In [219], [220] a regenerative downhill conveyor system is analyzed. The complete conveyor is composed of three sections and spans for more than $12 \mathrm{~km}$ long and lowers minerals a total height of $1.3 \mathrm{~km}$. Each conveyor section is composed of two 3L-NPCs in back-to-back configuration that are used to power a $2.5 \mathrm{MW}$ induction motor each, which drive the conveyor belt trough two gear boxes. The 12 pulse rectifiertransformer system plus the use of SHE effectively eliminate up to the $13^{\text {th }}$ harmonic. The system configuration and input current waveforms are depicted in Fig. 21.

\section{Future Trends And Challenges}

The evolution of multilevel converters over the last three decades has resulted in several commercial and proven topolo- gies and modulation methods. From this well established technology, summarized in this paper, some straightforward and other more arguable trends can be extracted. In addition, despite the industrial presence and recognizable maturity, there are still several challenges for the further development of this technology. Some of these trends and challenges are discussed in the following paragraphs.

Most of the manufacturers offer multilevel converter products that are operated with average device switching frequencies from 500 to $700 \mathrm{~Hz}$ (for IGBTs and IGCTS) [8]. The main reason is to improve efficiency, to extend the device limits, and to have a practically feasible cooling system. Operating at lower switching frequencies usually introduces lower order harmonics, so matching efficiency with high performance is still one of the mayor challenges in multilevel converter development. This tradeoff can be relaxed if higher number of levels are used, due to an intrinsic improvement in the multilevel waveforms. This is why many of the newer topologies discussed in this paper are able to generate more voltage levels (5L-HNPC, modular multilevel converter, cascaded matric converter, etc.). This is a trend expected to continue in the next years. It is worth noticing that great part of the contributions made related to multilevel converter technology are obtained with unrealistic device average switching frequencies (of even several $\mathrm{kHz}$ ), mainly because they are tested in low power prototypes where higher frequencies are admissible. Nevertheless, an effort should be made to present results with more realistic values.

Switching losses are very important, in part because they depend on the modulation scheme, hence they can be modified through the modulation scheme selection and parameter design for a given topology. On the other side, conduction losses are substantially higher, but once the topology is chosen not much can be done to change them. In this respect, conduction losses are extremely important at the stage in which the converter is conceived, designed or selected. This happens because in multilevel topologies there is presence of series connected devices compared to more simple converter structures as the load commutated inverter or current source inverter. Hence, attractive multilevel converter topologies will be those that are capable of sharing among the semiconductors the total voltage (to reach higher voltage operation), but minimize the number of components connected in series for a given switching state. Diodes and bidirectional switches, in particular, can potentially reduce the converter efficiency since the first needs high reverse recovery currents during turn-off that introduce high switching losses in other semiconductors of the power circuit, and the second because always a power transistor and a diode are conducing per switch instead just one of them. A comparison of switching and conduction losses in classic multilevel converter topologies is presented in [36], [37]. The switching losses in CHB and NPC converters depending on the modulation methods are given in [142] and [143] respectively. However, an assessment comparing the classic and newer multilevel converter topologies in relation to witching and conduction losses is something still pending and is a challenge for further research that can provide valuable insight on the newer topologies. 
In addition to conduction and switching losses, the harmonics generated by the converter also affect negatively the efficiency, and therefore also need to be taken into consideration. The harmonic losses at motor and grid side depend both on the topology and the modulation scheme. It is very clear by now that in this aspect any multilevel topology outperforms the classic 2L-VSI, however there is still room for further improvements. In relation to the topology, more output voltage levels will always have a positive impact on the harmonics reduction. The effects of the modulation scheme can be measured by means of the THD, since this measure gives an estimate of the amount of energy present in other frequencies that the fundamental component. In other words, the conception of new multilevel converter topologies cannot just be focused on maximizing the number of levels, since there is the added challenge to include all the aforementioned converter losses into the design considerations.

Reliability is also a key ingredient in the future development of multilevel converters. As discussed earlier in this paper, some multilevel converter topologies have sufficient degrees of freedom to operate under internal fault condition, with few added hardware. Nonetheless, the possibility to actually use this strength relies on the ability (accuracy and speed) to detect and diagnose a fault, so the fault tolerant reconfiguration of the converter can be performed before damage generated by the fault takes place. Since capacitor faults and semiconductor short-circuit or open-circuit faults occur so fast, and due to the amount of power involved in these applications, it is still not practically feasible with the present state of technology to have a completely functional fault detection-diagnosisoperation system that is fully reliable. This is definitely a challenge for further research and development in this field.

Another interesting and difficult challenge related to reliability, is to analyze and compare all commercially available and promising topologies in this respect. The fact that new topologies are being developed at a faster rate, and that many of them not necessarily are aimed at same power rates and applications, makes a fair comparison even more difficult. Furthermore, beside the straightforward parameters used for reliability analysis such as switch and passive component count, there are other aspects that also affect reliability and need to be considered, for example: power and usage distribution of the semiconductors, voltage stress, thermal distribution, circuit structure during open or short circuit fault, to name a few. This is a mayor challenge, but equally important, and needs to be done specially for those new unproven topologies entering the market.

Multilevel converters were developed to enable the use of voltage source converters in high power applications. Nonetheless, as the price of semiconductors go down and the costs of energy and grid codes become more restrictive, the use of multilevel topologies as active front end rectifiers becomes more and more attractive even in low voltage low power utility applications [270]. All the advantages mentioned throughout this paper can reduce long term operational costs, despite the higher initial investment, justifying their use at lower power levels.

The development of power converter technology (like any other power converter) has always been, and seems will always be, closely related to the development power semiconductors. Currently there are two dominating technologies used for multilevel converters (see Table I): the IGCT and the IGBT (and their variations). They define two clear different trends in current multilevel development: the first in which more simple circuit structures are used (NPC, ANPC, H-NPC, etc.) which require higher rated components like the IGCT to reach medium voltage level; and the second with modular structures, more complex in nature (CHB, FC and MMC), which use lower rated components like the IGBT and reach higher voltages through converter cell series connection. Both approaches have been very successful and are expected to coexist in the upcoming years aimed at different application fields. On the other hand, the development of mature Silicon Carbide (SiC) devices will benefit the multilevel converters penetration reducing drastically the switching losses [271], [272]. Nowadays, $\mathrm{SiC}$ diodes are present in commercial products for low current applications [273]. These SiC diodes could substitute the conventional silicon diodes of the multilevel converter topologies when their nominal current ratings increase. In the future, high voltage $\mathrm{SiC}$ power semiconductors could allow extending the applicability of multilevel converters to higher voltage applications, especially for those related to electrical utilities.

Multilevel converters have slowly started to penetrate some applications still dominated by thyristor based load commutated inverters and cycloconverters (grinding mills, ship propulsion, hydro-pumped storage, very large fans, etc.). It is expected that this trend will continue in the next decade. Since multilevel converters have better performance and power quality than these two topologies, it is the availability, reliability, efficiency, size and costs the key challenges for the development of multilevel converter technology to make it more competitive against these topologies for these applications.

Another aspect that also will motivate further developments in multilevel technology is size and weight reduction. While most current industrial applications involve large machinery used in processes where space and weight restrictions are not the most important (pumps, fans, compressors, etc.), there are quite a few in which these variables are critical, mainly in transportation (train traction and marine propulsion). Also in wind power conversion, specially in off-shore turbines, the converter needs to be integrated in the top of the tower, and weight and size reduction can lead to important structural stress relief. Hence, the need to increase the power density will produce developments in several components of the power conversion system, from the topology design up to the transformer, dc-link, filters and heat dissipation stages.

Although most non-regenerative commercial multilevel topologies presented in this paper feature multiwinding transformers with multipulse diode rectifiers front ends to adapt the grid voltages to the application levels, provide galvanic isolation and improve grid side current quality, the transformerless operation is still a desirable feature and at the same time a challenge for further research in the upcoming years. The elimination of the transformer implies a significant cost, volume and weight reduction, and it also would reduce system 
complexity and losses. It seems that transformerless commercial products will be easier to see in regenerative applications, where the active front end rectifier can provide even better input current quality, and galvanic isolation can be replaced by a proper control of the common mode voltages, and the iron and copper transformer is replaced by the silicon and capacitor devices of the active front end, which can be considered as a non-magnetic or all-power-electronics transformer.

During the last two decades industrial applications of multilevel converters were mainly aimed to medium-voltage high-power motor drives (pumps, fans, compressors, etc.), many of which do not require high performance variable frequency operation. This has changed in the last few years, in fact, as explained in previous section, there are now several commercial products for wind power converters, STATCOMs, HVDC transmission, centralized photovoltaic converters, ship propulsion drives, high speed train traction and hydro-pumped storage, among others. This shows a clear trend in the diversification of multilevel powered applications. It is expected that this trend will continue and more applications will be enabled by this technology, due to the more demanding grid codes, the continue increase in power demand of the applications, the further development of power semiconductors and the benefits of multilevel technology. In this respect, the application of multilevel converters to FACTS and HVDC systems is very promising. Similarly, for distributed generation system involving multiple energy sources and networks of different voltage levels, multilevel voltage source converters can be effectively used as a power management system. These and many other applications will be the central focus in multilevel converter development for researchers in academia and industry worldwide.

\section{CONCLUSION}

This paper has reviewed the present state of the art in Multilevel Converter technology by discussing the most recent contributions on topologies, modulation and applications. At this point it can be concluded that multilevel converters have reached a certain level of maturity given their industrial presence and successful practical application. Nevertheless, the high amount of recent publications on the subject and the fact that the number of commercially available topologies has doubled in the past few years, reveals that there is still plenty of room for further development. It is clear that the development of power electronic devices, the changes and evolution of the industrial processes and the new more demanding standards and regulations, will drive and shape the future of multilevel converter technology.

\section{REFERENCES}

[1] J. Rodriguez, J.-S. Lai, and F. Z. Peng, "Multilevel inverters: a survey of topologies, controls, and applications," IEEE Trans. Ind. Electron., vol. 49, no. 4, pp. 724-738, Aug. 2002.

[2] S. Rizzo and N. Zargari, "Medium voltage drives: what does the future hold?" in Power Electronics and Motion Control Conference, 2004. IPEMC 2004. The 4th International, vol. 1, Aug. 14-16, 2004, pp. 82-89.

[3] R. D. Klug and N. Klaassen, "High power medium voltage drives innovations, portfolio, trends," in Power Electronics and Applications, 2005 European Conference on.
[4] B. Wu, High-Power Converters and AC Drives. Wiley-IEEE Press, March 2006.

[5] J. Rodriguez, S. Bernet, B. Wu, J. O. Pontt, and S. Kouro, "Multilevel Voltage-source-converter Topologies for Industrial Medium-voltage Drives," IEEE Trans. Ind. Electron., vol. 54, no. 6, pp. 2930-2945, Dec. 2007.

[6] P. Steimer, "High power electronics, trends of technology and applications," in in Proc. PCIM'07, May 2007, germany.

[7] L. G. Franquelo, J. Rodriguez, J. I. Leon, S. Kouro, R. Portillo, and M. A. M. Prats, "The age of multilevel converters arrives," IEEE Industrial Electronics Magazine, vol. 2, no. 2, pp. 28-39, Jun. 2008.

[8] J. Rodriguez, B. Wu, S. Bernet, N. Zargari, J. Rebolledo, J. Pontt, and P. Steimer, "Design and Evaluation Criteria for High Power Drives," in Industry Applications Society Annual Meeting, 2008. IAS '08. IEEE, Oct. 5-9, 2008, pp. 1-9.

[9] J. Rodriguez, L. G. Franquelo, S. Kouro, J. I. Leon, R. C. Portillo, M. A. M. Prats, and M. A. Perez, "Multilevel Converters: An Enabling Technology for High-power Applications," Proc. IEEE, vol. 97, no. 11, pp. 1786-1817, Nov. 2009.

[10] B. K. Bose, "Power Electronics and Motor Drives Recent Progress and Perspective," IEEE Trans. Ind. Electron., vol. 56, no. 2, pp. 581-588, Feb. 2009.

[11] “ABB." [Online]. Available: www.abb.com

[12] "SIEMENS." [Online]. Available: www.siemens.com

[13] "TMEIC-GE." [Online]. Available: www.tmeic-ge.com

[14] "Ansaldo Sistemi Industriali." [Online]. Available: www.asiansaldo. com

[15] "Converteam." [Online]. Available: www.converteam.com

[16] "Eaton." [Online]. Available: www.eaton.com

[17] "Arrowspeed." [Online]. Available: www.arrowspeed.com

[18] "Ingeteam." [Online]. Available: www.ingeteam.com

[19] "WEG." [Online]. Available: www.weg.net

[20] "Rongxin Power Electronic co. RXPE." [Online]. Available: www. rxpe.co.uk

[21] "LS Industrial Systems." [Online]. Available: http://eng.lsis.biz/

[22] "Yaskawa." [Online]. Available: www.yaskawa.eu.com

[23] "Beijing Leader \& Harvest Electric Technologies." [Online]. Available: www.ld-harvest.com

[24] "Schneider-Electric." [Online]. Available: www.schneider-electric.com

[25] "Alstom." [Online]. Available: www.alstom.com

[26] "Grupo Jema." [Online]. Available: www.grupojema.com

[27] W. McMurray, "Fast response stepped-wave switching power converter circuit," US Patent No. 3,581,212, Filed 31 July 1969 Granted 25 May 1971.

[28] J. A. Dickerson and G. H. Ottaway, "Transformerless power supply with line to load isolation," US Patent No. 3,596,369, Filed 22 December 1969 Granted 3 August 1971.

[29] R. H. Baker, "High-voltage converter circuit," US Patent No. 4,203,151, Filed 21 September 1978 Granted 13 May 1980

[30] — , "Bridge converter circuit," U.S. Patent No. 4,270,163, Filed 2 August 1979 Granted 26 May 1981.

[31] A. Nabae, I. Takahashi, and H. Akagi, "A neutral-point-clamped pwm inverter," in IAS Annual Meeting 1980, vol. 3, Sep. 28 - Oct. 3 1980, pp. 761-766, cincinnati, OH, USA.

[32] _ _A New Neutral-point-clamped PWM Inverter," IEEE Trans. Ind. Applicat., pp. 518-523, 1981.

[33] M. Marchesoni, M. Mazzucchelli, and S. Tenconi, "A non conventional power converter for plasma stabilization," in Power Electronics Specialists Conference, 1988. PESC '88 Record., 19th Annual IEEE, Apr. 11-14, 1988, pp. 122-129.

[34] P. W. Hammond, "A new approach to enhance power quality for medium voltage drives," in Petroleum and Chemical Industry Conference, 1995. Record of Conference Papers., Industry Applications Society 42nd Annual, Sep. 11-13, 1995, pp. 231-235.

[35] T. Meynard and H. Foch, "Dispositif électronique de conversion d'énergie électrique," French Patent No. 2679715B1, Filed 25 July 1991 Issued 29 January 1993.

[36] D. Krug, S. Bernet, S. S. Fazel, K. Jalili, and M. Malinowski, "Comparison of 2.3-kv Medium-voltage Multilevel Converters for Industrial Medium-voltage Drives," IEEE Trans. Ind. Electron., vol. 54, no. 6, pp. 2979-2992, Dec. 2007.

[37] S. S. Fazel, S. Bernet, D. Krug, and K. Jalili, "Design and Comparison of 4-kv Neutral-point-clamped, Flying-capacitor, and Series-connected H-bridge Multilevel Converters," IEEE Trans. Ind. Applicat., vol. 43, no. 4, pp. 1032-1040, Jul./Aug. 2007. 
[38] K. D. Papastergiou, P. W. Wheeler, and J. C. Clare, "Comparison of losses in multilevel converters for aerospace applications," in Power Electronics Specialists Conference, 2008. PESC 2008. IEEE, Jun. 1519, 2008, pp. 4307-4312.

[39] M. Marchesoni and P. Tenca, "Theoretical and practical limits in multilevel mpc inverters with passive front ends," in in Proc. European Conference on Power Electronics and Applications, EPE 2001, August 2001, graz, Austria.

[40] J. Pou, R. Pindado, and D. Boroyevich, "Voltage-balance limits in fourlevel diode-clamped converters with passive front ends," IEEE Trans. Ind. Electron., vol. 52, no. 1, pp. 190-196, Feb. 2005.

[41] S. Busquets-Monge, S. Alepuz, J. Bordonau, and J. Peracaula, "Voltage Balancing Control of Diode-clamped Multilevel Converters With Passive Front-ends," IEEE Trans. Power Electron., vol. 23, no. 4, pp. 1751-1758, Jul. 2008

[42] Z. Cheng and B. Wu, "A Novel Switching Sequence Design for Fivelevel NPC/h-bridge Inverters With Improved Output Voltage Spectrum and Minimized Device Switching Frequency," IEEE Trans. Power Electron., vol. 22, no. 6, pp. 2138-2145, Nov. 2007.

[43] I. Etxeberria-Otadui, A. L. de Heredia, J. San-Sebastian, H. Gaztaaga, U. Viscarret, and M. Caballero, "Analysis of a H-NPC topology for an AC traction front-end converter," in Power Electronics and Motion Control Conference, 2008. EPE-PEMC 2008. 13th, Sep. 1-3, 2008, pp. $1555-1561$.

[44] V. Guennegues, B. Gollentz, L. Leclere, F. Meibody-Tabar, and S. Rael, "Selective harmonic elimination PWM applied to H-bridge topology in high speed applications," in Power Engineering, Energy and Electrical Drives, 2009. POWERENG '09. International Conference on, Mar. 18 20, 2009, pp. 152-156.

[45] C. M. Wu, W. H. Lau, and H. Chung, "A five-level neutral-pointclamped H-bridge PWM inverter with superior harmonics suppression: a theoretical analysis," in 1999 IEEE Int. Symp. Circuits and Systems, Orlando, FL, vol. 5, May 30-Jun. 2, 1999, pp. 198-201.

[46] T. Bruckner, S. Bernet, and H. Guldner, "The active NPC converter and its loss-balancing control," IEEE Trans. Ind. Electron., vol. 52, no. 3, pp. 855-868, Jun. 2005.

[47] O. Apeldoorn, B. Odegard, P. Steimer, and S. Bernet, "A 16 MVA ANPC-PEBB with 6 ka IGCTs," in Industry Applications Conference, 2005. Fourtieth IAS Annual Meeting. Conference Record of the 2005, vol. 2, Oct. 2-6, 2005, pp. 818-824.

[48] J. Meili, S. Ponnaluri, L. Serpa, P. K. Steimer, and J. W. Kolar, "Optimized Pulse Patterns for the 5-level ANPC Converter for High Speed High Power Applications," in IEEE Industrial Electronics, IECON 2006 - 32nd Annual Conference on, Nov. 6-10, 2006, pp. 2587-2592.

[49] L. A. Serpa, P. M. Barbosa, P. K. Steimer, and J. W. Kolar, "Five-level virtual-flux direct power control for the active neutral-point clamped multilevel inverter," in Power Electronics Specialists Conference, 2008. PESC 2008. IEEE, Jun. 15-19, 2008, pp. 1668-1674.

[50] F. Kieferndorf, M. Basler, L. A. Serpa, J.-H. Fabian, A. Coccia, and G. A. Scheuer, "A new medium voltage drive system based on anpc51 technology," in Proceedings of the IEEE-ICIT 2010 International Conference on Industrial Technology, March 2010, pp. 605-611, viña del Mar, Chile.

[51] T. Chaudhuri, P. Steimer, and A. Rufer, "Introducing the Common Cross Connected Stage (c3s) for the 51 ANPC multilevel inverter," in Power Electronics Specialists Conference, 2008. PESC 2008. IEEE, Jun. 15-19, 2008, pp. 167-173.

[52] P. K. Steimer, O. Apeldoorn, B. Odegard, S. Bernet, and T. Bruckner, "Very High Power IGCT PEBB technology," in Power Electronics Specialists Conference, 2005. PESC '05. IEEE 36th, Jun. 16-16, 2005, pp. 1-7.

[53] P. Barbosa, P. Steimer, J. Steinke, L. Meysenc, M. Winkelnkemper, and N. Celanovic, "Active Neutral-point-clamped Multilevel Converters," in Power Electronics Specialists Conference, 2005. PESC '05. IEEE 36th, Jun. 16-16, 2005, pp. 2296-2301.

[54] T. Chaudhuri, P. Barbosa, P. Steimer, and A. Rufer, "Cross-connected Intermediate Level (CCIL) Voltage Source Inverter," in Power Electronics Specialists Conference, 2007. PESC 2007. IEEE, Jun. 17-21, 2007, pp. 490-496.

[55] B. Gemmell, J. Dorn, D. Retzmann, and D. Soerangr, "Prospects of multilevel VSC technologies for power transmission," in Transmission and Distribution Conference and Exposition, 2008. T\&D. IEEE/PES, Apr. 21-24, 2008, pp. 1-16.

[56] SIEMENS, "Introduction to hvdc plus." [Online]. Available: https://www.energy-portal.siemens.com/static/hq/en/products_ solutions/1652_kn03011203.html
[57] R. Marquardt, "Stromrichterschaltungen mit verteilten energiespeichern," German Patent No. DE10103031A1, Filed 25 July 2002 Issued 24 January 2001.

[58] A. Lesnicar, J. Hildinger, and R. Marquardt, "Modulares stromrichterkonzept für netzkupplungsanwendungen bei hohen spannungen," in ETG-Fachbericht, vol. 88, 2002.

[59] A. Lesnicar and R. Marquardt, "A new modular voltage source inverter topology," in 10th European conference on power electronics and applications, EPE 2003, 2003.

[60] M. Glinka, "Prototype of multiphase modular-multilevel-converter with 2 MW power rating and 17-level-output-voltage," in Power Electronics Specialists Conference, 2004. PESC 04. 2004 IEEE 35th Annual, vol. 4 , 2004, pp. 2572-2576.

[61] M. Glinka and R. Marquardt, "A new AC/AC multilevel converter family," IEEE Trans. Ind. Electron., vol. 52, no. 3, pp. 662-669, Jun. 2005

[62] M. Hagiwara and H. Akagi, "Control and Experiment of Pulsewidthmodulated Modular Multilevel Converters," IEEE Trans. Power Electron., vol. 24, no. 7, pp. 1737-1746, Jul. 2009.

[63] J. Holtz, "Selbstgefuhrte wechselrichter mit treppenformiger ausgangsspannung fur grose leistung und hohe frequenz," Siemens Forschungs- und Entwicklungsberichte, vol. 6, no. 3, pp. 164-171, 1977.

[64] J. Dixon and L. Morán, "High-level multistep inverter optimization using a minimum number of power transistors," IEEE Trans. Power Electron., vol. 21, no. 2, pp. 330-337, March 2006.

[65] V. Guennegues, B. Gollentz, F. Meibody-Tabar, S. Rael, and L. Leclere, "A converter topology for high speed motor drive applications," in 13th European Conference on Power Electronics and Applications EPE'09, October 2009, p. 8.

[66] B. Gollentz and V. Guennegues, "Three-level inverter," US Patent No 20100084922A1, Filed July 01, 2009 April 08, May 2010.

[67] J. Wang, B. Wu, and N. R. Zargari, "High-power multi-modular matrix converters with sinusoidal input/output waveforms," in 35th Annual Conference of the IEEE Industrial Electronics Society, IECON 1009, 3-5 November 2009, pp. 547-552.

[68] P. C. Loh, F. Blaabjerg, F. Gao, A. Baby, and D. A. C. Tan, "Pulsewidth Modulation of Neutral-point-clamped Indirect Matrix Converter," IEEE Trans. Ind. Applicat., vol. 44, no. 6, pp. 1805-1814, Nov./Dec. 2008.

[69] P. Wheeler, X. Lie, M. Y. Lee, L. Empringham, C. Klumpner, and J. Clare, "A review of multi-level matrix converter topologies," in 4th IET Conference on Power Electronics, Machines and Drives, PEMD 2008, 2-4 April 2008, pp. 286-290.

[70] Y. Shi, X. Yang, Q. He, and Z. Wang, "Research on a novel capacitor clamped multilevel matrix converter," IEEE Trans. Power Electron. vol. 20, no. 5, pp. 1055-1065, Sep. 2005.

[71] O. M. Mueller and J. N. Park, "Quasi-linear IGBT inverter topologies," in Applied Power Electronics Conference and Exposition, 1994. APEC '94. Conference Proceedings 1994., Ninth Annual, Feb. 13-17, 1994, pp. 253-259.

[72] A.Rufer, M.Veenstra, and K.Gopakumar, "Asymmetric multilevel converter for high resolution voltage phasor generation," in $E P E$ ' 99,1999 , p. p. 10.

[73] J. Dixon, A. A. Breton, F. E. Rios, J. Rodriguez, J. Pontt, and M. A. Perez, "High-power Machine Drive, Using Nonredundant 27level Inverters and Active Front End Rectifiers," IEEE Trans. Power Electron., vol. 22, no. 6, pp. 2527-2533, Nov. 2007.

[74] Y. Liu and F. L. Luo, "Trinary hybrid 81-level multilevel inverter for motor drive with zero common-mode voltage," IEEE Trans. Ind. Electron., vol. 55, no. 3, pp. 1014-1021, March 2008.

[75] S. Kouro, R. Bernal, H. Miranda, J. Rodriguez, and J. Pontt, "Direct Torque Control With Reduced Switching Losses for Asymmetric Multilevel Inverter Fed Induction Motor Drives," in Industry Applications Conference, 2006. 41st IAS Annual Meeting. Conference Record of the 2006 IEEE, vol. 5, Oct. 8-12, 2006, pp. 2441-2446.

[76] C. Rech and J. R. Pinheiro, "Hybrid Multilevel Converters: Unified Analysis and Design Considerations," IEEE Trans. Ind. Electron., vol. 54, no. 2, pp. 1092-1104, Apr. 2007

[77] F. S. Kang, S. J. Park, M. H. Lee, and C. U. Kim, "An efficient multilevel synthesis approach and its application to a 27 -level inverter," IEEE Trans. Ind. Electron., vol. 52, no. 6, pp. 1600-1606, 2005.

[78] C. Rech and J. R. Pinheiro, "Impact of Hybrid Multilevel Modulation Strategies on Input and Output Harmonic Performances," IEEE Trans. Power Electron., vol. 22, no. 3, pp. 967-977, 2007.

[79] P. Steimer and M. Veenstra, "Converter with additional voltage addition or substraction at the output," US Patent No. 6,621,719 B2, Filed 17 Apr. 2002 Granted 16 Sep. 2003 
[80] M. Veenstra and A. Rufer, "Control of a hybrid asymmetric multilevel inverter for competitive medium-voltage industrial drives," IEEE Trans. Ind. Applicat., vol. 41, no. 2, pp. 655-664, Mar./Apr. 2005.

[81] K. A. Corzine and S. Lu, "Comparison of hybrid propulsion drive schemes," in Electric Ship Technologies Symposium, 2005 IEEE, Jul. 25-27, 2005, pp. 355-362.

[82] C. Silva, S. Kouro, J. Soto, and P. Lezana, "Control of an hybrid multilevel inverter for current waveform improvement," in Industrial Electronics, 2008. ISIE 2008. IEEE International Symposium on, Jun. 30-Jul. 2008, 2008, pp. 2329-2335.

[83] J. A. Ulrich and A. R. Bendre, "Floating capacitor voltage regulation in diode clamped hybrid multilevel converters," in Electric Ship Technologies Symposium, 2009. ESTS 2009. IEEE, Apr. 20-22, 2009, pp. 197-202.

[84] Z. Du, L. M. Tolbert, J. N. Chiasson, and B. Ozpineci, "A cascade multilevel inverter using a single DC source," in Applied Power Electronics Conference and Exposition, 2006. APEC '06. Twenty-First Annual IEEE, Mar. 19-23, 2006.

[85] S. Vazquez, J. I. Leon, L. G. Franquelo, J. J. Padilla, and J. M. Carrasco, "DC-voltage-ratio Control Strategy for Multilevel Cascaded Converters Fed With a Single DC Source," IEEE Trans. Ind. Electron., vol. 56, no. 7, pp. 2513-2521, Jul. 2009.

[86] H. Stemmler and P. Guggenbach, "Configurations of high-power voltage source inverter drives," in Fifth European Conference on Power Electronics and Applications, EPE93, vol. 5, 1993, pp. 7-14.

[87] K. A. Corzine, S. D. Sudhoff, and C. A. Whitcomb, "Performance characteristics of a cascaded two-level converter," IEEE Transaction on Energy Conversion, vol. 14, no. 3, pp. 433-439, Sep. 1999.

[88] K. A. Corzine, M. W. Wielebski, F. Z. Peng, and J. Wang, "Control of cascaded multilevel inverters," IEEE Trans. Power Electron., vol. 19, no. 3, pp. 732-738, May 2004.

[89] X. Kou, K. A. Corzine, and M. W. Wielebski, "Overdistention operation of cascaded multilevel inverters," IEEE Trans. Ind. Applicat., vol. 42, no. 3, pp. 817-824, May/Jun. 2006.

[90] K. A. Corzine, S. Lu, and T. H. Fikse, "Distributed Control of Hybrid Motor Drives," IEEE Trans. Power Electron., vol. 21, no. 5, pp. 1374 1384, Sep. 2006

[91] S. Lu and K. A. Corzine, "Advanced Control and Analysis of Cascaded Multilevel Converters Based on P-q Compensation," IEEE Trans. Power Electron., vol. 22, no. 4, pp. 1242-1252, Jul. 2007.

[92] V. T. Somasekhar, K. Gopakumar, M. R. Baiju, K. K. Mohapatra, and L. Umanand, "A multilevel inverter system for an induction motor with open-end windings," IEEE Trans. Ind. Electron., vol. 52, no. 3, pp. 824-836, Jun. 2005.

[93] S. Lu and K. Corzine, "Multilevel multi-phase propulsion drives," in Electric Ship Technologies Symposium, 2005 IEEE, Jul. 25-27, 2005, pp. 363-370.

[94] R. S. Kanchan, P. N. Tekwani, and K. Gopakumar, "Three-level Inverter Scheme With Common Mode Voltage Elimination and DC Link Capacitor Voltage Balancing for an Open-end Winding Induction Motor Drive," IEEE Trans. Power Electron., vol. 21, no. 6, pp. 16761683, Nov. 2006

[95] P. N. Tekwani, R. S. Kanchan, and K. Gopakumar, "A Dual Fivelevel Inverter-fed Induction Motor Drive With Common-mode Voltage Elimination and DC-link Capacitor Voltage Balancing Using Only the Switching-state Redundancy-part I," IEEE Trans. Ind. Electron., vol. 54 , no. 5 , pp. $2600-2608$, Oct. 2007.

[96] — , "A Dual Five-level Inverter-fed Induction Motor Drive With Common-mode Voltage Elimination and DC-link Capacitor Voltage Balancing Using Only the Switching-state Redundancy-part II,' IEEE Trans. Ind. Electron., vol. 54, no. 5, pp. 2609-2617, Oct. 2007.

[97] G. Mondal, K. . Gopakumar, P. N. Tekwani, and E. . Levi, "A Reduced-switch-count Five-level Inverter With Common-mode Voltage Elimination for an Open-end Winding Induction Motor Drive," IEEE Trans. Ind. Electron., vol. 54, no. 4, pp. 2344-2351, Aug. 2007.

[98] D. Casadei, G. Grandi, A. Lega, and C. Rossi, "Multilevel Operation and Input Power Balancing for a Dual Two-level Inverter with Insulated DC Sources," IEEE Trans. Ind. Applicat., vol. 44, no. 6, pp. 1815-1824, Nov./Dec. 2008.

[99] M. Rotella, G. Penailillo, J. Pereda, and J. Dixon, "PWM Method to Eliminate Power Sources in a Nonredundant 27-level Inverter for Machine Drive Applications," IEEE Trans. Ind. Electron., vol. 56, no. 1, pp. 194-201, Jan. 2009.

[100] G. Mondal, K. Sivakumar, R. Ramchand, K. Gopakumar, and E. Levi, "A Dual Seven-level Inverter Supply for an Open-end Winding Induction Motor Drive," IEEE Trans. Ind. Electron., vol. 56, no. 5, pp. 1665-1673, May 2009.
[101] K. K. Mohapatra, K. Gopakumar, V. T. Somasekhar, and L. Umanand, "A harmonic elimination and suppression scheme for an open-end winding induction motor drive," IEEE Trans. Ind. Electron., vol. 50, no. 6, pp. 1187-1198, Dec. 2003.

[102] S. Lakshminarayanan, R. S. Kanchan, P. N. Tekwani, and K. Gopakumar, "Multilevel inverter with 12-sided polygonal voltage space vector locations for induction motor drive," IEE Proceedings Electric Power Applications, vol. 153, no. 3, pp. 411-419, May 2006

[103] S. Lakshminarayanan, G. Mondal, P. N. Tekwani, K. K. Mohapatra, and K. Gopakumar, "Twelve-sided Polygonal Voltage Space Vector Based Multilevel Inverter for an Induction Motor Drive With Common-mode Voltage Elimination," IEEE Trans. Ind. Electron., vol. 54, no. 5, pp. 2761-2768, Oct. 2007.

[104] A. Das, K. Sivakumar, R. Ramchand, C. Patel, and K. Gopakumar, "A Combination of Hexagonal and 12-sided Polygonal Voltage Space Vector PWM Control for IM Drives Using Cascaded Two-level Inverters," IEEE Trans. Ind. Electron., vol. 56, no. 5, pp. 1657-1664, May 2009.

[105] A. Das, K. Gopakumar, C. Patel, R. Ramchand, and K. Sivakumar, "A pulse width modulated control of induction motor drive using multilevel 12-sided polygonal voltage space vectors," IEEE Trans. Ind. Electron., vol. to come, 2010.

[106] S. Lakshminarayanan, K. Gopakumar, G. Mondal, S. Figarado, and N. S. Dinesh, "Eighteen-sided polygonal voltage space-vector-based pwm control for an induction motor drive," IET Electric Power Applications, vol. 2, no. 1, pp. 56-63, January 2008.

[107] E. Cengelci, S. U. Sulistijo, B. O. Woo, P. Enjeti, R. Teodorescu, and F. Blaabjerg, "A new medium voltage PWM inverter topology for adjustable speed drives," in Industry Applications Conference, 1998. Thirty-Third IAS Annual Meeting. The 1998 IEEE, vol. 2, Oct. 12-15, 1998, pp. 1416-1423.

[108] J. Wen and K. M. Smedley, "Synthesis of Multilevel Converters Based on Single- and/or Three-phase Converter Building Blocks," IEEE Trans. Power Electron., vol. 23, no. 3, pp. 1247-1256, May 2008

[109] — "Hexagram Inverter for Medium-voltage Six-phase Variablespeed Drives," IEEE Trans. Ind. Electron., vol. 55, no. 6, pp. 2473 2481, Jun. 2008

[110] —, "Hexagram rectifier - Active front end of hexagram inverter for medium voltage variable speed drives," in Transmission and Distribution Conference and Exposition, 2008. T\&D. IEEE/PES, Apr. 21-24, 2008, pp. $1-8$.

[111] D. Xu and B. Wu, "Multilevel Current Source Inverters with Phase Shifted Trapezoidal PWM," in Power Electronics Specialists Conference, 2005. PESC '05. IEEE 36th, Jun. 16-16, 2005, pp. 2540-2546.

[112] Z. Bai and Z. Zhang, "Conformation of Multilevel Current Source Converter Topologies Using the Duality Principle," IEEE Trans. Power Electron., vol. 23, no. 5, pp. 2260-2267, Sep. 2008.

[113] P. Lezana, J. Rodriguez, and D. A. Oyarzun, "Cascaded Multilevel Inverter With Regeneration Capability and Reduced Number of Switches," IEEE Trans. Ind. Electron., vol. 55, no. 3, pp. 1059-1066, Mar. 2008.

[114] S. Inoue and H. Akagi, "A Bidirectional Isolated DC-DC Converter as a Core Circuit of the Next-generation Medium-voltage Power Conversion System," IEEE Trans. Power Electron., vol. 22, no. 2, pp. 535-542, Mar. 2007.

[115] M. Carpita, M. Marchesoni, M. Pellerin, and D. Moser, "Multilevel Converter for Traction Applications: Small-scale Prototype Tests Results," IEEE Trans. Ind. Electron., vol. 55, no. 5, pp. 2203-2212, May 2008.

[116] V. Blahnik, Z. Peroutka, J. Zak, and T. Komrska, "Traction converter with medium-frequency transformer for railway applications: Direct current control of primary active rectifiers," in Power Electronics and Applications, 2009. EPE '09. 13th European Conference on, Sep. 8-10, 2009, pp. 1-8.

[117] J. Clare, "Advanced power converters for universal and flexible power management in future electricity networks," in Power Electronics and Applications, 2009. EPE '09. 13th European Conference on, Sep. 8-10, 2009, pp. 1-29.

[118] G. Gateau, T. A. Meynard, and H. Foch, "Stacked multicell converter (SMC): properties and design," in Power Electronics Specialists Conference, 2001. PESC. 2001 IEEE 32nd Annual, vol. 3, Jun. 17-21, 2001, pp. $1583-1588$

[119] B. P. McGrath, T. Meynard, G. Gateau, and D. G. Holmes, "Optimal Modulation of Flying Capacitor and Stacked Multicell Converters Using a State Machine Decoder," IEEE Trans. Power Electron., vol. 22, no. 2, pp. 508-516, Mar. 2007. 
[120] M. B. Smida and F. B. Ammar, "Modelling and DBC-PSC-PWM Control of a Three-phase Flying Capacitor Stacked Multilevel Voltage Source Inverter," IEEE Transactions on : Accepted for future publication Industrial Electronics, pp. 1-1, / 2009.

[121] S. Busquets-Monge, J. Rocabert, P. Rodriguez, S. Alepuz, and J. Bordonau, "Multilevel Diode-clamped Converter for Photovoltaic Generators With Independent Voltage Control of Each Solar Array," IEEE Trans. Ind. Electron., vol. 55, no. 7, pp. 2713-2723, Jul. 2008.

[122] M. M. Renge and H. M. Suryawanshi, "Five-level Diode Clamped Inverter to Eliminate common Mode Voltage and Reduce $d v / d t$ inmedium Voltage Rating Induction Motor Drives," IEEE Trans. Power Electron., vol. 23, no. 4, pp. 1598-1607, Jul. 2008.

[123] S. Busquets-Monge, S. Alepuz, J. Rocabert, and J. Bordonau, "Pulsewidth Modulations for the Comprehensive Capacitor Voltage Balance of $n$-level Three-leg Diode-clamped Converters," IEEE Trans. Power Electron., vol. 24, no. 5, pp. 1364-1375, May 2009.

[124] N. Hatti, K. Hasegawa, and H. Akagi, "A 6.6-kv Transformerless Motor Drive Using a Five-level Diode-clamped PWM Inverter for Energy Savings of Pumps and Blowers," IEEE Trans. Power Electron., vol. 24, no. 3, pp. 796-803, Mar. 2009.

[125] G. Carrara, S. Gardella, M. Marchesoni, R. Salutari, and G. Sciutto, "A new multilevel PWM method: a theoretical analysis," IEEE Trans. Power Electron., vol. 7, no. 3, pp. 497-505, Jul. 1992.

[126] B. P. McGrath and D. G. Holmes, "Multicarrier PWM strategies for multilevel inverters," IEEE Trans. Ind. Electron., vol. 49, no. 4, pp. 858-867, Aug. 2002.

[127] M. S. A. Dahidah and V. G. Agelidis, "Selective Harmonic Elimination PWM Control for Cascaded Multilevel Voltage Source Converters: A Generalized Formula," IEEE Trans. Power Electron., vol. 23, no. 4, pp. 1620-1630, Jul. 2008.

[128] Z. Du, L. M. Tolbert, J. N. Chiasson, and B. Ozpineci, "Reduced Switching-frequency Active Harmonic Elimination for Multilevel Converters," IEEE Trans. Ind. Electron., vol. 55, no. 4, pp. 1761-1770, Apr. 2008.

[129] N. Celanovic and D. Boroyevich, "A fast space-vector modulation algorithm for multilevel three-phase converters," IEEE Trans. Ind. Applicat., vol. 37, no. 2, pp. 637-641, Mar./Apr. 2001.

[130] M. Saeedifard, A. Bakhshai, and G. Joos, "Low switching frequency space vector modulators for high power multimodule converters," IEEE Trans. Power Electron., vol. 20, no. 6, pp. 1310-1318, Nov. 2005.

[131] L. G. Franquelo, M. A. M. Prats, R. C. Portillo, J. I. L. Galvan, M. A. Perales, J. M. Carrasco, E. G. Diez, and J. L. M. Jimenez, "Threedimensional space-vector modulation algorithm for four-leg multilevel converters using abc coordinates," IEEE Trans. Ind. Electron., vol. 53, no. 2, pp. 458-466, Apr. 2006.

[132] R. S. Kanchan, K. Gopakumar, , and R. Kennel, "Synchronised carrierbased svpwm signal generation scheme for the entire modulation range extending up to six-step mode using the sampled amplitudes of reference phase voltages," IET Electric Power Applications, vol. 1, no. 3, pp. 407-415, May 2007.

[133] A. K. Gupta and A. M. Khambadkone, "A General Space Vector PWM Algorithm for Multilevel Inverters, Including Operation in Overmodulation Range," IEEE Trans. Power Electron., vol. 22, no. 2, pp. 517 526, Mar. 2007.

[134] A. Cataliotti, F. Genduso, A. Raciti, and G. R. Galluzzo, "Generalized PWM-VSI Control Algorithm Based on a Universal Duty-cycle Expression: Theoretical Analysis, Simulation Results, and Experimental Validations," IEEE Trans. Ind. Electron., vol. 54, no. 3, pp. 1569-1580, Jun. 2007.

[135] O. Lopez, J. Alvarez, J. Doval-Gandoy, and F. D. Freijedo, "Multilevel Multiphase Space Vector PWM Algorithm," IEEE Trans. Ind. Electron., vol. 55, no. 5, pp. 1933-1942, May 2008.

[136] L. Dalessandro, S. D. Round, U. Drofenik, and J. W. Kolar, "Discontinuous Space-vector Modulation for Three-level PWM Rectifiers," IEEE Trans. Power Electron., vol. 23, no. 2, pp. 530-542, Mar. 2008.

[137] M. A. S. Aneesh, A. Gopinath, and M. R. Baiju, "A Simple Space Vector PWM Generation Scheme for Any General $n$-level Inverter," IEEE Trans. Ind. Electron., vol. 56, no. 5, pp. 1649-1656, May 2009

[138] O. Lopez, J. Alvarez, J. Doval-Gandoy, and F. D. Freijedo, "Multilevel Multiphase Space Vector PWM Algorithm With Switching State Redundancy," IEEE Trans. Ind. Electron., vol. 56, no. 3, pp. 792-804, Mar. 2009.

[139] J. I. Leon, S. Vazquez, R. Portillo, L. G. Franquelo, J. M. Carrasco, P. W. Wheeler, and A. J. Watson, "Three-dimensional Feedforward Space Vector Modulation Applied to Multilevel Diode-clamped Converters," IEEE Trans. Ind. Electron., vol. 56, no. 1, pp. 101-109, Jan. 2009
[140] A. Gopinath, A. S. A. Mohamed, and M. R. Baiju, "Fractal Based Space Vector PWM for Multilevel Inverters-a Novel Approach," IEEE Trans. Ind. Electron., vol. 56, no. 4, pp. 1230-1237, Apr. 2009.

[141] J. Leon, S. Vazquez, J. Sanchez, R. Portillo, L. Franquelo, J. Carrasco, and E. Dominguez, "Conventional Space-vector Modulation Techniques versus the Single-phase Modulator for Multilevel Converters," IEEE Transactions on : Accepted for future publication Industrial Electronics, pp. 1-1, / 2010.

[142] S. Kouro, M. Perez, H. Robles, and J. Rodriguez, "Switching loss analysis of modulation methods used in cascaded H-bridge multilevel converters," in Power Electronics Specialists Conference, 2008. PESC 2008. IEEE, Jun. 15-19, 2008, pp. 4662-4668.

[143] D. Andler, S. Kouro, M. Perez, J. Rodriguez, and B. Wu, "Switching loss analysis of modulation methods used in neutral point clamped converters," in Energy Conversion Congress and Exposition, 2009. ECCE. IEEE, Sep. 20-24, 2009, pp. 2565-2571.

[144] L. G. Franquelo, J. Napoles, R. C. P. Guisado, J. I. Leon, and M. A. Aguirre, "A Flexible Selective Harmonic Mitigation Technique to Meet Grid Codes in Three-level PWM Converters," IEEE Trans. Ind. Electron., vol. 54, no. 6, pp. 3022-3029, Dec. 2007.

[145] J. Napoles, J. I. Leon, R. Portillo, L. G. Franquelo, and M. A. Aguirre, "Selective Harmonic Mitigation Technique for High Power Converters," IEEE Transactions on : Accepted for future publication Industrial Electronics, pp. 1-1, / 2010.

[146] J. Holtz and N. Oikonomou, "Synchronous optimal pulsewidth modulation and stator flux trajectory control for medium voltage drives," in Industry Applications Conference, 2005. Fourtieth IAS Annual Meeting. Conference Record of the 2005, vol. 3, Oct. 2-6, 2005, pp. 1748-1791.

[147] A. R. Beig, G. Narayanan, and V. T. Ranganathan, "Modified SVPWM Algorithm for Three Level VSI With Synchronized and Symmetrical Waveforms," IEEE Trans. Ind. Electron., vol. 54, no. 1, pp. 486-494, Feb. 2007.

[148] J. A. Pontt, J. R. Rodriguez, A. Liendo, P. Newman, J. Holtz, and J. M. S. Martin, "Network-friendly Low-switching-frequency Multipulse High-power Three-level PWM Rectifier," IEEE Trans. Ind. Electron., vol. 56, no. 4, pp. 1254-1262, Apr. 2009.

[149] Z. Du, L. M. Tolbert, and J. N. Chiasson, "Active harmonic elimination for multilevel converters," IEEE Trans. Power Electron., vol. 21, no. 2, pp. 459-469, Mar. 2006

[150] Z. Du, L. M. Tolbert, B. Ozpineci, and J. N. Chiasson, "Fundamental Frequency Switching Strategies of a Seven-level Hybrid Cascaded Hbridge Multilevel Inverter," IEEE Trans. Power Electron., vol. 24, no. 1, pp. 25-33, Jan. 2009.

[151] V. G. Agelidis, A. I. Balouktsis, and M. S. A. Dahidah, "A Fivelevel Symmetrically Defined Selective Harmonic Elimination PWM Strategy: Analysis and Experimental Validation," IEEE Trans. Power Electron., vol. 23, no. 1, pp. 19-26, Jan. 2008.

[152] S. R. Pulikanti and V. G. Agelidis, "Control of neutral point and flying capacitor voltages in five-level SHE-PWM controlled ANPC converter," in Industrial Electronics and Applications, 2009. ICIEA 2009. 4th IEEE Conference on, May 25-27, 2009, pp. 172-177.

[153] M. T. Hagh, H. Taghizadeh, and K. Razi, "Harmonic Minimization in Multilevel Inverters Using Modified Species-based Particle Swarm Optimization," IEEE Trans. Power Electron., vol. 24, no. 10, pp. 22592267, Oct. 2009.

[154] J. Li, Y. Liu, S. Bhattacharya, and A. Q. Huang, "An optimum PWM Strategy for 5-level active NPC (ANPC) converter based on real-time solution for THD minimization," in Energy Conversion Congress and Exposition, 2009. ECCE. IEEE, Sep. 20-24, 2009, pp. 1976-1982.

[155] Y. Liu, H. Hong, and A. Q. Huang, "Real-time Calculation of Switching Angles Minimizing THD for Multilevel Inverters With Step Modulation," IEEE Trans. Ind. Electron., vol. 56, no. 2, pp. 285-293, Feb. 2009.

[156] S. Kouro, B. L. Rocca, P. Cortes, S. Alepuz, B. Wu, and J. Rodriguez, "Predictive control based selective harmonic elimination with low switching frequency for multilevel converters," in Energy Conversion Congress and Exposition, 2009. ECCE. IEEE, Sep. 20-24, 2009, pp. 3130-3136.

[157] A. Sapin, P. K. Steimer, and J. J. Simond, "Modeling, simulation, and test of a three-level voltage-source inverter with output lc filter and direct torque control," vol. 43, no. 2, pp. 469-475, March 2007.

[158] C. Martins, X. Roboam, T. Meynard, and A. Carvalho, "Switching frequency imposition and ripple reduction in dtc drives by using a multilevel converter," IEEE Trans. Power Electron., vol. 17, no. 2, pp. 286-297, March 2002.

[159] J. Rodríguez, J. Pontt, S. Kouro, and P. Correa, "Direct torque control 
with imposed switching frequency in an 11-level cascaded inverter,' IEEE Trans. Ind. Electron., vol. 51, no. 4, pp. 827-833, August 2004.

[160] G. S. Buja and M. P. Kazmierkowski, "Direct torque control of pwm inverter-fed ac motors-a survey," IEEE Trans. Ind. Electron., vol. 51, no. 4, pp. 744-757, August 2004.

[161] H. Miranda, C. Silva, and J. Rodriguez, "Torque regulation by means of stator flux control for induction machines," in 32nd Annu. Conf. IEEE Industrial Electronics Society (IECON 2006), 2006, pp. 1218-1222.

[162] S. Kouro, R. Bernal, H. Miranda, C. A. Silva, and J. Rodriguez, "High-performance Torque and Flux Control for Multilevel Inverter Fed Induction Motors," IEEE Trans. Power Electron., vol. 22, no. 6 , pp. 2116-2123, Nov. 2007.

[163] M. Malinowski, M. P. Kazmierkowski, and A. M. Trzynadlowski, "A comparative study of control techniques for pwm rectifiers in ac adjustable speed drives," IEEE Trans. Power Electron., vol. 18, no. 6, pp. 1390-1396, November 2003.

[164] M. Malinowski, M. P. Kazmierkowski, S. Hansen, F. Blaabjerg, and G. D. Marques, "Virtual-flux-based direct power control of three-phase pwm rectifiers," vol. 37, no. 4, pp. 1019-1025, July/August 2001.

[165] M. Malinowski, S. Stynski, W. Kolomyjski, and M. P. Kazmierkowski, "Control of Three-level PWM Converter Applied to Variable-speedtype Turbines," IEEE Trans. Ind. Electron., vol. 56, no. 1, pp. 69-77, Jan. 2009.

[166] J. Eloy-García, S. Arnaltes, and J. L. Rodríguez-Amenedo, "Extended direct power control for multilevel inverters including dc link middle point voltage control," IET Electronic Power Applications, vol. 1, no. 4, pp. 571-580, 2007.

[167] J. Pou, J. Zaragoza, P. Rodriguez, S. Ceballos, V. M. Sala, R. P. Burgos, and D. Boroyevich, "Fast-processing Modulation Strategy for the Neutral-point-clamped Converter With Total Elimination of Lowfrequency Voltage Oscillations in the Neutral Point," IEEE Trans. Ind. Electron., vol. 54, no. 4, pp. 2288-2294, Aug. 2007.

[168] L. Zhang and S. Watkins, "Capacitor voltage balancing in multilevel flying capacitor inverters by rule-based switching pattern selection," IET Electric Power Applications, vol. 1, no. 3, pp. 339-347, May 2007.

[169] O. Bouhali, B. Francois, E. M. Berkouk, and C. Saudemont, "DC Link Capacitor Voltage Balancing in a Three-phase Diode Clamped Inverter Controlled by a Direct Space Vector of Line-to-line Voltages," IEEE Trans. Power Electron., vol. 22, no. 5, pp. 1636-1648, Sep. 2007.

[170] C. Feng, J. Liang, and V. G. Agelidis, "Modified Phase-shifted PWM Control for Flying Capacitor Multilevel Converters," IEEE Trans. Power Electron., vol. 22, no. 1, pp. 178-185, Jan. 2007.

[171] S. Busquets-Monge, S. Somavilla, J. Bordonau, and D. Boroyevich, "Capacitor Voltage Balance for the Neutral-point- Clamped Converter using the Virtual Space Vector Concept With Optimized Spectral Performance," IEEE Trans. Power Electron., vol. 22, no. 4, pp. 1128 1135, Jul. 2007.

[172] B. P. McGrath and D. G. Holmes, "Analytical Modelling of Voltage Balance Dynamics for a Flying Capacitor Multilevel Converter,' IEEE Trans. Power Electron., vol. 23, no. 2, pp. 543-550, Mar. 2008.

[173] G. P. Adam, S. J. Finney, A. M. Massoud, and B. W. Williams, "Capacitor Balance Issues of the Diode-clamped Multilevel Inverter Operated in a Quasi Two-state Mode," IEEE Trans. Ind. Electron., vol. 55, no. 8, pp. 3088-3099, Aug. 2008.

[174] J. Zaragoza, J. Pou, S. Ceballos, E. Robles, P. Ibaez, and J. L. Villate, "A Comprehensive Study of a Hybrid Modulation Technique for the Neutral-point-clamped Converter," IEEE Trans. Ind. Electron., vol. 56, no. 2, pp. 294-304, Feb. 2009.

[175] M. Saeedifard, R. Iravani, and J. Pou, "A Space Vector Modulation Strategy for a Back-to-back Five-level HVDC Converter System,' IEEE Trans. Ind. Electron., vol. 56, no. 2, pp. 452-466, Feb. 2009.

[176] S. Busquets-Monge, S. Alepuz, J. Bordonau, and J. Peracaula, "Erratum to "voltage Balancing Control of Diode-clamped Multilevel Converters With Passive Front-ends" [jul 08 1751-1758]," IEEE Trans. Power Electron., vol. 24, no. 6, pp. 1666-1666, Jun. 2009.

[177] B. P. McGrath and D. G. Holmes, "Analytical Determination of the Capacitor Voltage Balancing Dynamics for Three-phase Flying Capacitor Converters," IEEE Trans. Ind. Applicat., vol. 45, no. 4, pp. 1425-1433, Jul./Aug. 2009.

[178] R. Stala, S. Pirog, M. Baszynski, A. Mondzik, A. Penczek, J. Czekonski, and S. Gasiorek, "Results of Investigation of Multicell Converters With Balancing Circuit-part I," IEEE Trans. Ind. Electron., vol. 56, no. 7, pp. 2610-2619, Jul. 2009.

[179] R. Stala, S. Pirog, A. Mondzik, M. Baszynski, A. Penczek, J. Czekonski, and S. Gasiorek, "Results of Investigation of Multicell Converters With Balancing Circuit-part II," IEEE Trans. Ind. Electron., vol. 56, no. 7 , pp. 2620-2628, Jul. 2009.
[180] S. Allebrod, R. Hamerski, and R. Marquardt, "New transformerless, scalable Modular Multilevel Converters for HVDC-transmission," in Power Electronics Specialists Conference, 2008. PESC 2008. IEEE, Jun. 15-19, 2008, pp. 174-179.

[181] S. Daher, J. Schmid, and F. L. M. Antunes, "Multilevel Inverter Topologies for Stand-alone PV Systems," IEEE Trans. Ind. Electron., vol. 55, no. 7, pp. 2703-2712, Jul. 2008.

[182] R. Gonzalez, E. Gubia, J. Lopez, and L. Marroyo, "Transformerless Single-phase Multilevel-based Photovoltaic Inverter," IEEE Trans. Ind. Electron., vol. 55, no. 7, pp. 2694-2702, Jul. 2008.

[183] E. Ozdemir, S. Ozdemir, and L. M. Tolbert, "Fundamental-frequencymodulated Six-level Diode-clamped Multilevel Inverter for Three-phase Stand-alone Photovoltaic System," IEEE Trans. Ind. Electron., vol. 56, no. 11, pp. 4407-4415, Nov. 2009.

[184] T. Kerekes, M. Liserre, R. Teodorescu, C. Klumpner, and M. Sumner, "Evaluation of Three-phase Transformerless Photovoltaic Inverter Topologies," IEEE Trans. Power Electron., vol. 24, no. 9, pp. 2202 2211, Sep. 2009

[185] L. Ma, X. Jin, T. Kerekes, M. Liserre, R. Teodorescu, and P. Rodriguez, "The PWM strategies of grid-connected distributed generation active NPC inverters," in Energy Conversion Congress and Exposition, 2009. ECCE. IEEE, Sep. 20-24, 2009, pp. 920-927.

[186] F. S. Kang, S. J. Park, C. U. Kim, and T. Ise, "Multilevel pwm inverters suitable for the use of stand-alone photovoltaic power system," IEEE Trans. on Energy Conversion, vol. 20, no. 4, pp. 906-915, 2005.

[187] E. Villanueva, P. Correa, J. Rodriguez, and M. Pacas, "Control of a Single-phase Cascaded H-bridge Multilevel Inverter for Grid-connected Photovoltaic Systems," IEEE Trans. Ind. Electron., vol. 56, no. 11, pp. 4399-4406, Nov. 2009.

[188] S. Kouro, A. Moya, E. Villanueva, P. Correa, B. Wu, and J. Rodriguez, "Control of a cascaded h-bridge multilevel converter for grid connection of photovoltaic systems." Porto, Portugal: 35th Annual Conference of the IEEE Industrial Electronics Society (IECON09), November, pp. 1-7.

[189] G. Grandi, C. Rossi, D. Ostojic, and D. Casadei, "A New Multilevel Conversion Structure for Grid-connected PV Applications," IEEE Trans. Ind. Electron., vol. 56, no. 11, pp. 4416-4426, Nov. 2009.

[190] J. Selvaraj and N. A. Rahim, "Multilevel Inverter For Grid-connected PV System Employing Digital PI Controller," IEEE Trans. Ind. Electron., vol. 56, no. 1, pp. 149-158, Jan. 2009.

[191] N. A. Rahim and J. Selvaraj, "Multi-string Five-level Inverter with Novel PWM Control Scheme for PV Application," IEEE Transactions on : Accepted for future publication Industrial Electronics, pp. 1-1, I 2009.

[192] P. Flores, J. Dixon, M. Ortuzar, R. Carmi, P. Barriuso, and L. Moran, "Static Var Compensator and Active Power Filter With Power Injection Capability, Using 27-level Inverters and Photovoltaic Cells," IEEE Trans. Ind. Electron., vol. 56, no. 1, pp. 130-138, Jan. 2009.

[193] J.-S. Lai, "Power conditioning circuit topologies," IEEE Industrial Electronics Magazine, vol. 3, no. 2, pp. 24-34, Jun. 2009.

[194] S. Alepuz, S. Busquets-Monge, J. Bordonau, J. Gago, D. Gonzalez, and J. Balcells, "Interfacing Renewable Energy Sources to the Utility Grid Using a Three-level Inverter," IEEE Trans. Ind. Electron., vol. 53, no. 5, pp. 1504-1511, Oct. 2006.

[195] R. C. Portillo, M. M. Prats, J. I. Leon, J. A. Sanchez, J. M. Carrasco, E. Galvan, and L. G. Franquelo, "Modeling Strategy for Back-to-back Three-level Converters Applied to High-power Wind Turbines," IEEE Trans. Ind. Electron., vol. 53, no. 5, pp. 1483-1491, Oct. 2006.

[196] M. Winkelnkemper, F. Wildner, and P. K. Steimer, "6 MVA fivelevel hybrid converter for windpower," in Power Electronics Specialists Conference, 2008. PESC 2008. IEEE, Jun. 15-19, 2008, pp. 45324538 .

[197] M. Winkelnkemper, F. Wildner, and P. Steimer, "Control of a 6MVA hybrid converter for a permanent magnet synchronous generator for windpower," in Electrical Machines, 2008. ICEM 2008. 18th International Conference on, Sep. 6-9, 2008, pp. 1-6.

[198] S. Alepuz, S. Busquets-Monge, J. Bordonau, J. A. Martinez-Velasco, C. A. Silva, J. Pontt, and J. Rodriguez, "Control Strategies Based on Symmetrical Components for Grid-connected Converters Under Voltage Dips," IEEE Trans. Ind. Electron., vol. 56, no. 6, pp. 21622173, Jun. 2009

[199] C. H. Ng, M. A. Parker, L. Ran, P. J. Tavner, J. R. Bumby, and E. Spooner, "A multilevel modular converter for a large, light weight wind turbine generator," IEEE Trans. Power Electron., vol. 23, no. 3, pp. 1062-1074, May 2008. 
[200] A. K. Adnanes, "Maritime electrical installations and diesel electric propulsion," ABB Marine, 2003. [Online]. Available: www.abb.com/ industries/us/9AAC131439.aspx

[201] D. Gritter, S. S. Kalsi, and N. Henderson, "Variable speed electric drive options for electric ships," in Electric Ship Technologies Symposium, 2005 IEEE, Jul. 25-27, 2005, pp. 347-354.

[202] S. Bernet, "Recent developments of high power converters for industry and traction applications," IEEE Trans. Power Electron., vol. 15, no. 6, pp. 1102-1117, Nov. 2000.

[203] J. Helmer, U. Henning, P. Kamp, and J. Nothhaft, "Advanced converter module for high speed maglev system transrapid," in Proc. 9th Eur. Conf. Power Electron.(EPE 2001), 2001, p. p. 10, graz.

[204] U. Henning, R. Hoffmann, and J. Hochleitner, "Advanced static power converter and control components for TRANSRAPID maglev system," in Power Conversion Conference, 2002. PCC Osaka 2002. Proceedings of the, vol. 3, Apr. 2-5, 2002, pp. 1045-1049.

[205] A. L. de Heredia, H. Gaztanaga, U. Viscarret, I. Etxeberria-Otadui, L. Aldasoro, and T. Nieva, "Comparison of H-NPC and parallel-h topologies for AC traction front-end converters," in Power Electronics and Applications, 2009. EPE '09. 13th European Conference on, Sep. 8-10, 2009, pp. 1-9.

[206] M. Pittermann, P. Drabek, M. Cedl, and J. Fort, "The study of using the traction drive topology with the middle-frequency transformer," in Power Electronics and Motion Control Conference, 2008. EPE-PEMC 2008. 13th, Sep. 1-3, 2008, pp. 1593-1597.

[207] S. Dieckerhoff, S. Bernet, and D. Krug, "Power loss-oriented evaluation of high voltage IGBTs and multilevel converters in transformerless traction applications," IEEE Trans. Power Electron., vol. 20, no. 6, pp. 1328-1336, Nov. 2005.

[208] J. Dixon and L. Moran, "A clean four-quadrant sinusoidal power rectifier using multistage converters for subway applications," IEEE Trans. Ind. Electron., vol. 52, no. 3, pp. 653-661, Jun. 2005.

[209] T. A. Meynard, H. Foch, P. Thomas, J. Courault, R. Jakob, and M. Nahrstaedt, "Multicell converters: basic concepts and industry applications," IEEE Trans. Ind. Electron., vol. 49, no. 5, pp. 955-964, Oct. 2002.

[210] S. Stynski, J. San-Sebastian, M. Malinowski, and I. Etxeberria-Otadui, "Analysis of multilevel PWM converter based on FLC modules for an AC traction application," in Industrial Technology, 2009. ICIT 2009. IEEE International Conference on, Feb. 10-13, 2009, pp. 1-6.

[211] J. Li, A. Huang, S. Bhattacharya, and S. Lukic, "ETO light multilevel converters for large electric vehicle and hybrid electric vehicle drives," in Vehicle Power and Propulsion Conference, 2009. VPPC '09. IEEE, Sep. 7-10, 2009, pp. 1455-1460.

[212] Z. Du, L. M. Tolbert, J. N. Chiasson, B. Ozpineci, H. Li, and A. Q. Huang, "Hybrid Cascaded H-bridges Multilevel Motor Drive Control for Electric Vehicles," in Power Electronics Specialists Conference, 2006. PESC '06. 37th IEEE, Jun. 18-22, 2006, pp. 1-6.

[213] Z. Du, B. Ozpineci, L. M. Tolbert, and J. N. Chiasson, "Inductorless DC-AC Cascaded H-bridge Multilevel Boost Inverter for Electric/hybrid Electric Vehicle Applications," in Industry Applications Conference, 2007. 42nd IAS Annual Meeting. Conference Record of the 2007 IEEE, Sep. 23-27, 2007, pp. 603-608.

[214] — "DC-AC Cascaded H-bridge Multilevel Boost Inverter With No Inductors for Electric/hybrid Electric Vehicle Applications," IEEE Trans. Ind. Applicat., vol. 45, no. 3, pp. 963-970, May/ 2009.

[215] F. H. Khan and L. M. Tolbert, "5 kw Multilevel DC-DC Converter for Hybrid Electric and Fuel Cell Automotive Applications," in Industry Applications Conference, 2007. 42nd IAS Annual Meeting. Conference Record of the 2007 IEEE, Sep. 23-27, 2007, pp. 628-635.

[216] _ "Multiple-load-source Integration in a Multilevel Modular Capacitor-clamped DC-DC Converter Featuring Fault Tolerant Capability," IEEE Trans. Power Electron., vol. 24, no. 1, pp. 14-24, Jan. 2009.

[217] F. H. Khan, L. M. Tolbert, and W. E. Webb, "Hybrid Electric Vehicle Power Management Solutions Based on Isolated and Nonisolated Configurations of Multilevel Modular Capacitor-clamped Converter,' IEEE Trans. Ind. Electron., vol. 56, no. 8, pp. 3079-3095, Aug. 2009.

[218] W. Qian, F. Z. Peng, and L. M. Tolbert, "Development of a $55 \mathrm{kw} \mathrm{3x}$ dc-dc converter for HEV systems," in Vehicle Power and Propulsion Conference, 2009. VPPC '09. IEEE, Sep. 7-10, 2009, pp. 433-439.

[219] J. Rodriguez, J. Pontt, G. Alzarnora, N. Becker, O. Einenkel, and A. Weinstein, "Novel 20-MW downhill conveyor system using threelevel converters," IEEE Trans. Ind. Electron., vol. 49, no. 5, pp. 1093 1100, Oct. 2002.

[220] J. R. Rodriguez, J. Pontt, R. Huerta, G. Alzamora, N. Becker, S. Kouro, P. Cortes, and P. Lezana, "Resonances in a high-power active-front-end rectifier system," IEEE Trans. Ind. Electron., vol. 52, no. 2, pp. 482 488, Apr. 2005.

[221] V. M. E. Antunes, V. F. Pires, and J. F. Silva, "Digital multilevel audio power amplifier with a MASH sigma-delta modulator to reduce harmonic distortion," in Industrial Electronics, 2005. ISIE 2005. Proceedings of the IEEE International Symposium on, vol. 2, Jun. 20-23, 2005, pp. 525-528.

[222] V. M. E. Antunes, V. F. Pires, and J. F. A. Silva, "Narrow Pulse Elimination PWM for Multilevel Digital Audio Power Amplifiers Using Two Cascaded H-bridges as a Nine-level Converter," IEEE Trans. Power Electron., vol. 22, no. 2, pp. 425-434, Mar. 2007.

[223] C. W. Lin, B.-S. Hsieh, and Y. C. Lin, "Enhanced design of filterless class-d audio amplifier," in Design, Automation \& Test in Europe Conference \& Exhibition, 2009. DATE '09., Apr. 20-24, 2009, pp. 1397-1402.

[224] J. A. Suul, K. Uhlen, and T. Undeland, "Variable speed pumped storage hydropower for integration of wind energy in isolated gridscase description and control strategies," in Nordic Workshop on Power and Industrial Electronics NORPIE2008, June 9-11 2008.

[225] D. Soto and T. C. Green, "A comparison of high-power converter topologies for the implementation of FACTS controllers," IEEE Trans. Ind. Electron., vol. 49, no. 5, pp. 1072-1080, Oct. 2002.

[226] M. Ciobotaru, F. Iov, P. Zanchetta, Y. D. Novaes, and F. Blaabjerg, "Study and analysis of a natural reference frame current controller for a multi-level H-bridge power converter," in Power Electronics Specialists Conference, 2008. PESC 2008. IEEE, Jun. 15-19, 2008, pp. 2914 2920.

[227] L. Maharjan, S. Inoue, H. Akagi, and J. Asakura, "State-of-charge (SOC)-balancing Control of a Battery Energy Storage System Based on a Cascade PWM Converter," IEEE Trans. Power Electron., vol. 24, no. 6, pp. 1628-1636, Jun. 2009.

[228] Y. Cheng, C. Qian, M. L. Crow, S. Pekarek, and S. Atcitty, "A comparison of diode-clamped and cascaded multilevel converters for a STATCOM with energy storage," IEEE Trans. Ind. Electron., vol. 53, no. 5, pp. 1512-1521, Oct. 2006.

[229] G. Almandoz, G. Abad, I. Zamakona, M. Telleria, M. Zulaika, and F. J. Pazos, "MV Grid Reactive Power Compensator Based on a Four Level NPC Converter," in Power Electronics and Motion Control Conference, 2006. EPE-PEMC 2006. 12th International, Aug. 30-Sep. 2006, 2006, pp. $148-153$

[230] S. Yonetani, Y. Kondo, H. Akagi, and H. Fujita, "A 6.6-kv Transformerless STATCOM Based on a Five-level Diode-clamped PWM Converter: System Design and Experimentation of a 200-v 10-kVA Laboratory Model," IEEE Trans. Ind. Applicat., vol. 44, no. 2, pp. 672-680, Mar./ 2008 .

[231] Y. Liu and F. L. Luo, "Trinary hybrid multilevel inverter used in statcom with unbalanced voltages," IEE- Proceedings on Electric Power Applications, vol. 152, no. 5, pp. 1203-1222, September 2005.

[232] H. Akagi, S. Inoue, and T. Yoshii, "Control and Performance of a Transformerless Cascade PWM STATCOM With Star Configuration," IEEE Trans. Ind. Applicat., vol. 43, no. 4, pp. 1041-1049, Jul./Aug. 2007.

[233] Q. Song, W. Liu, and Z. Yuan, "Multilevel Optimal Modulation and Dynamic Control Strategies for STATCOMs Using Cascaded Multilevel Inverters," IEEE Trans. Power Delivery, vol. 22, no. 3, pp. 1937-1946, Jul. 2007.

[234] R. Gupta, A. Ghosh, and A. Joshi, "Switching Characterization of Cascaded Multilevel-inverter-controlled Systems," IEEE Trans. Ind. Electron., vol. 55, no. 3, pp. 1047-1058, Mar. 2008.

[235] O. Vodyakho, D. Hackstein, A. Steimel, and T. Kim, "Novel direct current-space-vector controlfor shunt active power filters basedon the three-level inverter," IEEE Trans. Power Electron., vol. 23, no. 4, pp. 1668-1678, Jul. 2008.

[236] O. Vodyakho, T. Kim, and S. Kwak, "Three-level inverter based active power filter for the three-phase, four-wire system," in Power Electronics Specialists Conference, 2008. PESC 2008. IEEE, Jun. 15-19, 2008, pp. 1874-1880.

[237] H. Zhang, S. J. Finney, A. Massoud, and B. W. Williams, "An SVM Algorithm to Balance the Capacitor Voltages of the Three-level NPC Active Power Filter,' IEEE Trans. Power Electron., vol. 23, no. 6, pp. 2694-2702, Nov. 2008.

[238] J. D. Barros and J. F. Silva, "Optimal Predictive Control of Threephase NPC Multilevel Converter for Power Quality Applications,' IEEE Trans. Ind. Electron., vol. 55, no. 10, pp. 3670-3681, Oct. 2008.

[239] H. Akagi and T. Hatada, "Voltage Balancing Control for a Three-level Diode-clamped Converter in a Medium-voltage Transformerless Hybrid 
Active Filter," IEEE Trans. Power Electron., vol. 24, no. 3, pp. 571579, Mar. 2009.

[240] M. E. Ortuzar, R. E. Carmi, J. W. Dixon, and L. Moran, "Voltage-source active power filter based on multilevel converter and ultracapacitor DC link," IEEE Trans. Ind. Electron., vol. 53, no. 2, pp. 477-485, Apr. 2006.

[241] C. Junling, L. Yaohua, W. Ping, Y. Zhizhu, and D. Zuyi, "A closedloop selective harmonic compensation with capacitor voltage balancing control of cascaded multilevel inverter for high-power active power filters," in Power Electronics Specialists Conference, 2008. PESC 2008. IEEE, Jun. 15-19, 2008, pp. 569-573.

[242] A. Varschavsky, J. Dixon, M. Rotella, and L. Moran, "Cascaded Ninelevel Inverter for Hybrid Series Active Power Filter, Using Industrial Controller," IEEE Transactions on : Accepted for future publication Industrial Electronics, pp. 1-1, / 2009.

[243] F. Defay, A. M. Llor, and M. Fadel, "A Predictive Control With Flying Capacitor Balancing of a Multicell Active Power Filter," IEEE Trans. Ind. Electron., vol. 55, no. 9, pp. 3212-3220, Sep. 2008.

[244] P. Xiao, G. K. Venayagamoorthy, and K. A. Corzine, "Seven-level Shunt Active Power Filter for High-power Drive Systems," IEEE Trans. Power Electron., vol. 24, no. 1, pp. 6-13, Jan. 2009.

[245] J. Dixon, L. Moran, J. Rodriguez, and R. Domke, "Reactive power compensation technologies: State-of-the-art review," Proc. IEEE, vol. 93, no. 12, pp. 2144-2164, Dec. 2005.

[246] N.-Y. Dai, M.-C. Wong, and Y.-D. Han, "Application of a three-level NPC inverter as a three-phase four-wire power quality compensator by generalized 3DSVM," IEEE Trans. Power Electron., vol. 21, no. 2, pp. 440-449, Mar. 2006

[247] I. A. Rubilar, J. R. Espinoza, J. A. Munoz, and L. A. Moran, "DC link voltage unbalance control in three-phase UPQCs based on NPC topologies," in Industry Applications Conference, 2007. 42nd IAS Annual Meeting. Conference Record of the 2007 IEEE, Sep. 2007, pp. 597-602.

[248] J. Wang and F. Z. Peng, "Unified power flow controller using the cascade multilevel inverter," IEEE Trans. Power Electron., vol. 19, no. 4, pp. 1077-1084, Jul. 2004.

[249] P. C. Loh, D. M. Vilathgamuwa, S. K. Tang, and H. L. Long, "Multilevel dynamic voltage restorer," IEEE Power Electronics Letters, vol. 2, no. 4, pp. 125-130, Dec. 2004.

[250] A. K. Sadigh, E. Babaei, S. H. Hosseini, and M. Farasat, "Dynamic Voltage Restorer based on stacked multicell converter," in Industrial Electronics \& Applications, 2009. ISIEA 2009. IEEE Symposium on, vol. 1, Oct. 4-6, 2009, pp. 419-424.

[251] A. K. Gupta and A. M. Khambadkone, "A Space Vector Modulation Scheme to Reduce Common Mode Voltage for Cascaded Multilevel Inverters," IEEE Trans. Power Electron., vol. 22, no. 5, pp. 1672-1681, Sep. 2007.

[252] R. Vargas, P. Cortes, U. Ammann, J. Rodriguez, and J. Pontt, "Predictive Control of a Three-phase Neutral-point-clamped Inverter," IEEE Trans. Ind. Electron., vol. 54, no. 5, pp. 2697-2705, Oct. 2007.

[253] S. Kouro, P. Cortes, R. Vargas, U. Ammann, and J. Rodriguez, "Model Predictive Control-a Simple and Powerful Method to Control Power Converters," IEEE Trans. Ind. Electron., vol. 56, no. 6, pp. 1826-1838, Jun. 2009.

[254] P. Barriuso, J. Dixon, P. Flores, and L. Moran, "Fault-tolerant Reconfiguration System for Asymmetric Multilevel Converters Using Bidirectional Power Switches," IEEE Trans. Ind. Electron., vol. 56, no. 4, pp. 1300-1306, Apr. 2009.

[255] S. Ceballos, J. Pou, I. Gabiola, J. L. Villate, J. Zaragoza, and D. Boroyevich, "Fault-tolerant Multilevel Converter Topology," in Industrial Electronics, 2006 IEEE International Symposium on, vol. 2, Jul. 913, 2006, pp. 1577-1582.

[256] P. Bordignon, M. Carpaneto, M. Marchesoni, and P. Tenca, "Faults analysis and remedial strategies in high power neutral point clamped converters," in Power Electronics Specialists Conference, 2008. PESC 2008. IEEE, Jun. 15-19, 2008, pp. 2778-2783.

[257] S. Ceballos, J. Pou, E. Robles, I. Gabiola, J. Zaragoza, J. L. Villate, and D. Boroyevich, "Three-level Converter Topologies With Switch Breakdown Fault-tolerance Capability," IEEE Trans. Ind. Electron., vol. 55 , no. 3, pp. 982-995, Mar. 2008

[258] S. Ceballos, J. Pou, J. Zaragoza, J. L. Martin, E. Robles, I. Gabiola, and P. Ibanez, "Efficient Modulation Technique for a Four-leg Faulttolerant Neutral-point-clamped Inverter," IEEE Trans. Ind. Electron., vol. 55, no. 3, pp. 1067-1074, Mar. 2008.

[259] J. Li, A. Q. Huang, S. Bhattacharya, and G. Tan, "Three-level Active Neutral-point-clamped (ANPC) Converter with Fault Tolerant Ability," in Applied Power Electronics Conference and Exposition, 2009. APEC 2009. Twenty-Fourth Annual IEEE, Feb. 15-19, 2009, pp. 840-845.

[260] B. Wu, J. Pontt, J. Rodriguez, S. Bernet, and S. Kouro, "Current-source Converter and Cycloconverter Topologies for Industrial Mediumvoltage Drives," IEEE Trans. Ind. Electron., vol. 55, no. 7, pp. 27862797, Jul. 2008.

[261] "Grid code - high and extra high voltage," E.ON Netz Gmbh, April 2006.

[262] F. Iov, F. Blaabjerg, R. Bassett, J. Clare, A. Rufer, S. Savio, P. Biller, P. Taylor, and B. Sneyers, "Advanced power converter for universal and flexible power management in future electricity network," in 19th International Conference on Electricity Distribution, CIRED2007, May 21-24, 2007, pp. 1-29, Vienna.

[263] S. Bifaretti, P. Zanchetta, Y. Fan, F. Iov, and J. Clare, "Power flow control through a multi-level h-bridge based power converter for universal and flexible power management in future electrical grids," in Power Electronics and Motion Control Conference, 2008. EPE-PEMC 2008. 13th, Sep. 1-3, 2008, pp. 1771-1778.

[264] E. Levi, R. Bojoi, F. Profumo, H. A. Toliyat, , and S. Williamson, "Multiphase induction motor drives, a technology status review," IET Electric Power Applications, vol. 1, no. 4, pp. 489-516, July 2007.

[265] F. Blaabjerg, Z. Chen, and S. B. Kjaer, "Power electronics as efficient interface in dispersed power generation systems," IEEE Trans. Power Electron., vol. 19, no. 5, pp. 1184-1194, Sep. 2004.

[266] O. Anaya-Lara, N. Jenkins, J. Ekanayake, P. Cartwright, and M. Hughes, Wind Energy Generation: Modelling and Control. Wiley, September 2009

[267] pvresources.com, "Large-scale photovoltaic power plants: ranking," available at http://www.pvresources.com/en/top50pv.php.

[268] Renewable Energy Policy Network for the 21st Century, "Renewables global status report-2009 update," available at http://www.ren21.net/publications, 2009.

[269] S. Cole and R. Belmans, "Transmission of bulk power," IEEE Industrial Electronics Magazine, vol. 3, no. 3, pp. 19-24, Sep. 2009.

[270] R. Teichmann, M. Malinowski, and S. Bernet, "Evaluation of threelevel rectifiers for low-voltage utility applications," IEEE Trans. Ind. Electron., vol. 52, no. 2, pp. 471-481, Apr. 2005.

[271] J. Wang, A. Huang, W. Sung, Y. Liu, and B. J. Baliga, "Smart grid technologies," IEEE Industrial Electronics Magazine, vol. 3, no. 2, pp. 16-23, Jun. 2009.

[272] M. Schweizer, T. Friedli, and J. W. Kolar, "Comparison and implementation of a 3-level npc voltage link back-to-back converter with sic and si diodes," in IEEE Applied Power Electronics Conference and Exposition, 2006. APEC 2010., February 2010.

[273] R. Singh and M. Pecht, "Commercial impact of silicon carbide," IEEE Industrial Electronics Magazine, vol. 2, no. 3, pp. 19-31, Sep. 2008.

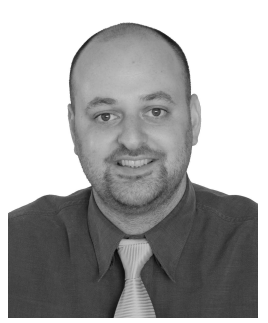

Samir Kouro (S'04-M'08) was born in Valdivia, Chile, in 1978. He received the M.Sc. and Ph.D. degrees in electronics engineering from the Universidad Técnica Federico Santa María (UTFSM), Valparaíso, Chile, in 2004 and 2008, respectively.

In 2004 he joined as Research Assistant the Electronics Engineering Department of UTFSM, and became Associated Researcher in 2008. Since 2009 he is a Post Doctoral Fellow at Ryerson University, Toronto, ON, Canada. His main research interests include power converters, variable-speed drives and renewable energy power conversion systems.

Dr. Kouro was distinguished by the President of the Republic as the youngest researcher of the Chilean National Fund of Scientific and Technological Development (FONDECYT) in 2004. He also received the "Ismael Valdés Award" from the Institute of Engineers of Chile, in recognition for the ability to organize and direct, moral conditions and technical preparation, in 2005. He is co-recipient of the IEEE Industrial Electronics Magazine Best Paper Award of 2008 from the IEEE Industrial Electronics Society. 


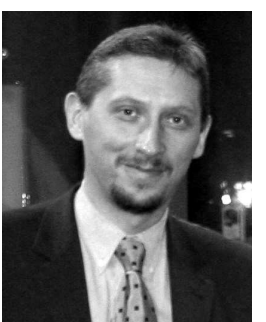

Mariusz Malinowski (S'99-M'03-SM'08)received the M.Sc.E.E. and Ph.D. degrees in electrical engineering (with awards) from the Institute of Control and Industrial Electronics, Warsaw University of Technology (WUT), Warsaw, Poland, in 1997 and 2001, respectively.

$\mathrm{He}$ is currently with the Institute of Control and Industrial Electronics, WUT. He was a Visiting Scholar at Aalborg University, Denmark, at the University of Nevada, Reno, at Technical University of Berlin, Germany and at the ETH Zurich (Switzerland). He was also Visiting Professor at Universidad Tecnica Federico Santa Mar?a, Valparaíso (Chile), University of Cergy-Pontoise (France) and ENSEEIHT - Laplace, Toulouse (France).

$\mathrm{He}$ is an author of two implemented patents and over 90 technical papers. His current research activities include control and modulation of PWM rectifiers, multilevel converters and active filters and power generation systems based on renewable energies.

Dr. Malinowski received the Siemens Prize $(2002,2007)$, a WUT President Prize $(2001,2005,2007)$, a paper awards at the IECON'2000 and EPEPEMC'2004, a Polish Minister of Science and Higher Education Awards (2003, 2008). His industry application received many awards and medals e.g. Innovation Exhibition in Geneva (2006), Exhibition in Brussels "Eureco" (2006).

$\mathrm{He}$ is active member of the IEEE Industrial Electronics Society (IES) and IEEE Poland Section. Within the IES, he was responsible for student activity (2005-2009). Mariusz Malinowski is associate editor of IEEE Transaction on Industrial Electronics and Editor in Chief of IEEE Industrial Electronics Magazine.

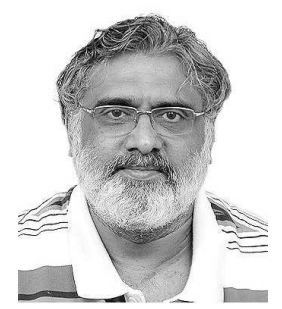

K. Gopakumar (M'94-SM'96) received his B.E., M.Sc.(Engg.) and Ph.D. degrees from Indian Institute of Science in 1980, 1984 and 1994 respectively. He was with the Indian Space Research Organization from 1984 to 1987 . He is currently Professor and Chairman at CEDT (Centre for Electronics Design and Technology), Indian Institute of Science, Bangalore, INDIA. He is a Fellow of Institution of Electrical and Telecommunication Engineers (IETE), India. Fellow of Indian national academy of engineers (INAE). He currently serves as an associate editor for IEEE Transactions on Industrial Electronics. His fields of interest are Power Converters, PWM Techniques and AC Drives.

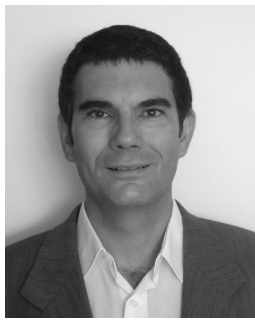

Josep Pou (S'97-M'03) received the B.S., M.S., and $\mathrm{Ph} . \mathrm{D}$. degrees in electrical engineering from the Technical University of Catalonia (UPC), Catalonia, Spain, in 1989, 1996, and 2002, respectively.

During 1989, he was the Technical Director of Polylux S.A. In 1990, he joined the faculty of UPC as an Assistant Professor. He became an Associate Professor in 1993. From February 2001 to January 2002, and from February 2005 to January 2006, he was a Researcher in the Center for Power Electronics Systems, Virginia Polytechnic Institute and State University (Virginia Tech), Blacksburg. He has authored more than 80 published technical papers and has been involved in several industrial projects and educational programs in the fields of power electronics and systems. His research interests include modeling and control of power converters, multilevel converters, power quality, renewable energy systems, and motor drives.

Dr. Pou is a member of the IEEE Industrial Electronics, IEEE Power Electronics, and IEEE Industrial Applications Societies.

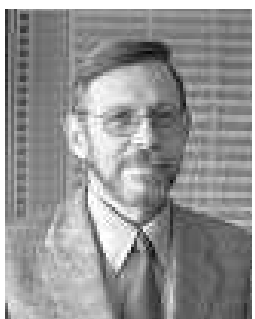

Leopoldo G. Franquelo (M'84-SM'96-F'05) was born in Málaga, Spain. He received the M.Sc. and $\mathrm{Ph} . \mathrm{D}$. degrees in electrical engineering from the University de Seville (US), Seville, Spain in 1977 and 1980 respectively.

He was the Vice-President of the Industrial Electronics Society (IES) Spanish Chapter (2002-2003), member at Large of the IES AdCom (2002-2003). He was the Vice-President for Conferences (20042007), and President Elect of the IES (2008-2009). Currently is a Distinguished Lecturer since 2006, Associated Editor for the IEEE Transactions on Industrial Electronics since 2007 and President of the IEEE Industrial Electronics Society (2010).

His current research interest lies on modulation techniques for multilevel inverters and its application to power electronic systems for renewable energy systems.

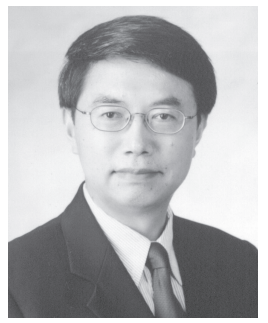

Bin Wu (S'89-M'92-SM'99-F'08) received his $\mathrm{Ph} . \mathrm{D}$. degree in electrical and computer engineering from the University of Toronto, Canada, in 1993. After being with Rockwell Automation Canada as a Senior Engineer, he joined Ryerson University, Toronto, Canada, where he is currently a Professor and NSERC/Rockwell Industrial Research Chair in Power Electronics and Electric Drives. Dr. Wu has published more than 190 technical papers, authored a Wiley-IEEE Press book, and holds over 20 issued and pending patents in the area of power conversion, advanced controls, adjustable-speed drives and renewable energy systems.

Dr. Wu is the recipient of the Gold Medal of the Governor General of Canada, the Premier's Research Excellence Award, Ryerson Distinguished Scholar Award, and the NSERC Synergy Award for Innovation. He is the founder of Laboratory for Electric Drive Applications and Research (LEDAR) at Ryerson University. He is a Fellow of Engineering Institute of Canada (EIC) and Canadian Academy of Engineering (CAE), and Associate Editor of IEEE Transactions on Power Electronics and IEEE Canadian Review.

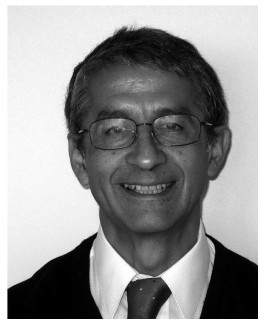

José Rodríguez (M'81-SM'94) received the Engineer degree in electrical engineering from the Universidad Tecnica Federico Santa Maria (UTFSM), Valparaiso, Chile, in 1977 and the Dr.-Ing. degree in electrical engineering from the University of Erlangen, Erlangen, Germany, in 1985.

He has been with the Department of Electronics Engineering, University Tecnica Federico Santa Maria since 1977, where he is currently a Professor. From 2001 to 2004, he was the Director of the Department of Electronics Engineering of the same university. From 2004 to 2005, he was the Vice Rector of academic affairs, and since 2005, he has also been the Rector of the same university. During his sabbatical leave in 1996, he was responsible for the Mining Division of Siemens Corporation, Santiago, Chile. He has extensive consulting experience in the mining industry, particularly in the application of large drives such as cycloconverter-fed synchronous motors for SAG mills, high-power conveyors, and controlled AC drives for shovels and power-quality issues. He has directed more than $40 \mathrm{R} \& \mathrm{D}$ projects in the field of industrial electronics. He has co-authored more than 250 journal and conference papers and contributed one book chapter. His research group has been recognized as one of the two Centers of Excellence in Engineering in Chile from 2005 to 2008. His main research interests include multilevel inverters, new converter topologies, control of power converters, and adjustable-speed drives.

Prof. Rodriguez has been an active Associate Editor of the IEEE TRANSACTIONS ON POWER ELECTRONICS and IEEE TRANSACTIONS ON INDUSTRIAL ELECTRONICS since 2002. He has served as Guest Editor for the IEEE TRANSACTIONS ON INDUSTRIAL ELECTRONICS in six instances [Special Sections on Matrix Converters (2002), Multilevel Inverters (2002), Modern Rectifiers (2005), High Power Drives (2007), Predictive Control of Power Converters and Drives (2008), and Multilevel Inverters (2009)]. He received the Best Paper Award from the IEEE TRANSACTIONS ON INDUSTRIAL ELECTRONICS in 2007 and from the IEEE INDUSTRIAL ELECTRONICS MAGAZINE in 2008. 


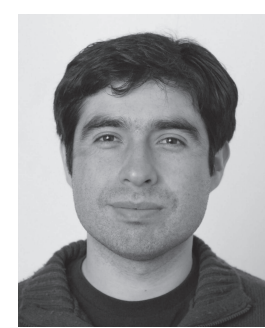

Marcelo A. Pérez (M’06) was born in Concepción, Chile, in 1976. He received the Engineer degree in electronic engineering, the M.Sc. degree in electrical engineering, and the D.Sc. degree in electrical engineering from the University of Concepción, Concepción, Chile, in 2000, 2003, and 2006, respectively. From 2006 to 2009 he hold a postdoctoral position at the Universidad Técnica Federico Santa María, Valparaíso, Chile, conducting research in the area of power converters. In 2009 he becomes an Associate Researcher at the same institution.

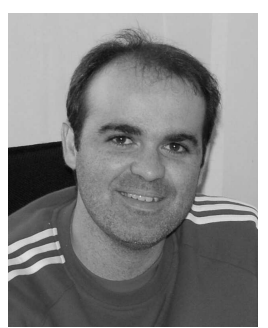

Electronics Magazine.
Jose I. Leon (S'04-M'07) was born in Cádiz, Spain, in 1976. He received the B.S. and M.S. and PhD degrees in telecommunications engineering from the University of Seville (US), Spain, in 1999, 2001 and 2006 respectively.

Currently, he is an Associate Professor with the Department of Electronic Engineering, US. His research interests include electronic power systems, modulation and control of power converters and industrial drives. He was recipient as co-author of the 2008 Best Paper Award of the IEEE Industrial 